SAND- $-79-1382$

SAND79-13日2

Unlimited Release

Printed October 1981

\title{
GENERIC PHYSICAL PROTECTION LOGIC TREES
}

William $x$. Paulus Division 1768

\footnotetext{
Sandis National Laboratories

Albuquerque, New Hexico 83185 operated by

Sandia Corporation

for the

U.5. Department of Euergy
} 


\section{ABSTRACT}

Generic phyaical protection logic trees, designed for application to nuclear facilities and materials, are presented together with a method of qualitative evaluation of the trees for design and analysis of physical protection systems. Information must be gathered or assumptions made about the threat spectrum and site characteristics. The objectives of physical protection are used to define one or more defense zones where adversaries interact with the physical protection system. Logic trees that are needed to describe the possible ccenarlos within a defense zone are selected. Each tree is edited to accurately reflect the characteristics of the site. For design or analysis, elements of a postulated or existing physical protection system are tagged to the primary events of the logic tree. The likelihood of adversary success in overcoming these elements is evaluated on a binary, yes/no basis. The effect of these evaluations is propagated through the logic of each tree to determine whether the adversary is likely to acconplish the end event of the tree. To be effective, the physical protection gysten nust be highly likely to overcone the adversary before he accomplishes his objectlve using any combination of tactics: deceit, force, or stealth. The evaluation must be conducted for all significant states of the site. Deficiencies uncovered become inputs to redesign and further analysis, cloaing the loop on tlie design/analyeis cycle.

Qualitative evaluation using logic trees is especially sultable as an introductory technigue. The effectiveness of the total physical protection system is analyzed. The technique 1a general, not specialized. Any sort of interaction between adversary and physical protection syetem can be analyzed by qualitative techniques, though with less detail than is provided by quantitative techniques. Qualitative evaluation can be performed quickly through use of logic trees and is acsomplished entirely by the actluity of the analyat. Logic trees can be uged in preliminary screening to select attack scenarios for quantitative analysis.

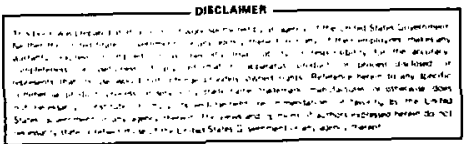

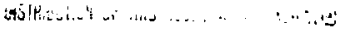

$$
\begin{aligned}
& \text { is }
\end{aligned}
$$


CONTENTS

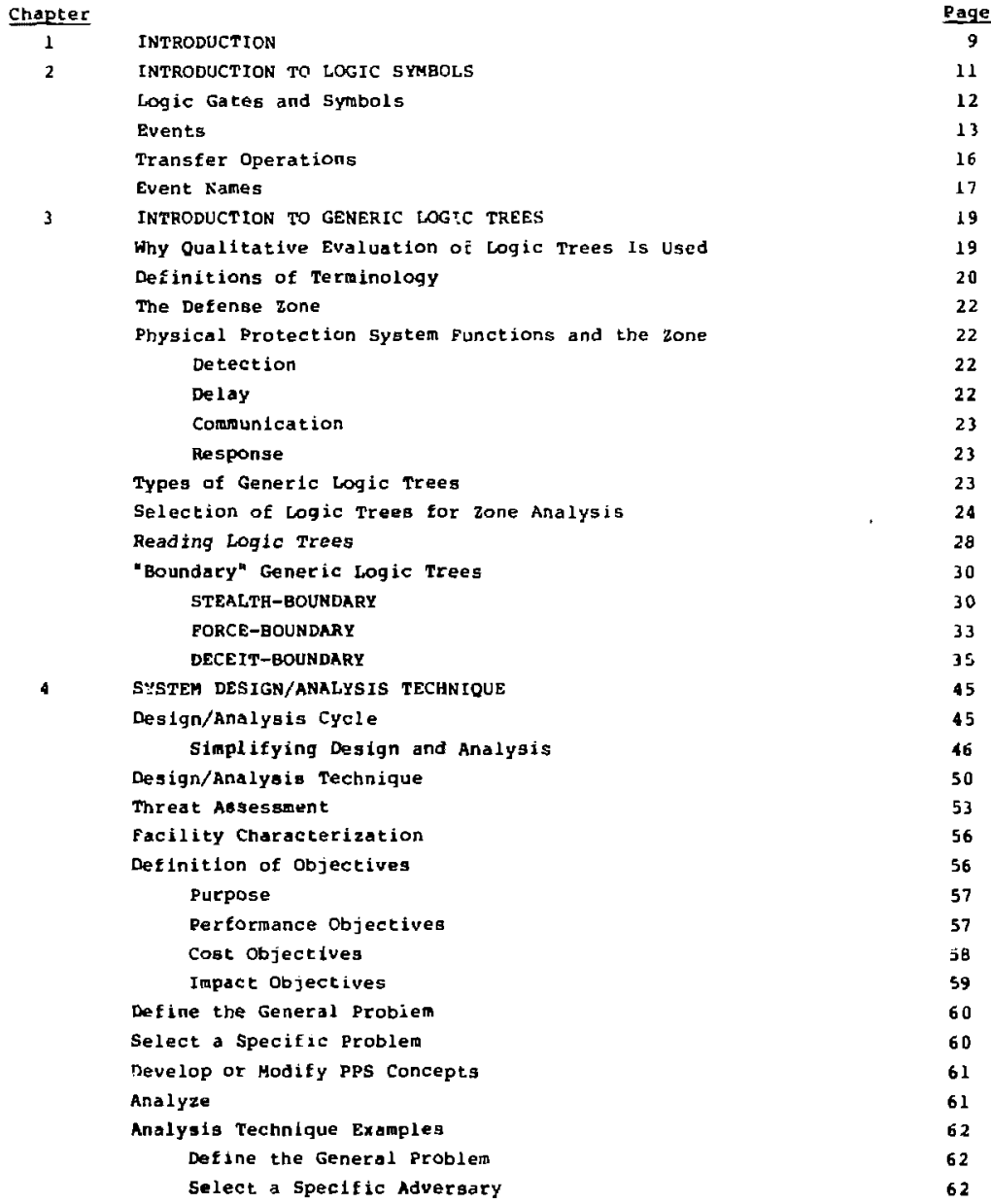


contents (Continued)

Chapter

APPENDICES

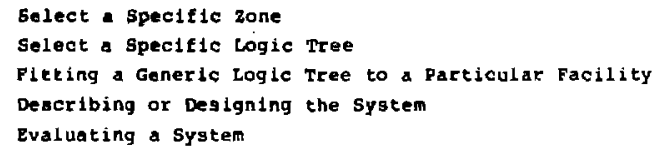

A - Abridged Generic Physical Protection Logic Trees il

"Area" Gentric Logic Trees

STEALTH-AREA

PORCE -AREA $\quad 75$

$\begin{array}{ll}\text { DECEIT-AREA } & 77\end{array}$

"Building" Genertc Logic Trees 80

STEALTH-BUILDING

FORCE-BUILDING

"Acquire SNH" Genertc Logle Trees

STEALTH-ACOUIRE SNH $\quad 86$

FORCE-ACQUIRE SNM

DECEIT-ACQUIRE SNH

"Releave" Generic Logic Trees

STEALTH-RELEASE

FOACE-RELEASE $\quad$. 98

B -- Complete Generic Physical Protection Loglc Trees 101

C -- Alternate version of DECEIT-Boundary Logle Tree 121

\section{ILLUSTRATIONS}

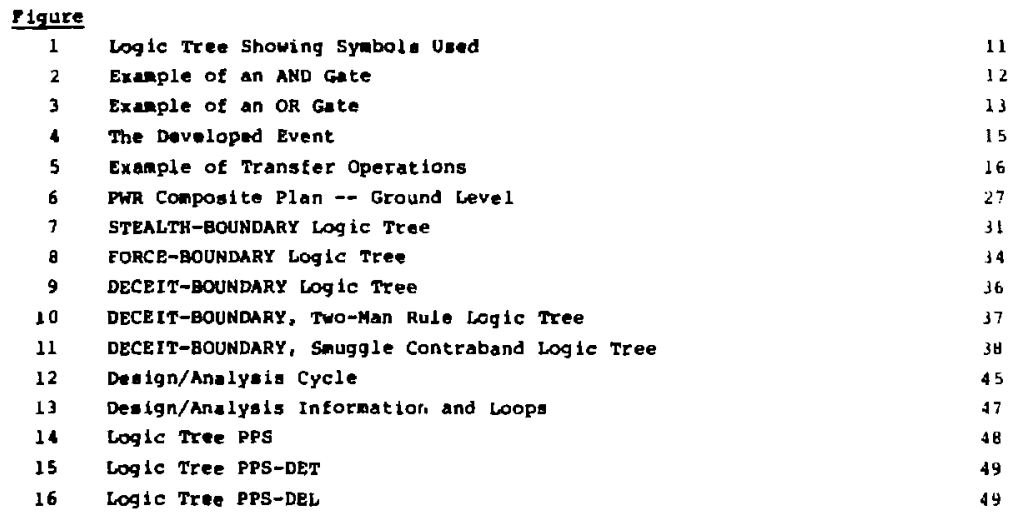




\section{ILLUBTRArIONS (continued)}

\begin{tabular}{|c|c|c|}
\hline Plgure & & Page \\
\hline 17 & Logic Tree ZONE-DET & 51 \\
\hline 18 & Logic Tree ZONE-DEL & 51 \\
\hline 19 & An Hypothetical Power Reactor Site & 63 \\
\hline 20 & Example of a zone & 63 \\
\hline 21 & STEALTH-BOUNDARY, Simpl ifted & 64 \\
\hline 22 & Generic Loglc Tree Fitted to site Boundary & 66 \\
\hline 23 & Evaluating a Generic Logic Tree & 67 \\
\hline$A-1$ & STEALTH-AREA Logic Tree & 74 \\
\hline$A-2$ & FORCE-AREA LOg ic Tree & 76 \\
\hline$A-3$ & DECEIT-AREA LOgic Tree & $7 \mathrm{a}$ \\
\hline$A=4$ & DECEIT-AREA, Two-kan Rule Logic Tree & $7 y$ \\
\hline$A-5$ & STEALTH-BUILDING LOgic Tree & 81 \\
\hline$A-6$ & PORCE-BUILDING Logic Tree & 85 \\
\hline$A-7$ & STEALTH-ACQUIRE SHM Logic Tree & 87 \\
\hline$A-B$ & FORCE-ACQUIRE SNM LOgiC TTEe & 90 \\
\hline$A=9$ & DECEIT-ACQUIRE SNM LOgiC TRee & 91 \\
\hline$A-10$ & DECEIT-ACOUIRE SNM, Two-Man Rule Loqic Tree & 92 \\
\hline$A-11$ & STEALTH-RELEASE SKH LOglC Tree & 96 \\
\hline$A=12$ & FORCE-RELEASE SAM Logic TYee & 99 \\
\hline
\end{tabular}

TABLES

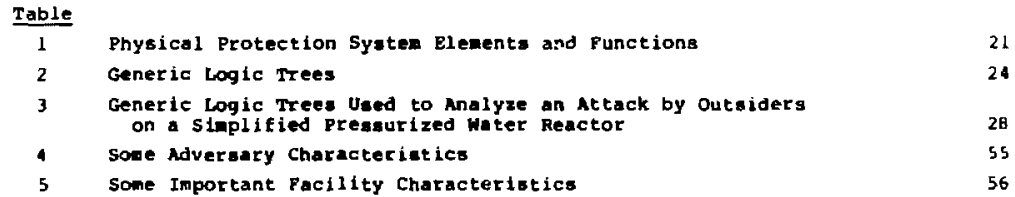




\title{
GENERIC PHYSICAL PROTECTION LOGIC TREES
}

\author{
1. INTRODUCTION
}

This report presents 13 generic physical protection logic trees and discusseg their qualitative application to nuclear facilities and materials for both system evaluation and design. The text extends portions of the "Interrational Training Course on Physical Protection of Nucleor Facilitieg and Materials" (sponsored by the International Atorif Energy Agency and the US/DOE). The generlc trees are the direct descendants of a set developed in 1976 for analysis of nuclear facilities of the Department of Energy. Doth trees and application methodology have evolved toward greater simplicity, speed of use, and flexibility to match the unique needs of a variety of applications. Even so, these are relative advantages over alternative methods. lof course, if depth of detail for one particular scenario or extensive quantitative reaults are needed, these can be relative disadvantages.) In absolute terms, a full qualitative analysid of a realistic site can be complex and extensive. For thig reason, it has been necessary to illugtrate the applications guidelines with sinple, abbrevlated examples. These, however, cover the essential techniques and point the way to carry out a conplete degign and analysis of a physical protection system (PPS).

There are three major subdivisions of the text, supplemented by appendices that contain the generic logic trees in both complete and abridged forw. "Introduc$t$ ion to Logic Symbols" defines the symbols used in logic trees. The AND gate, OR gate, and the transfer operation are explained. The three prinary events and the end event are defined. The naming of events is explainea.

"Introduction to Generic Logic Trees" explains why qualitative evaluation of logic trees is used. Physical protection tereinology is defined. Topics discussed are the concept of a defense zone. the relationships between the zone and physical protection system functions, the types of generic logic trees, how to select generic logic trees to design or evaluate physical protection in a zone, the method of reading loglc tree, and the common properties of Boundary trees. Each of the three trees, STEALTH-BOUNDARY, FORCE-BOUNDARY, and DECEIT-BOUNDARY is presented in abridned form and explained.

"System Design/Analysis Technique" diecusses qualitative evaluacion of physical protection systems. The qualitative evaluation technique employs generic ligic trees and the zone concept. Suggested wethod ahould wake the deaign and analysis cycle efficient. Topics discusaed are the design/analysis cycle, analyais technique, information regulted about the adveraary and the afte, examples of applying the onalysis technigue (using only the tree, stzalth-Bounbary), fittlig a generic logic tree to a particular facility, describing or denigning the PPS, and evaluating a PPS. 


\section{INTRODUCTION TO LOGIC SYMBOLS}

The logic tree is an important tool used to evaluate the effectiveness of physical protection of nuclear facilitiea and materials. The purpose of the logic tree is to describe all of the vaye that an adversary can achieve his objective by defeating elenente of a phyoical protection systen. An event is an act thar an adverady must pertor againat a phrolcal protection syaten to achieve $h$ is objective. In a $\log 1 \mathrm{c}$ tree, these events, which are represented by special symbols, are $\operatorname{logically}$ connected. In order to use $\log 1 \mathrm{c}$ trees, it is necessary to undetstand the individual parte of the tree and the aybols used in the composition of the trees. Figure 1 illustrates the symole thet are umed for logic trees.

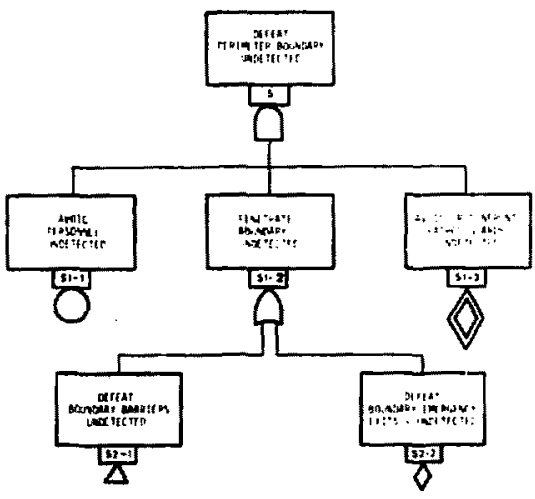

Figure 1. Legie tree showing Symbols Uaed

Each event hes witten deecription which is contalned in a rectangular symbol in the logic tres diegran. The deseription of the topmost event in figure 1 is "Defent Perineter soundary undetected." A saller rectangle, which is placed imediately under the anceription, lo ued to provide the event nane. For example, $s$ is the name of the topest event chown in pigure l. Cuent nanes are usually brief and are formed trom combinatione of letters and numbers. Event names are used in the computer processing of $\log 1 \mathrm{c}$ trees. 


\section{LOGIC GATES AND SYMROLS}

The symbol which appears below the event name is used to designace either how that event is logically related to other events or how well the causes of the event are known. Two kinds of logic gates, the AND gate and the or gate, are used in the $\log 1 \mathrm{c}$ trees. Gates must have at least two inputs and maj or may not have an output. Inputs enter the bottom of the gate; outputs exit the top of the description $r \geq c-$ tangle above the gate. If a gate does not input to another gate, it generates an $t$ nd event. The abjective of the adversary is always the end event of a lagic tree. The logic trees which are described in this module each have only one end event, the topmost event of the tree. In Pigure $1, S$ (Defeat Perimeter Boundary undetected) is the end event. The shape of the AND gate is a round acch with a flat bottom (see Figure 2). For an adversary to accomplish the event described above the AND gate, the adversary nust accomplish all of the events which input into the AND gate. If the physical protection system can prevent any one of the input events, the adversary is prevented from acconplishing the event.described above the AND gate. For example, suppose event E-AND is generated by an AND gate whose inputs are events $1-1,1-2$, and 1-3. Event E-AND w1ld occur if and only if event $1-1$ and event $1-2$ and event $1-3$ all occur. Figure 2 sumarizeg the properties of the AND gate.

ADVERSARY WUST ACCOMPLISH ALL CVENTS IHPUTTIHG TO THE GATE. PREVERTING ANY ONE IRPUT EVENT DEFEATS THE ADVERSARY.

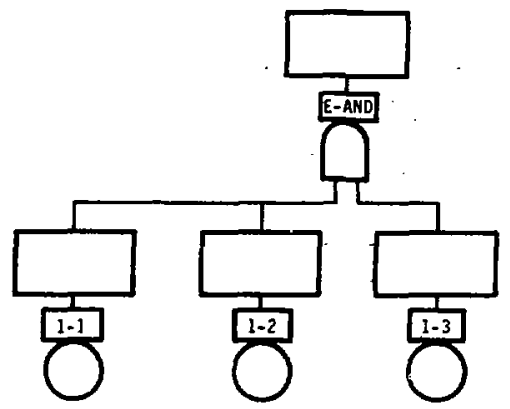

EVENT E-AHD OCCURS If EVEHT 1-1 AND EVENT 1-2 AIIO EVENT 1-3 CCCUR.

Figure 2. Example of an AND Gate

For the $\log$ ic tree shown in Figure 1 , event $S$ vili occur only if event $51-1$ (Avoid Perconnel Undetected), event sl-2 (Penetrace Boundary Undetected), and event Si-3 (Avoid or Confront patrol Guarda Undetected) all occur. The adveraary can penetrate a boundary without being detacted only by acconpliahing all three of the takk associated with events sl-1, sl-2, and s1-3; i,e., (1) by avoiding accidental detection by perzonnel, (2) by physically surmounting the boundary undetected by 
elements of the physical protection syten which are designed to detect an intrum sion, and (3) by avoiding detection by patrol guards.

The shape of the on gate is a pointed orch with a curved botton fsee figure 3). For an adversary to accomplish the event described above the OR gate, the adversary need only accomplish any one (or nore) of the events which input to the OR gate. The physical protection syetem mus: prevent $\Delta 11$ of the input events in order to prevent the adversary from accomplighiny the event described above the or gate. For example, suppose event $E-O R$ is defined by an OR gate whose inpurs are events 1-1, 1-2, and 1-3. Event E-OR occurs if any one af evenes 1-1, 1-2, or 1-3 uccurs. Figure 3 sumarizes the properties of the OR gate. For the logic tree shown in Figure 1, event 51-2 (Penetrate Boundary Undetected) will occur if either event s2-1 (Defeat Boundary Barriers Undetected) or event s2-2 (Defeat Boundary Bnergency Exits undetected; occurs. Thus, the odversary can penetrate a boundary without being detected in either of two ways: (1) by undetected passage through an emergency exit or (2) by undetected penetration of the barriers which constitse the boundary.

ADVERSAPY HAS ALTERNATIVE WAYS TO ACHIEVE SUCCESS.

ALL EVENTS INPUT TO THE GATE MUST GE PREVEHTEO.

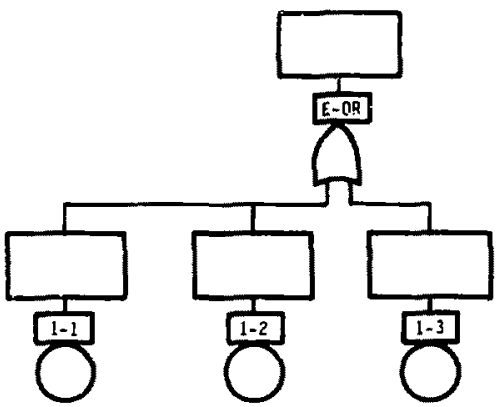

EVENT E-0R OCCURS IF EYENT E-1 OR EVEIT E=2 DR EYENT E-3 OCCU:

Figure 3. Example of an or Gate

\section{EVENTS}

Events which have toth inputs and outputs are called internediate events. In Figure 1 triere is only one internediate event, sl-2.

Events which do not have an input are called primary eventaf they represent the causes of the end event. A $\log i c$ trec is a logical combination of primary events. Tnree types of primary events are distingulahed by the aybol which appears imediately below the nawe of the primary event; the basic event, the undeveloped ovent, and the developed event. 
The befle erent is apbolised by a circle a baole event cen be underatood and ovalustad quelitatively or quentitatively, depanding on the purpose of the analyeis, without furtber developing the event into causer or cases. In Figure 1 , event s1-1 (avold Pereonnel Undetected) la the only beolc event. Eventa that deacribe unlikely accidental circunetences by which en adversary could avold detection by nonsecurity perconnel are uaubliy excluded from the logic tree. sl-1 can be evaluated. It is judged that, except for an accident, an adversary could easily avold personnel undetected. 5l-1 need not be developed further since an analyst is required to evaluate only one posalbility: Can an adversary avold facility personnel without being detected? Event sl-1 can be contrasted with event sl-j which is not a basic event. For event $51-3$, the analyat is asked to evaluate whether the advergary can avoid or conftont patrol guards without being detected.

The undeveloped event is aymbolized by a dianond. An undeveloped event is an event whoe causen are insufficiently understood to be included in the loolc tree. It is not posaible to say wether, given more intormation, an undeveloped event would be developed or treated as a basic event. The conclusions drawn fron the andyais of a tree wich contains an undeveloped event are tentative and oubject to revision. In Figure 1, event S2-2 (Defeat Boundary Emergency Exits Undetected) is the only unteveloped event. This event lo considered an undeveloped evont gince al! of the variou kinde of energency exits have not been stwijed. $A l s a$, there is no information by wich the logic tree could show how all of the types of energency' exits could be defented without the adversary's being detected.

The developed event is sypbolized by two concentric diamonda. The causes of a developed svent have been hown in another $\log f \mathrm{c}$ tree* or elsewhere on the same logic tree. The developed event is used as a sace-saving convenience. For exanple, a full logic tree wight be Inconveniently large. To becone faniliar with the type of information contained in the tree, it aay be sufficient to exanine the uppermost parta of the tree. Expendable events could be deleted from the tree and logic gates no longer having inputs would be replaced by developed events. The resultant tree would be simpler than the original tree, which could be referred to for more development as neceuery.

Another example is hown in Pigure 1. Assune that two events on the same tree have virtually the and developent, differing only in sone detall of event descriptions. The development can be show in detall for one event. The other event can be aade a developed event with a coment added that tells where to find the appropriate development. The topmost tree in Figure 4 ghows similar developinents for events S1-1 (Avoid or Confront Personnel) and s1-3 (Avold or confront guards). Both developuents consiat of two basic events as inputs to an oR gate. Lvents $52-1$ and s2-3 are sinilar (Avold Pereonnel versua Avoid Guards). Events 52-z and s2-4 are -imilar (Confront Pereonnel versub Confront Guards). Because of these sirilarities, it i. posable to draw the equivalent tree shown at the botcom of Figure 4 . The

In the other $\log i c$ tree, the event would be generated by a logic gate. It would have "developante conalating of a abtree generated from prinary events through a network of logic gatee. It would not be a "developed" primary ovent. 

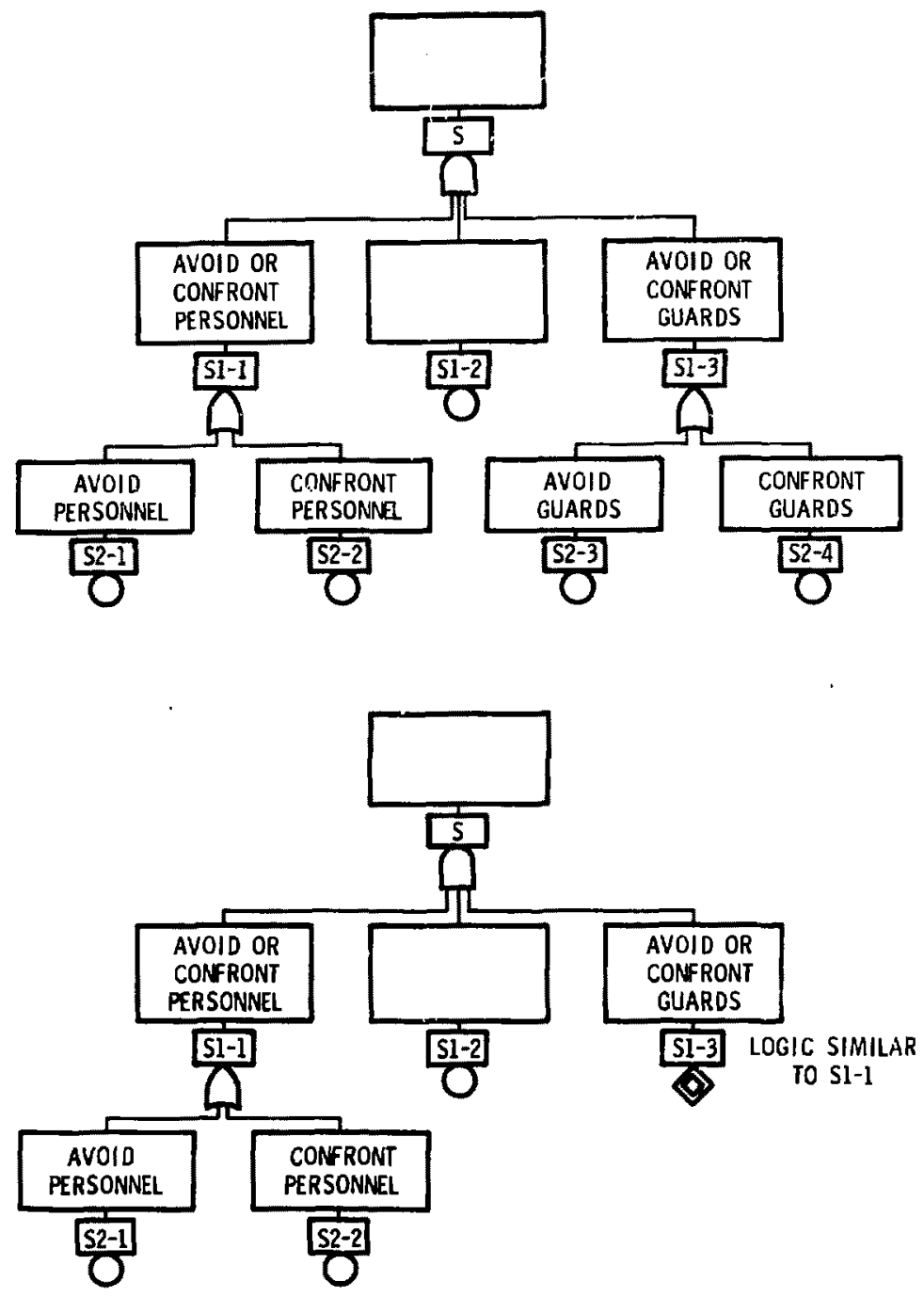

Figure 4. The Developed Event 
full development of event sl-l is retained, but sl-3 has been made a developed event with this comitent added, "Loglc similar to Sl-1." Seeing this, the analyot looks at the development of $\mathrm{sl}-1$ and mentally substitutes "Guards" for "Personnel" as he reads the event descriptions. The reader can find a nontrivial application of this techaigue on the complete logic tree FORCE-BoundARY. Developed events F3-30 and E3-40 both have "Loglc Similar to F3-20." The development of F3-20, which thus appears once rather than three times, consists of 16 events and 7 logic gates.

\section{TRANSFER OPERATIONS}

The transfer operation is represented by an upright triangle. Since many logic trees, as they are developed, expand greatly from left to right across a page, it might be necessary to disconnect the development of an event and place it at a more convenient position on the page or on another page. To relate the event and its development, since they are not connected by a line, the transfer symbol is used. An exanple of the transfer symbol is shown in Figure 5. A tree is shown on the left that contains no transfer symbol. Its eguivalent, using the transfer syanbol, is shown on the $r$ ight as a tree in two seemingly unconnected parta. In the righthand tree, the development of event $1-2$ is transferred so that it is centered

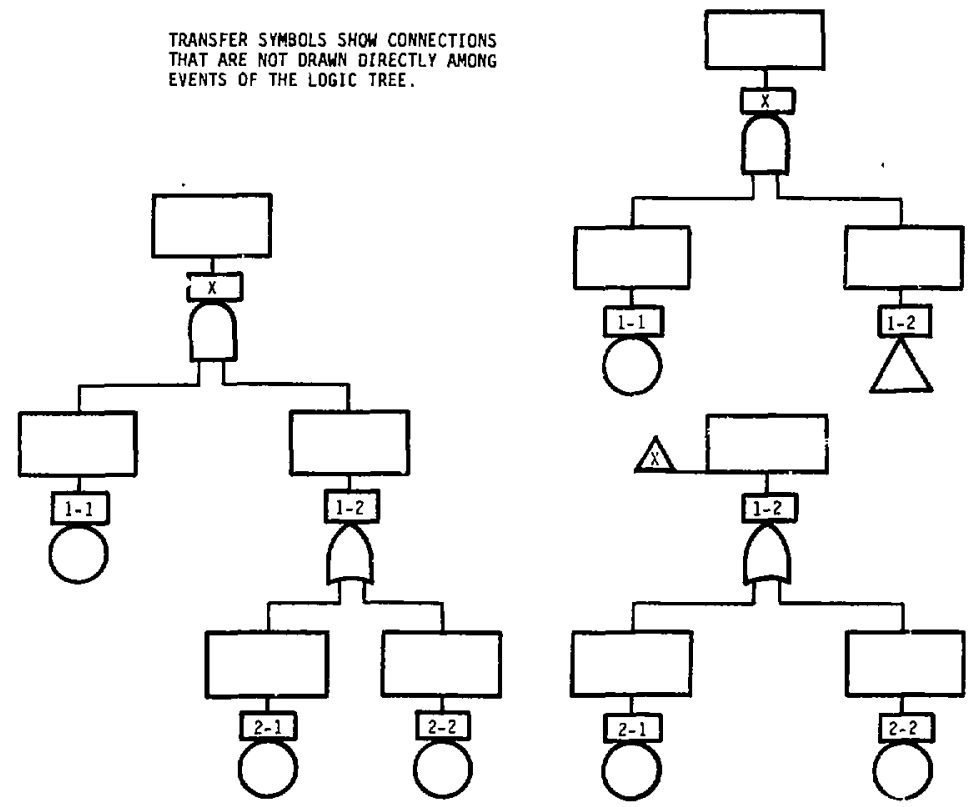

Elgure 5. Example of Transfer Operations 
directly below event $x$. Nate that event $1-2$ is shown twice: once in the tree whose development is truncated by the iransfer and once at the top of the subtree shat develops event 1-2. In general, an event may occur at geveral placeg in a logic tree, and the cammon development of that event may be transferred. The development will appear only once on the page. The $X$ which appearg below the transfer symbol and to the left of event $1-2$ is the name of the event for which event $1-2$ is an input. In general, there will be a list of every event to which the transferred event is an input.

\section{EVENT NAMES}

To assist in the location of events on logic trees that appear in this module, a convention for event names has been adopted. The end event can be arbitrarily named; it may have a mnemonic name suggesting the purpose of its development. All other event names have at least two numerical parts separated by a hyphen. Tinese may be preceded by one or two alphabetic characters. The first optional alphabetic character denotes the tacticB for which the tree is developed: D-deceit, F-force, or s-stealth. The second optional alphabetic character, $x$, denotes that no similar event occurs on the force tree which has a similar end event. This helps the reader to find quickly the similaritieg and dissimilarities among, for example, all logic trees for crossing a boundary. The number to the left of the hyphen is the row in which the event appears. Rows are numbered in increasing order from the top to the bottom of the tree. The row immediately below the end event is row number one. The number to the right of the hyphen denotes the relative position of the event in its row. These numbers need not be consecutively assigned. It is only necessary that the position number of any event be higher than the position numbe of the event to its immediate left, and lower than the position number of the event to its inaediate right.

For example, find event $52-3$ in the topmost tree of Figure 4 . The letter 5 which begins the event name indicates that the tree deals with stealth tactics. The absence of an $X$ following the $S$ indicates that if there is a tree for using force tactics to achieve a similar end event, there is an event on the force tree similar to event 52-3. (In this case, no such force tree exists; the tree $s$ is an isolated, artificial example.) The remainder, 2-3, of the event name indicates that the event will be found in the second row of events below the end event. In that row, read from left to right through increasing position numbers until 3 is reached and event s2-3 has been found. The leftmost event in row 2 has position number 1 , the next event to the right has position number 2 , and finally the event to ics right has position number 3 .

If part of the logic tree is transferred, rows in the transferred development are numbered consecutively from the row number of the trangferred event. Relative position numbers are sonetimes assigned as if the developnent had not been transferred.

For example, find event 55-60 in the complete generic logic tree, stEALTHBOUNDARY. ROW 5 in the main part of the tree ends with event sX5-30. This is evidence that S5-60 lies within a transferred developient. It is quickly geen that 
there Ie only one transterred dovelopment for STEALTH-Boundary. 55-60 will be found in the second cow below trancferred event s3-20. The leftmost position number in cranaferrad rov 3 ie 10 (event $55-40$ ). So, event $55-60$ lles farther to the right and can qulekly be found. 


\section{INTRODUCTION TO GENERIC LOGIC TREES}

Logic trees may be used by nanagers, designers, and analysts to pian anr

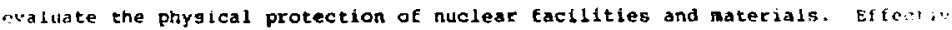
fless evaluacion of phyoical protection gystens requires knowing which pos: $1, \ldots$ actions by the adversacy must be opposed and which actions can be ignored. in: . trees are a tool for effectiveness evaluations. A qualitative estimate of l... effectivenegs of a physical protection systea and a list of physical prof..... maknesses can he obtained through the use of logic trees. Qualitat....... ancrips the question. "Hau effective is the phyaical protection 5ysturi." "ithe: of two cesponses: "The syaten if not effective," or "The systex. 1. 1) bu effective." This information can be used to estiblish the need for $1 .$. $\therefore 1, i$, rogether with cost data, to accept or reject systen designs.

stic topies included in this introduction to logic trees ar:"

i. Why gualitative evaluation whth logic trees is used,

$z$. Definitions of terminology,

i. The derense zone,

4. Physical protection systerk functions and the zone,

5. lypes of $\operatorname{logic}$ trees,

6. Splection of logic trees to analyze a zone, and

7. Reading $\log i c$ trees.

$\because$ w-tiof of constructing logic trees is not explained. The necessa." .. ailpilind with this text or as an appendix.

The rochnique of qualitative analysis using logic trees is thist:, . * of a nuclear power generating station which requires protoct in ..

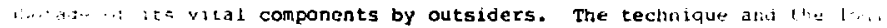

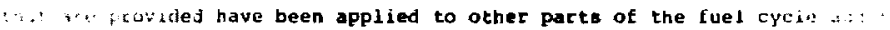

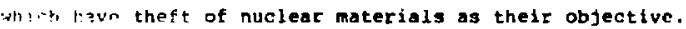

Twu . mportant preparatory steph for qualitative analysir using $1 \ldots, \ldots$

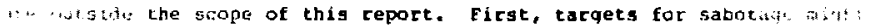

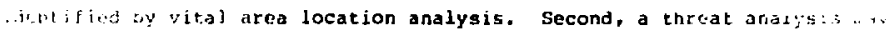
c...... T.dite so establish a spectrum of threats against which the powt: $A$ : : , ${ }_{i}$ in ptotnction. This information wlll be used as it is neeited.

\section{WHY OL AIITATIVE EVALUATION OF LOGIC TREES IS USED}

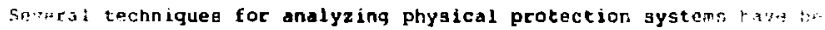

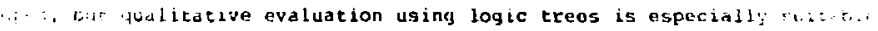

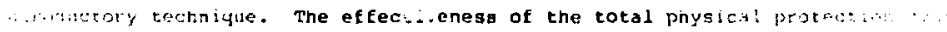

- anilyzer. The technique is genezal, not specialized. Any sote os wterdir 
Table 1

Fhyeleal Frotection system Fleanents and Functions

Function

Detection

a. Sencor

b. Alurm/dioplay

c. Aasesament (real time)

d. Track

De lay

Comunication

Raspones

\section{Example Elenent:}

\author{
Fence disturbance sensor \\ Identity check \\ Metal detector \\ Hicrowave \\ Televition \\ Warning lights/sounda \\ Guerd \\ Televiaion \\ Guard in a tower \\ Badar \\ Barrier \\ Distance of travel \\ pindio \\ Telephone \\ Guarde \\ Local lau enforcement (police)
}

- Functione -- The functions of a phyeicel protection aysten comprise the group of ralated ectlons wich together anke up the performance of the phyeical protection syaten, the functions are detection, deley, comunication, and response (bee Thble 1 ).

- Insider -- An inaider is a person authorized to enter a protected area or a vital area, insidere include enployees, contractors, aervice personnel, and visitors.

- gutsider -- an outsider is a person who it not authorized to enter a protected area.

- Positive Heegures -- Positive mencurer ore physical protection element: that have prodictable levele of performance for the purpose of preventing the completion of one or nore evente. Poaitive neacures will not dateriorate abruftly or unpredictably bhould the everity of the attect be increased by a mall anount. There are four methods of inplementing or recognizing positive weasures in a facility design.

1. Inplement a function with at least two elementa so that loss of one elesent will not cause complote loas of the function,

2. salect on leiwent to block as many kinde of atteck as poseible,

3. Use lements which hove compleentary etrength together. (For exanple, atcrowave intruetion ensor and e celemic intrueton ensor have complementary etrengthe. The aicrowave device can senes an intrusion mede using a bridge or ranp to isolate the intruder fron the seienic sennor. The colcicic device can enes an adveraary who is crawling on the ground to avold the microwave bean which le ained bigh to avold falee alarme ,)

4. Siaple redundancy can be used for rellabllity. (The use of two eivic intruetion eneore is an exemple of elpple redundency.)

- Reponse -- responee if the function of reacting to the detection of an unauthorized act to prevent adverary succese. 


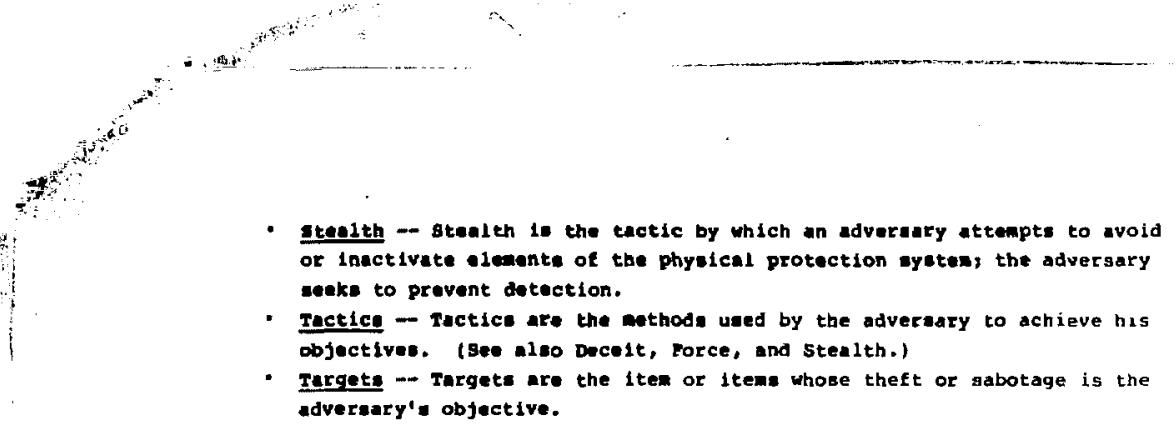

\section{THE DEFENSE ZONE}

A defense zone is apace which ourrounds but is not necessarily occupied by one or sore targets and within which any attack iw firat detected and ultimately terminated by the phyaical procection ayetem before an adversary can acconpl ish his goal. The initial boundary of a zone is the envelope of first potential detection of the advertary. The final boundary of a zone is the envelope of last potential tetmination of the adverary' attack.

A zone of defense surrounding a ste may be visualized as a shell that surrounds and protects the targete. The thell may be thin or thick (the thickness need not be uniform) depending on the space needed to terninate an attack. The zone extends into the air above the oite to detect attack mounted from the air. The zone also extends underground beneath the site to detect tunnel attacks.

An attack by outsidere may require a zone al far resoved from the targets as posible. An attack by Insiders nay require more than one zone very close to the targets, perhaps coinciding with the target: thenselves.

\section{PHYSICAL PLOTECTION SYSTEM FUNCTIONS AND THE ZONE}

\section{Detection}

The zone beging with a detection boundary becauee the phyaical protection system cannot begin to oppose an attack unt 11 the attack has been detected. Detection wight be deslred within the zone as wil at at a boundary to provide information on the location of the attacker. until they are intercepted by a response force. Detection nust occur within the zone, but some detection elements may not be located in the zone. An example to monotatic radar which can detect at a distance, and wich need not be installed within the zone in order to participate in the detection of intruders within the zone, outsiders should be detected at the outer boundary of the zone. Some tactica require that detection lenents shuuld alwo operate within the zone. Outriders attacking by deceit or stealth might not: be detected at the outer boundary of the zone, deponding on the effectiveness of the detection elements and the adversary'ak111.

\section{Delay}

Delay must follow detection and occur within the zone. To provide for alarm ascessment, attackers mut be prevented from moving too gulckly away from the place where they caused an alara. A barrier la necesercy to provide this delay. 
The time aftec detection required by the attackers to reach their target must se at least as long as the tise reguired for the physical protection system (I) co communicate with a response force, (2) to mobilize, transport, and deploy the rmsponse forso, and (3) to intercept and halt the progress of the attackers, ans $x ;$ mirn barriers may be necessary to slow the attackers sufficiently to qive th" rit. ial protection system time to respond effectively."

\section{Communicalkn}

Conmunication 13 the function wich unites all the physical protection $n 1 \ldots$ arents into a systen. Senere communicate with alarmo or digplays. The contrilt . At ir communicates with patrol guards, guards in observation posts, and othes r.sponse forces. The response force has internal communications. Control sign,: "ay be communicated zo lights, gates, television cameras, etc. The communiciti it. tistwork need not lie entirely within the zone. Comunication reliability $\boldsymbol{r}_{1}$, :

y ligh.

\section{Responae}

kesponse is the function of intercepting the attackers and halting in.. ir joross before their goal is achieved. The response element (response $f$ is. whtioned inside or outside the zone, but the reapone force must tarry wir . i . or within the zone.

\section{TYPES OF GENERIC LOGIC TREXS}

l'h loreth logic trees are availuble for applying the evaluation tochn,, ...... in this section. All of these trees have one characteristic in corning․ 1 li generic; therefore, each logic tree can be applied to any sitw. 'l?.. - uch the generic logic trees are applied to a se is the subject of lhajt: ".ystan Design/analysis Technique." For the present, it is necesgary anl.

: :fat no more than 13 trees are needed for qualitetive andysig of an; $;$

The generality of these $\log 1 \mathrm{c}$ trees implies not only their applifial. i. litually any nuclear site but almo the kind of unepecific event descrift ". : " * mat entrances - gete, portal, or building - undetected." $\because .$, i $i: \therefore 1 ; i r$ element of a gate or portal and to perforn similar tanuir: :if; ;vints would make the logic tree exceselvely large and unuieldy. ". Im.ras in the technology of physical protection systens could rapaly $i . .$, . $\therefore$ autively daveloped tree obsolete. If general event descriptions ur. .

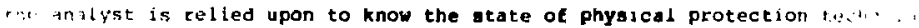

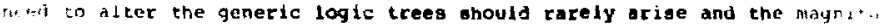
i ijk ls kept relatively onall.

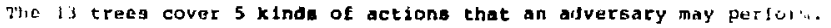
- ind uf fiction is developed on a set of generlc logic trees. In eact ar:, ", roi: troe for each adversary tactic by which the action can be acconpl lanfit. melate list of generic logic trees is given in Table 2.

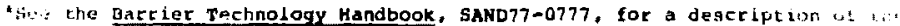

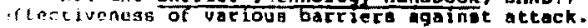


Table 2

Ceneric Logic mese

\begin{tabular}{|c|c|}
\hline (Tactic-Apolication) & Iind of Action Developed \\
\hline $\begin{array}{l}\text { FORCE-COUNDARY } \\
\text { STEALIT-SOUNDARY } \\
\text { DECEIT-SOWHBARY }\end{array}$ & Ponetrate protected boundary \\
\hline $\begin{array}{l}\text { FORCE-ARSA } \\
\text { STEALTH-AREA } \\
\text { DECEIT-NREA }\end{array}$ & Trevel ecrose protected aren \\
\hline $\begin{array}{l}\text { FORCE-RUILDING } \\
\text { STEALTH-DUILDIMG }\end{array}$ & Encer building \\
\hline 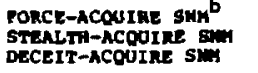 & Acquire apecial nuclear materiale \\
\hline $\begin{array}{l}\text { PORCE-nELESE } \\
\text { STELTth-RELESE }\end{array}$ & $\begin{array}{l}\text { Coube relgae of epecial nuclear } \\
\text { materiale }\end{array}$ \\
\hline
\end{tabular}

The five kinds of actione are (1) penetrate a protected boundary, (2) trovel acrose a protected area, (3) enter a building, (4) ecquire apecial nuclear materials, and (5) cause a celease of special nucleac materiale, Each oction, with two exceptione, can be accomplished by the ues of decelt, force, or stealth. The exceptione involve deceit. The tree osceir-boundary entisfactorily dencriber hou an adversery might enter a building by deceit, therefore, no DiceIr-burborwg tree exiets, Ho wethod has been found to couce a rolease of epecial nuclear materivis by deceit, therefore, no DecEIT-getenst tcee exivte. Attacke reoulting in a release of special nuclear eateriele mut be analyzed vith either the roncE-Retense tree or the STEACTH-RELCASE tree.

\section{SELECTION OF LOGIC TUEDS FON ZONE ANALYSIS}

since zone is a opace in wich the interactions betwen the adversary and the physicel protection aysten occur, analysis of thoes interactione by neans of generic logic trees requires selection of the correct logic trees to describe the actions which can occur within the zone. Before that can ba done, the sone must be described. The description abould be tone during denign whon the parfocmance goela for the phyalcal protection bisten are set. The locetion of the sone depends on the threat, Its tactice, and Ito objective. As a practical aatter the location of the zone further depends upon ate phyalcal attributes.

Outalders mut atteupt to penotcate the ite from the outeide, whatever thair objective aay be. The Initial boundary of the zone (the envalope of ficet potential detection) an reasonably be placed near (at or within) the property line of the eite. Detection would be undestrable whece the public could not be prohibited Eince alerme would be generated by innocent paseraby a wall al by adverueriet. 


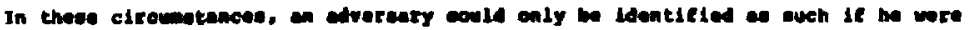
detected wile conittin an uarukeribed aot.

The finel bondary of the wase (the envelope of texination of the atteok)

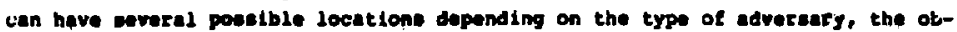
jective of the attack, and the apeed of the renpanse force. When the objective la sabotage, It way be reaseable, glven a eufficiently fart reaponse fotce, to prevent the wevecety from entering the bullding thet housen his target(s). In this cace, the outelde of the bullding ay be apecifled at a final boundary of the sone. sueb a sone would be allev whell aurrounding the targate (whleh are inalde the bulldting).

If the objact reneina sabotage, but the reoponae force eannot intercept the edverwery bafore he enters the bullding that house the tergat, than the ppe alght be designed to eccubulate enough delay for a reapana force to intereept the advereary by requiring the advarary to equentially disoble eavaral tergets but not enoogh to echieve an overall wabotege objective. It alght not be posible to waxe the adverwary mabotage the tergets in a spelfic order. It la then not postble to predict wich target(a) will not have been abotaged wen the attack has been term alnated. Those tergete which beve not been aboteged are enclowed by the thal boundary of the sone. The analyat alght thinit of the sone for this case as equivalent ta a apherold conesialng ace nuwer of bubblet (ubleh are the unabotenged targetel.

If theft is the object of an atteck, the final boundary at wich the, adverary ia neutralized by a reapone force can be the proparty line of the wite which may be virtunily the ane ae the boundary for firat detection. Alternatively, the final boludary wight be placed at the outside of ang bullding that houes targeta.

Insidera can only be detected a adversaries when they ocoit an uneuthorieod act. The Initial boundary ahould be placed where the firet unatporiaed act could be recognized as auch.

Once the boundarien af the wone are eatabliehed for the postulated threat.

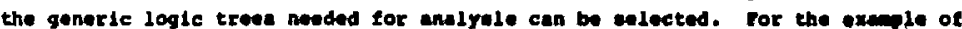
eabotage by outsiders, wetume thet the cesigh of the physical protection byaten has entablished the intelal boundary of the sone at the proparty line of the alte, risIng to a detoction "roof" wove the ground and deacending to a detection "floor"

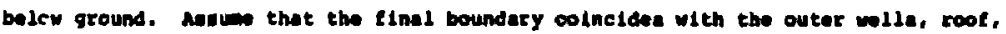
and foundation of the bypothetlcal pressur laed weter ractor bulldings.

The attackere nust firet panetrate the initial poundary. Shit acton wold

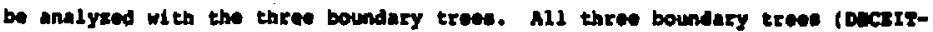

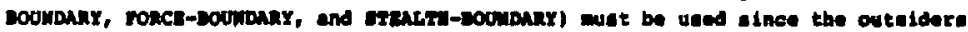
have a chotes of tactes at this and orery step of their attack. Eotwon che inttial boundary and the flral boundary, the outalders nay travel aoreat can tarratn.

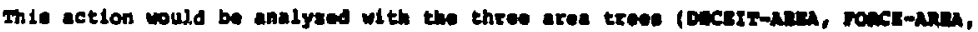

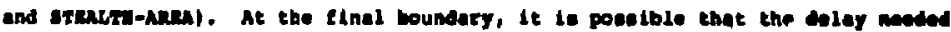




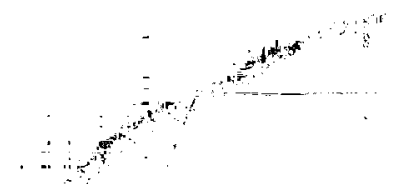

by the phyolcel protection. syatem to interrupt the attack and teminate it will be provided by the barter of the building otrueture. The two biliding treen (PORCE-

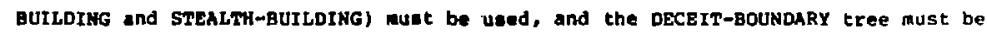
used agein, thin the co analyze -entry into the building.

If the design of the physical:protection aysten is found to be adequate through the une of these treed that idescribe actiona with the zone; thete is no need to analyze the release trees. If. the design it shown to be inaseguate, the analyst night relocate: the final boundary. The design of the system may prove adeginte, to protect the facility from tolease of nueliear aterials even though it could not terminate the attack as quickly as desired. It then becomes an option of the redesign either to nove the final boundary of the zone or to improve the physical protection system. of course, If the release cannot celiably be preverited, ?. there is no choice but to redegigh the aysiter.

As the final boundary ia. located deeper within the building, it becomes necessary to take into account how physical protection is provided for each member of a set of vital areas. The wets of yital areas with the fewest mabers should be analyzed before those with nore nembers. The analysis must coritinue either until a get is found for which phyaleal protection ls adequate or until it is found that, no set has adequate phyaical. protection, for these several analyas, the appropri/te generic logic trees are celected and revised as needed.

Assuming that the analyst evaluates the physical protection of the vital components themelves, what additional ganeric logic.tree wold be analyzed? For example, aseune that the advercary choores to danage the reactor vessel itself so that adequate cooling to avold a mitdown is impossible. The adverary aust enter the reactor containient to reach the reactor veasel, as shom in rigure 6 . He might choose to penetrate from the outslde directly into the concainaent through the wall. Thi = would require the use of force, or he aight choose to enter tne auxiliaxy building, pethapa by the door close to the personnel hatch of the containment. This aight be acconplished by any of the three tactics. Penetration of efther the auxiliary butlding or the containeant structure is already subject to

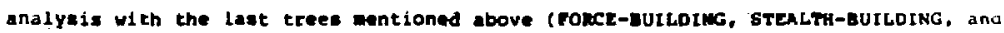
DECEIT-pounary). Fron this point on, nev analyeis 1s required. Fron the door of the auxiliory building to the personnel hatch, the edversary aust travel ecross an area. The generic logic trees, DECEIT-ARE, FOnCE-AREA, and STEALTh-AREA, are andyzed again. Their first analyais involved travel outdoorag thia time the travel is within a building. Oulte different elemants of a physical procection systex. may be involved in the two situationa. Meverthelens, the weme generic trees are suitable in both ituations.

The adversary" e entry into the containment through the personnel hatch (a device designed an airlock) is analogous to entering a bullding through a vesti-

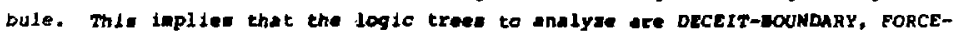
BULDING, and STEALTh-suILDIMG. Travel through the containent atructure to the location fron wich the ceactor veleel can bo sabotaged is analyzed with the 


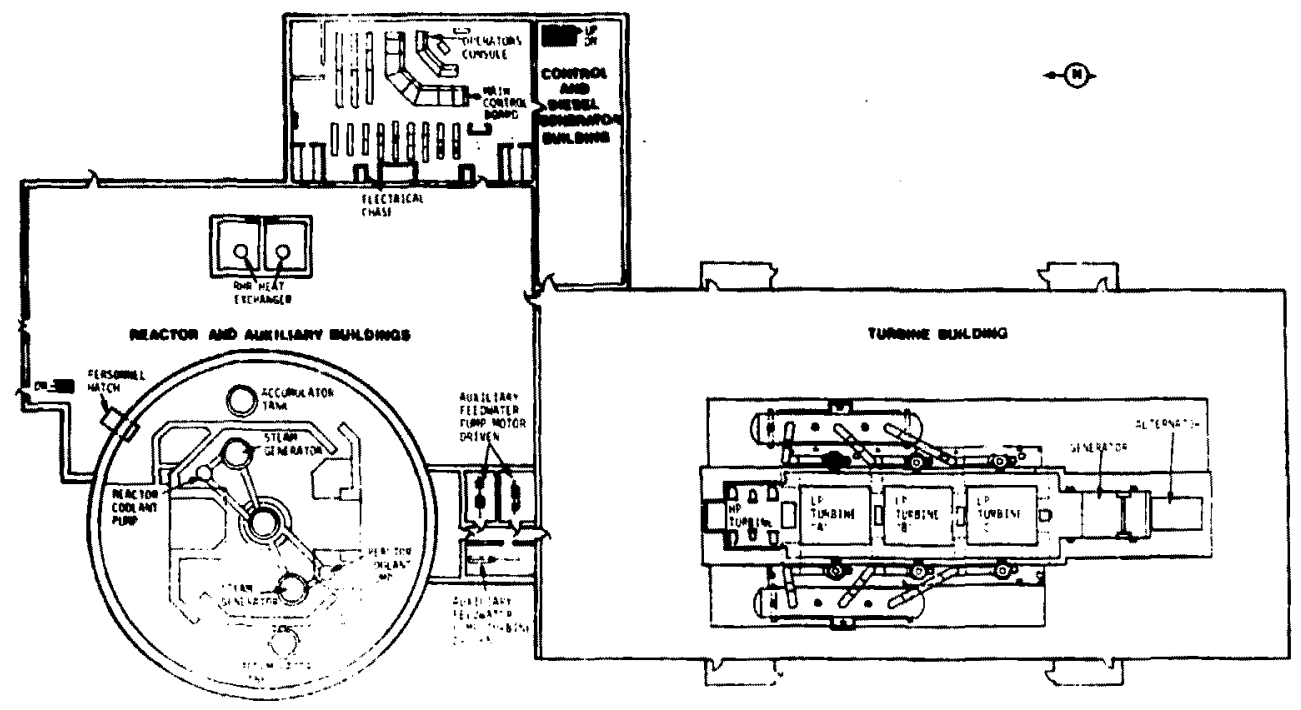




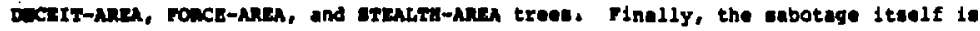

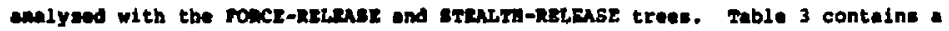
aumary of the trees enlected in this eraple.

Table 3

Ceneric Logic Trees Uaed to Analyze an Attack by Outeiders on a simplified preseurised Water Reactor
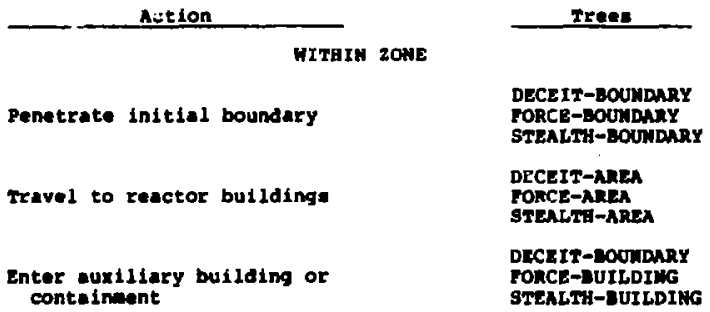

Enter ouxiliary building or conteineent STENLTH-DUILDING

Getrond ausys

Travel to personnel hatch

DECEIT-ARE

FORCE-AREA

BTALTH-ARE

Enter conteinment through

DICEIT-DONDARY pertonnel hatch

FonCE-DuILDInG STHALT-DUILDING

Travel through containent to locetion for eabotage

DECEIT-ALEA

EOXCE-AREA

STELTT-ANA

Comit sabotage leading to core meltdom and release

Fonce-MELPSE of nuclear material.

STEALTI-RTHAR

\section{FFADING LOGKC IIDXS}

Defore the generic logic trees are used, their content and the wathod of reading then must be underetood. The primery events of each of the 13 genaric logic trees can be divided into 2 groups. The first group concerne the adveranry's need to accomplieh the end avent of the tree whether te be croasing a boundary, travelling acrose an area, entering or leaving a bullding, acquiring spectal nuclear materiale, or causing a release of apecial nuclear materials. The second group concerns the adversary's need to resein undetected (when uaing atealth or decele tactics) or to ovarcais any opposition that he encountera (when uaing force toctics\}. The adversery using steslth or deceit tactice aight need to overcome unexpected opposition, but if the stenlth or deceit taceles are to be continued, the sdversary mut overcone his opposition without an alarm being generated, 1.e., opposicion must be considered a detection elewente to be disabled by the adverwary.

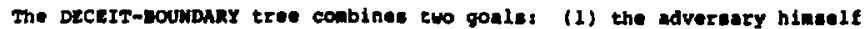
croselng the boundery and (2) suggling contraband across the boundary. For 
convenience of dieculeion, the primary ovente for each goal have bean treated separately. and the two collectione of evente have exch been divided into two groups as above, Conequently, tour groupa of primary events are ldentifled and discussed for the DEceIt-Boundary tree.

Physically, accompliahing any of the end events is readily possible unless one or more bartiers are present. Thus the primary events for boundary crossing reiate to barriera that must be overcone. The qualitative question to ask is, "Can the adversary overcone the barrier(a)?" The answer is generally "yes," if the adversary is guicably akilled and equipped. The analyst nust have a particular threat in aind if qualitotive analyols of these events is to be meaningful.

The adveraary will renain undetected wile atriping to accomplish the end event of $\log 1 \mathrm{c}$ tree unlese detection elemento are preant. Tbus, the priary events for detection relate to detection elenents that nust be avoided, disabled, or deceived (using stealth or decelt tactica), or ignored (ueing force tacticu). For stealth and deceit tre s the qualitative question to ask is, "Is it likely that the adperany can avold, disable, or decelve the detection elements without an alar being gonerated? For force trees the adverasy will ignore detection elemente by definition. But human detection eleanta aight oppose the adverary'. progrese, to the qualitative question to ask 1s, "Is it likely that the adversary can overcone any opposition that he encounters?" To answer "no" to these questions, the analyat aut be convinced that the detection elesents (or the opposition) provide positive neasures. The detection elemente (or opposition) must operate under victually any attack that the anpuned threat can mount. Data from field teste of pertorance and vulnetability could provide parsuanive support co claims of deslgit effectivenese. To anower "yes," the andyst wut find the detection elemente vulnerable to an attack witbin the capability of the agsued threat. whether this is a significant defect can only be determined by evoluating the whole $\log 1 \mathrm{c}$ tree.

If the adversary 19 not permanently stopped by some barcter within the rone. it w11 be nocesery to parfora a quantitative analysia to eatimote whether a response force can Antercept the adverary in tine to prevent hin from achleving his objective. The analyst evaluaten the boundary crosing evente on a tres by anking

\footnotetext{
EAsI, zotimate of Advereary Sequence Interruption, is anong the sinplest of the quantitative analyes to une. see the following:

A. A. Bennett, The "EAsI" Appronch to Phyeleal security Evaluntion,

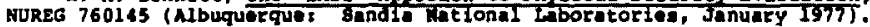

D. W. Saser, EMI on the HP-25, GP-65, and HP-67, MUREG-0231 (AIbuquerque:

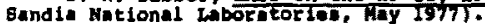

H. A. Eennett, Ueer'e Guide for Eveluating ghreicel Becurity Capabilities of

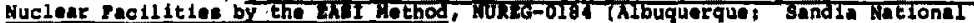
Eaboratories, June 1977$)$.

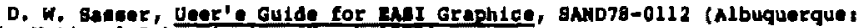

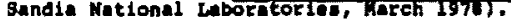

H. A. Eannett and D. W. Iateer, MgI Program Ingrovesante for HP-67 and TI-59

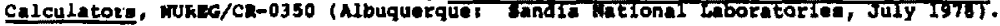


the quantitative question, "Bow nuch tise will the advertary use to overcome the barrier(s)?" Th1a tine 1a the delay provided by the barrier(s). It is also called a task time.

The analyst evaluates the detection events on a tree by asring the guantitative question. "What 1 the probabllity that the adversary will be detected as he strives to accomplish the end event of the logic tree?" These probabilities of detection (and associated standard deviations) are data used in quantitative evaluation.

\section{"BOUNDARY" GENERIC LOGIC TREES}

There are three generic logic trees: one each for crossing the boundary by stealth, force, and deceit tactics. The primary events of each tree can be divided into two grcups. One group concerns the adversary's need to cross the boundary. The other group concerns the adversary's need to remain undetected (stealth and deceit trees) or to overcome any opposition that he encounters while he crosses the boundary. The logic tree DECEIT-BoUNDARY has two cases for each group: (1) the adversary himself crossing the boundary and (2) smuggling contraband across the boundary.

Contraband is explicitly considered only in the dece1t logic tree. The adversary using force tactics and carrying contraband 1s, by definition, unconcerned about detection either of $1 t$ or of himself. The analyst ahould take into account the effect of the contraband as a burden. The adversary using stealth tactics and carrying contraband tries to avoid detection. He does so, generally, by crossing a boundary where there are no special detection syatens to sense explosives, netal, or SNM. The analyst should take into account the effect of the contraband as a burden and the possibility that a sensor will sense material carried by the adversary as well as, or rather than, the adversary hinself.

One question to ask in a qualitative evaluation of the logic tree is, "Can the: adversary overcone the barrier(a) to crossing the boundary?" Por the deceit and stealth trees a second question is, "Is it likely that the adversary can avoid, disable, or deceive the detection elements without an alare being generated?" Eor the force tree a second question is, "If it likely that the adversary can overcome any opposition that he encounters"

If a quantitative evaluation is needed, one question is, "How much time will the ajversary need to overcome the barrier(s) to crossing the boundary?" The other quantitative question is, "What is the probability that the adversary will be detected as he crossea the boundary?"

\section{STEALTH-BOUNDARY}

Figure 7 hows a simplified version of the generic logic tree, STEALTHBOUNDARY. Thle tree gives general logic for defeat of a boundary by stealth tactics. There are 10 primary evants $(51-1,51-3,52-1,52-3,52-4,53-1,53-2,53-3$, s3-4, and sx3-5). Thege can be divided into two groupe. One group concerns the 


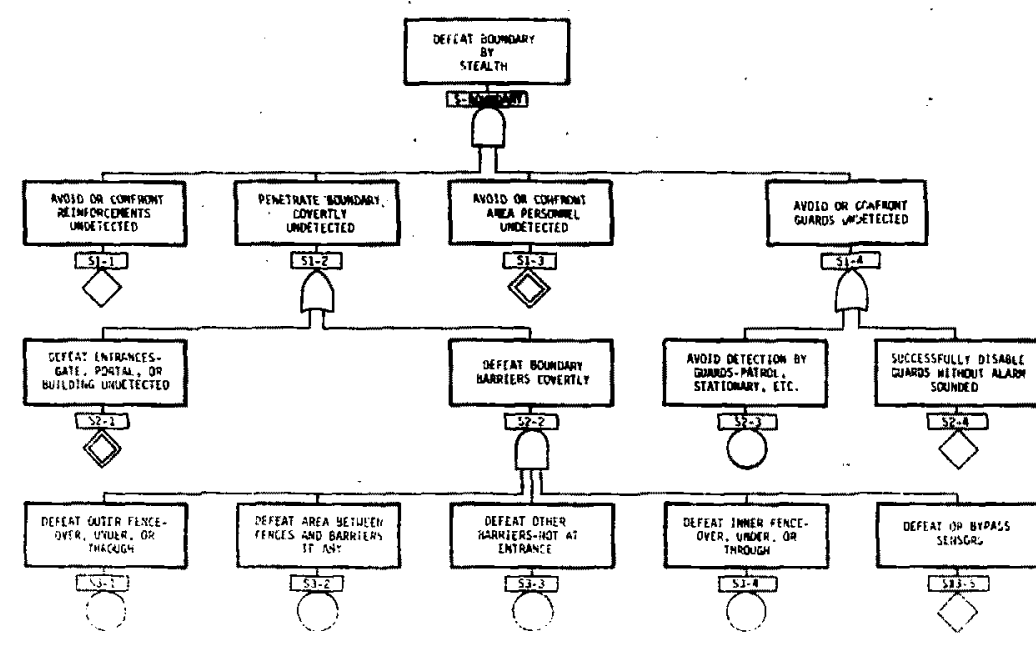




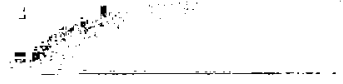

advereary's need to get ecrose the boundary (\$2-1, s3-1, s3-2, s3-3, and s3-4). The other group concerne the adverancy'a need to realn undetected while the boundary crosesing is ande (s1-1, s1-3, s2-3, s2-i, and 5x3-5).

The $\log 1 \mathrm{c}$ tree asaunes the boundary has two parts. In one part, croseings are ade normally, i.e., through a gate or portal (aee event 52-1); in the other, crossInga are prohibited, i.e.. everywhere other than a gate or portal (eee evento s3-1. 53-2, and s3-4). These two parts of the boundary should present different problems to the adversary.

The elements of the physical protection system at the gate or portal are not naned in event s2-1. It is the analyst's job to supply theare elenents from the design wich he is evaluating. However, s2-1 is a developed event; it is further developed on the complete generic logic tree, stenLTy-BounanRY. That development is ignored in this discusston.

Along the boundary elsewhere than at the gates or portals, one kind of element iv so frequently used that it it specified by the development of sa-2. That element is a fence or two fences with a cleared space between then (S3-1, S3-2, 53-4). A1) other posaible kinds of barriers (including any which inpede an attack fron aboveground or undergraund) are covered by event s3-3.

Three kinds of elemente detect boundary croseings. One is located at entrances (52-1, a developed event). No examples are naned on the aimplifled loglc tree. One or wore guarda posted at the entrance any be usad. But guarda alone may not be a positive measure for detection.

A second kind of element aenses along the boundary but not necesarily at entrances (SK3-5, a developed event). No exaples of the seneora are naned on the simplified $\log 1 \mathrm{c}$ tree, A combination of seneors may be used. The analyat's job is to evaluate whether the conbination produces a poitive measure for detection.

The third kind of element operates anywhere along the boundary, both at and away from entrances ( $51-1,31-3,52-3,52-4)$. cuarda on patrol or atationed in observation towers are one example (82-3, 82-4). If they alone could not be a positive meaure for detection, they any reinforce the other kinde of detection elemente to produce a positive measure.

The two evente that name guards a detection elements list two ways that an advereary may not be detected. He can avold being seen by the guerds (S2-3), or, if he is seen, he way be able to prevent the guards from counding an siarm (52-4). While the latter method of avoiding detection way be forceful rather than stealthy, it repreaente an action required of the adveraary if he is to continue his attack by steslth, undetected, after he accidentelly confronto a guard. In general, the adversary will probably be able to see where patrol guarde are and croat the boundary when they are abent and unable to wee the advertary. It ary be difficult for on advarsary to know whether or not he is being aeen from an obaervation tower or to prevent the sounding of an alerm if he knows that he has been eeen. 
Operations perconnel any be nearby and see the adversary when he crosece the boundary (sl-3). In many inatances, the adversary ohould be able to avoid them. Confrontation would be an unintended complication of an attack by stealth, and it any increase the chance of being aeen by a guard in an oberration tover.

Reinforcemente for the protective force (51-1) would be called only after detection. The time between notification of the protective force and ita arrival could be long enough to prevent the force from intercepting the adverara during the boundary crossing that gave rise to the detection. Thus, this event ary have no relevance for the crossing of the initial boundary of the zone. It way be meaningful with respect to crossing . boundary within the zone after detection has occurred.

Having exanined all primary evente on the aloplified $\log 1 \mathrm{c}$ tree, the $\log i c$ by which the prinary events generate the end event is now exalned. The adversary nust cross the boundary and he nuet aroid detection while doing so. This ia the fundanental logical aterement aade in the logic tree. All other detuil merely elaborates on the posibilities. The fundanentel logical atatenent is ade by the AHD gate s-BOUNDARY. The input for croseing the boundary comed from event $\$ 1-2$. All three other inpute $(91-1,51-3,51-4)$ supply requirenent for avolding detection by the elewents that can operate anywere on the boundary, regardless of where the crossing it ande.

The eleaent: that detect only at entrances or only way from entrances must be associated with those optional locations for croseing the boundary. The optional croseing locations are inputs s2-1 and s2-2 to the or gate s1-2. Crosaing the boundary at an entrance (S2-1) 1a developed prinary event. But croesing the boundary away from an entrence (52-2) in generated by an AND gate wich repeats the fundanental $\operatorname{logical}$ etatement of the logic tree. Crosaing the boundery away fron an entrance requires that four events $(53-1,83-2,53-3,53-6)$ be performed. These four events are inpute to the awD gate 52-2. Avolding detection during the crossing 1. represented by the aingle developed event sx3-5, which is an inpot to the AND gate s2-2.

One other developent appeara on the trea. Event $81-4$, "avold or confront

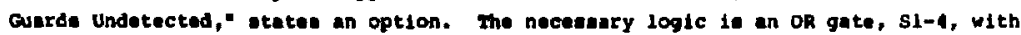
inputa s2-3 and s2-4. This ane cort of option is implied for s1-1 and s1-3. Their developents would have the ane logical fotw at the developant of s1-4.

\section{PORCF-SOUNDARY}

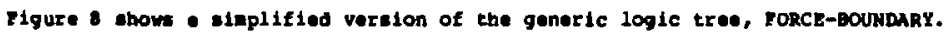
Ini. tree gives general logle for defent of boundary by force tectice. There ore 9 primary ovente (F1-1, F1-3, F2-1, F2-3, F2-4, F-1, F-2, F-3, F-1), Theee can be divided into two group. One group concerne the adverary'e need to get acroal the boundary $(F 2-1, F 3-1, F 3-2,73-3, F 3-4)$, The other group concerns the odverery's need to overcome any opposition that he encountere while the boundary crose-

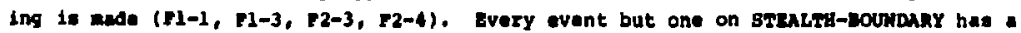




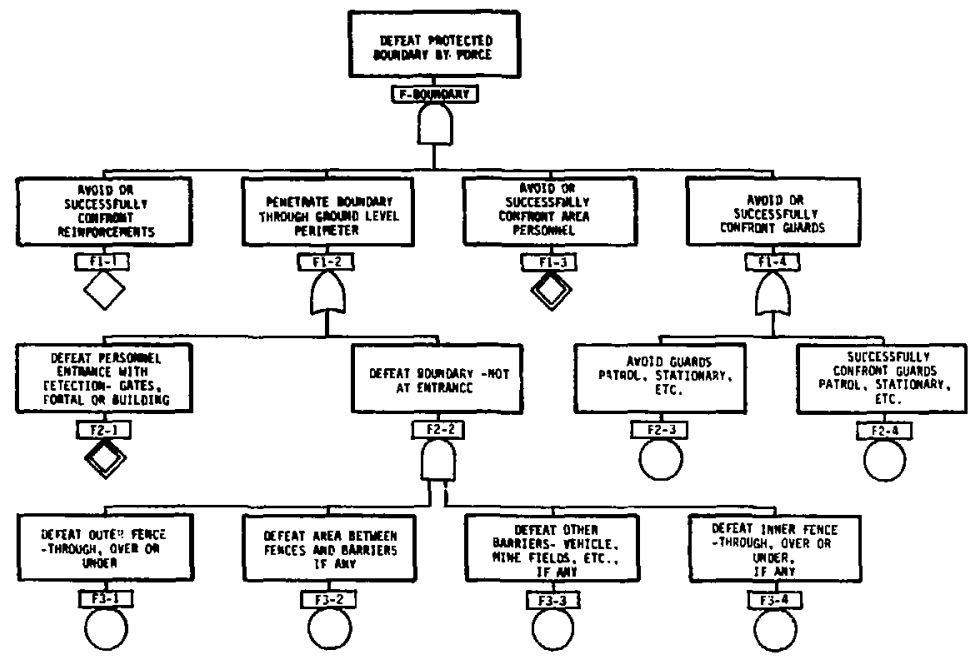

Figure 8. FORCE-BOUNDARY Logic Tree 
counterpart on rorce-Boupdary. The exception is sx3-5. "Defeat or Bypass Detection Syatem." By definition, when using the force tactic the advernary expects to be detected, so the EORCE trees have no events that require the adversacy to take action against the detection ayotem.

\section{DECEIT-BOUNDARY}

Figures 9, 10, and 11 show a simplified version of the generic logic tree, DECEIT-BOUNDARY. There are 23 prinary events (D1-1, DX1-3, DX2-1, DX2-2, DX?-3, $D \times 2-4, D \times 2-5, D \times 2-6, D \times 2-9, D \times 2-11, D \times 3-1, D \times 3-2, D \times 3-4, D \times 3-5, D \times 3-6, D \times 4-1, D \times 4-2$, DX4-3, DX4-4, DX4-5, DX4-6, DX4-7, DX4-8). They can be divided into four gruups. One group concerns the adverasy'a need to get across the boundary himself (1)1-1, $D \times 2-1, D \times 2-6, D X 4-1, D K 4-2)$, The necond group concerns the adversary's need to remain undetected wile crossing the boundary $[D \times 1-3, D \times 2-2, D \times 2-3, D \times 2-7, D \times 2-8$, DX3-1, Dx3-2, Dx3-4, Dx3-5, DX3-6). The third group concerns the adversary's po: . afble need to anuggle contraband across tbe boundary (DX2-9, DX2-11). The $1 i_{1: 1}$ ) group concerns the adversery's need to avoid detection of the contraband whics: $w_{3}$ might be saggling (DX4-3, DX4-4, DK4-5, DX4-6, DX4-7, DX4-8).

Questions to ank in a qualitative evaluation of DECEIT-BOUNDARY are, "(an) :." advertary overcone the barrler(e) to croselng the boundary at an entrance?" Arrl, "Can the adversary enuggle so thet the contraband passes the barrier(s)?" anci " the adversary almost alway avold, disable, or deceive the detection elenents so, detection of nather advergery nor contraband occurn" For both ingider ani ...; sider adveracies the answers depend on the features of the physical protectioil systen at the entrance, on the particular threet and contraband, and on the ste 1 and preparation of the advereary.

If a quantitative evaluation is needed, one question is, "tow much tine $y^{\prime}$ the odverwary need to overcoes the barrier(s) to crossing the boundary himself ing to suggling contraband" The other quantitative quention is, "What is the $p$ o ability that the adverary or the contraband will be detected as the boundary 15 croosed?"

The logle tree 1 s concerned with only one part of the boundary, the ent $i^{\prime} \cdots$ Crossing: are pade normally, 1.6, , through a gate or portal (aee event $01-1$ ). Th. elements of the physical protection system at the gate or portal are not namid it. basic evert Dl-1. This event 1 e in effect nerely a label, reminding the analyst that normality of route and procedure is the essential characteriatic of all des.in scenarios.

Insidera crosaing the boundary by decelt will have no difficulty except ais: dentally through wom fallure of the phyolcal protection syeten. The insidet viji: by definition have authentic credentiala to eatabliah his identity (see event DX2-1). In outaider who obtained identity credential ande on the same equipment with the same materials in the wane manner a all authentic credentials, and obtained through an insider, would atiafy thi event, Hi credentials would hive no flaw and thus would not be detectable as counterfeit. 


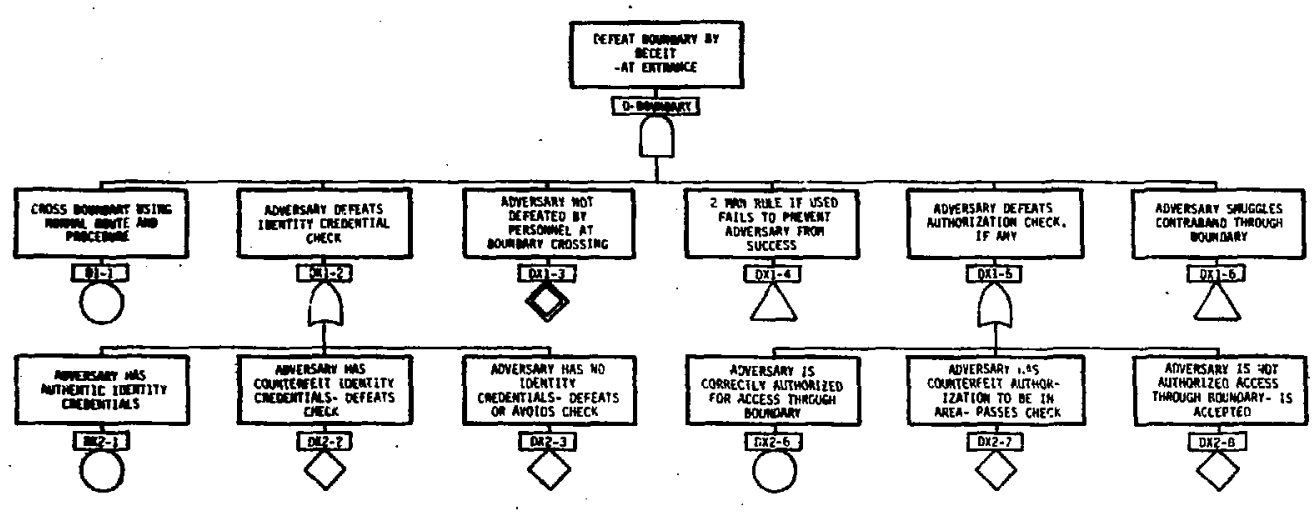

Figure 9. DECEIT-BOUMDARY Logic Tree 


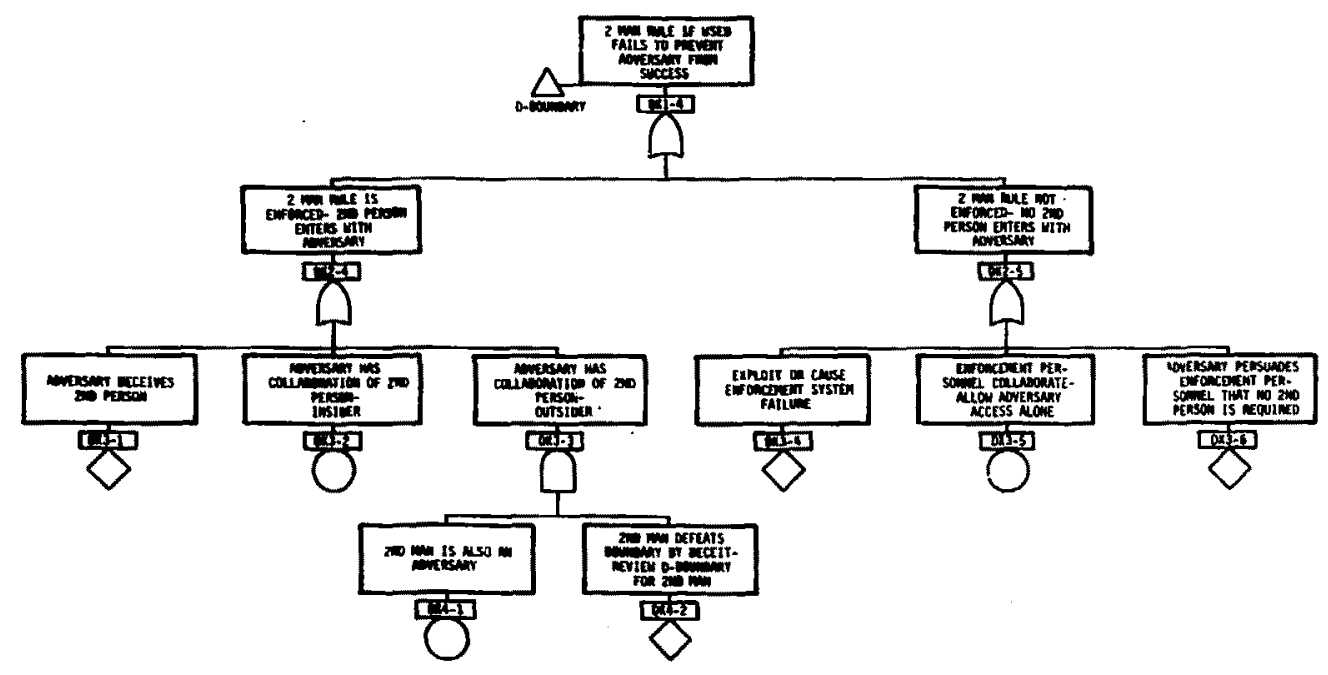

P1gure 10. DECEIT-BOUNDARY, Two-Man Rule Logie Tree 


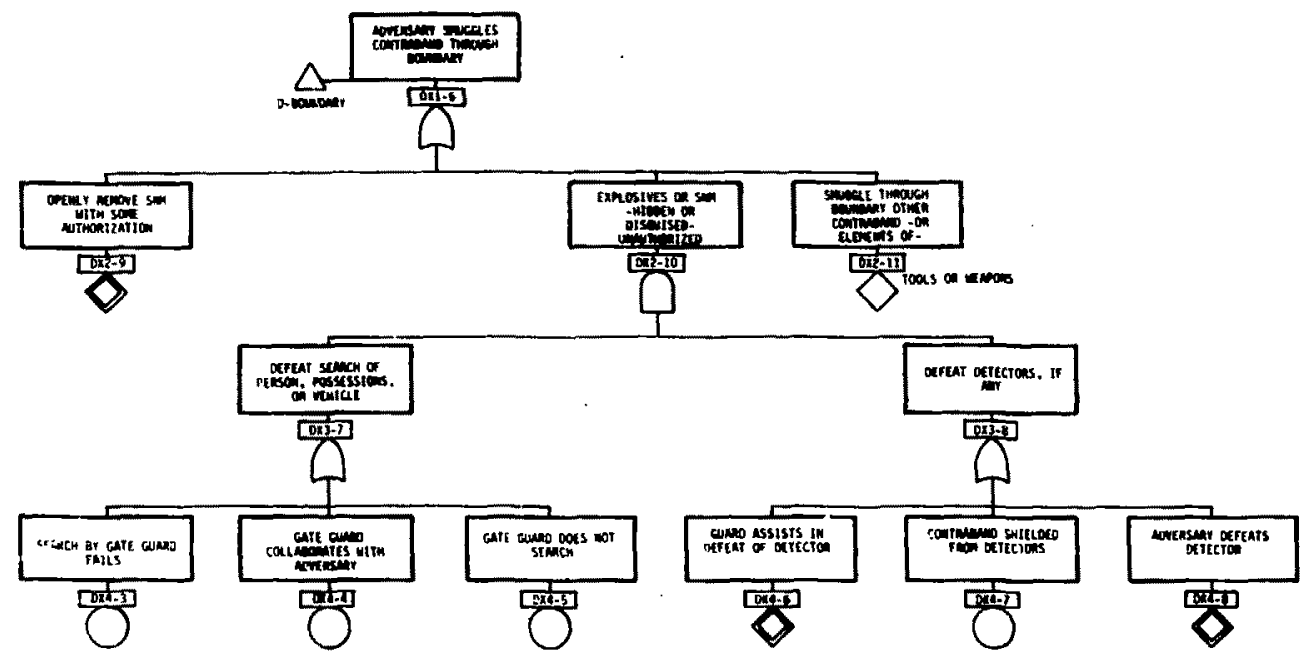

Figure 11. DECEIT-BOUMDARY, Seuggle contraband logic Tree 
If the Insider is athorized to crose the particular boundary in question when he seeks to do so, he will by definition be correctly authorired (aee event DX2-6). An outsider sho hag had authorization etablished in the physical protection system in the same manner as all correct authorizations, probably acconplished through an insider, would satisfy this event. His authorization would have no flaw and thus would not be detectable as counterfeit.

If at the boundary in question a two-nan rule is initiated, the adversary should not be allowed to proceed alone regardless of the acceptability of bis identity credentials or athorisation. In adueruary could try to defeat the physica pratection uyeten by having another, collaborating adversary act as the second man required for the physical protection syatem to admit the two adversary toam (see; event DX4-1). In this case the aecond adversary, as well as the first, must be analyzed for his ability to defort the logic tree DeCEIT-Boundary (aee event DX4-2).

If an adverwary is attenpting to euggle contraband across the boundary $h \mathrm{~L}$ : success in perconelly croseing the boundery becowes conditional on the success if the enuggling, and vice verea. Three clesese of enuggling are included on thr $\mathrm{J} x \mathrm{i}$ tree. The first class concerne openly removing siw with some authorization frow within the boundary (aee avent Dx2-9). This is a developed event, it is further jeveloped on the conplete generle logic tree, DECEIT-BOUNDARY.

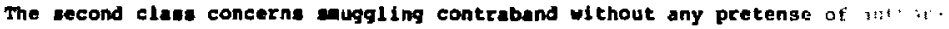
ization by hiding or diuguleing it. Exempes noted on the logic tree are expioss:?.. (which an adverany would enuggle into an area frcm outeide the boundary) and sfim (which an adverady would eauggle out of an area from inside the boundaryl. 'ihs. accompliahent of the uuggling te not ted explicitly to an event in the devolni: ment of DX2-10. The analyet if to asewe that if the adversary can satisfy the i:velopment, l.e., If the contraband is not detected, then the costraband is $3 .:$ cessfully suggled.

The third clase arely exists to collect other possibilitied leee evint Di2-11). For example, auggling of tools or wepone is not covered by the fi: : classes. This event a wo notes that the contraband aight be singgled whot ${ }^{\circ}$, disassembled elemente. Event DX2-11 is undeveloped.

All the kinde of elements thet detect boundary crouaings by deceit are $1 \mathrm{c}$. at entrances. The heart of a typical setection syete- is a chock of identity ant authorization to crost the boundary (bxz-2, bxz-3, Dx2-7, Dxz-1). Depending on :,

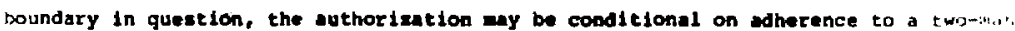
rule (DX3-1, DX3-2, Dx3-4, Dx3-5, Dx3-6). Purthernore, permiseton to complete thi. crossing of the boundery nay be wade conditional on the exeninetion for contrabanil of any material thet may be token werose the boundery (DX4-3, DX4-4, DX4-5, DX4-6, DXA-7, DX4-6). These are the formal parts of the phyeical protection aystem. An other feature wich is not generally a designed part of a physical protection gysion is the miscellaneous percomel wo bapen to be at the entrance at the ane time ai the adverancy and wo have the potential eapability to obeerve and react to sus-

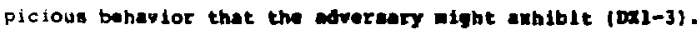





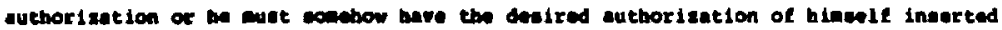
into the file. In this cese, the civereary rune a double risk. The file ontry mut be and vithout atection, and the tile entry wut be ade correctly if it le not to be detecteble as a counterfelt authorisetion. These comonte are applicable to bedge exchange aytere and, at wil, to a file of papar authorizationt or a conputorised authorization file. Won of these considerations are ande explicit in the logle treet avent $0.2-7$ is indereloped.

The dveraery tho is not eathor 1red accese through the boundary neede to find - way to be accepted by the phyaicel protection eyatem (Dx2-b). The adrarany might riek foining a hary flow of perconnel through the entrance, hoping to croes the boundary anonywouly in the aldet of the crowd, avolding the authorization check (and sie lontity credential check, a described in connection with event ox2-3). If the physical protection ayate te deaigned for paraonnel to carry autborization credentiala, an adveraery alght attent the excues that he had forgotten hill, with the hope or knowledge that the syetem does not require wom rigoroue alternate autborisation check. Or the adveraary may play the role of ecoene not expected to have an autborisetion in his pouseasion or on file, auch a a visitor or vendor who

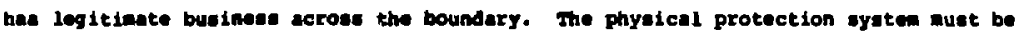

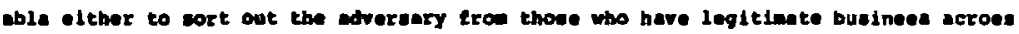
the boundary, or to control the wowement and activities of pareone tho are allowod to crose the boundery without the required authorizhtion for acceas. Another poeoible cateat of the phyalcal peotection syutem is to have the authorization checker collaborate with the edveriary. Wone of these considerationa are ade explicit in the logic tres, event Der-e is undeveloped.

Fiwe prieary wente (Dx3-1, Dx3-2, Dx3-4, Dx3-5, Dx3-6) relate to the adverEary'a need to avold detection arlain from ues of a two-an rule wile croseing a boundary. Om poesbility (Drj-1) te thit the drareary deceiven the econd an. In erely crosilin a boudery, an adversery probably nead not comit an obeervable unatborised ect, w the socond and, creating wh hin, would have no effective way to geation the edvereary' intention. Inis erent is wore meaningful ad a barrier

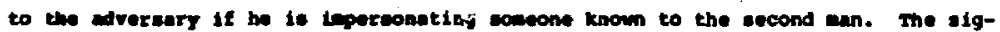
nifience of ment Dis-1 it etronty scenerio dependent, the event if undeveloped.

A seond poefbility (DX3-2) la that the edvareary hat the collaboretion of

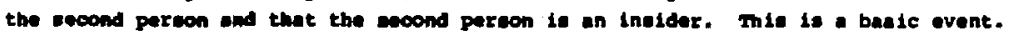
The peoblen tor the analyst to dectite is wother it is eredible that an insider will collaborate (either wilingly or under concion). The caes where the collaborating

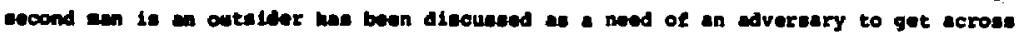
the boundary (evente re4-1 and ma-2).

A third poufbility (Dx3-4) is thet the edveranty crowes the boundary alone by expleitin, and pesibly causin, a fallure of the phraleal protection aysten to

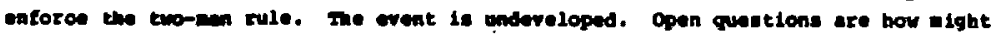

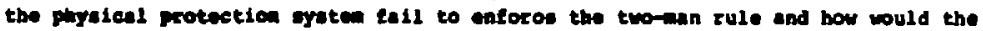
edverwary beowe were of the tellure, if be did not caued $1 t$, so that he could exploit it. 
The third and final poesibility $(D x+-8)$ is chat the advereary defeats the detector $(\theta)$. Since defeat by ahielding and by collaboration have already been züısidered, the remaining wethod of defeat inplied by this developed event is tanpering with the detection systen itself so that it will not indicate the presence of contraband. This is made explicitly clear on the development of DX4-8 which appears on the complete logic tree, D-BOUNDARY.

Having exanined all primary eventa on the simplified logic tree, the logic by which they generate the end event is examined next. The adversary must cross the boundary, and he mut avoid detection while doing so. He may anuggle contraband across the boundary and, if so, he nust avoid detection of the contraband. This is the fundanental stateant made in the logic tree. All other detail merely elaborates on the possibilities. The fundanental logical gtatenent is made by ano gate D-BOUNDARY. The input for crossing the boundary cones from event DI-1. The input for avoiding detection while crossing the boundary comes frod events DX1-2, 0x1-3, QX1-4, and DX1-5. The input for anuggling contraband across the boundary without detection cones from event DXl-6.

The types of identity crodentials wich an adversary night use (DX2-1, DX2-2, Dx2-3), expressed in terms of the degree of lae adversary's detectability, conplete the development of $\mathrm{DXI}-2$ as inputa to an oR gate.

The types of authorization which an adversary might have (DX2-6, DX2-7, Dx2-8), expreesed in terng of the degree of the advereary's detectability, complete the developnent of $\mathrm{DKI}-5$ as inpute to an or gate.

The adversary's options for defeating a two-nan rule (DX3-1, DX3-2, DX3-3, DX3-4, DX3-5, DX3-6) constitute the developent of DX1-4 as inputs to OR gates. For ease of reading this portion of the $\log i c$ tres $D \times 3-1, D \times 3-2$, and $D \times 3-3$ are grouped as inputs to DR gate DX2-4. Event Dx2-4 merely labela 1 ts inputs as all dealing with options in wich a wecond wan does cross the boundary with the adversary. Events DX3-4, DX3-5, and DX3-6 axe grouped a inputa to OR gate DX2-5. Event DX2-5 merely labels ite inputs as all dealing with options in which a second man does not cross the boundary with the adversary. The two label- events, DK2-4 and Dx2-5, are the input: to 0 g gate $D \times 1-4$. Finally, DX4-1 and DX4-2 are pseudo-eventa (equivalent to conentel pertaining to event Dx3-3. They reeind the onalyet of two things that are concurrently relevant: that the second man can also be an advorsary and that this additionsl advercary mut be analyzed by the full tree, D-Bousbary. So, DX4-1 and DX4-2 are inpute to NHD gate DX3-3.

The adverwary' optione tor anggling contraband (DX2-9, Dx2-10, DX2-11) begin the developaent of $\mathrm{Dxl}-6$ as inpute to an OR gate. The basis for differentiating anong the options is whether the contraband is angigled in the open (0X2-9), 1.e., with wowe authorization or pretenes of auboriation, or whether the concraband is hidden or dieguided for anggling (DX2-10), 1.0., authorization la not a consideration. The wot important contraband is sMy and explosivas. The resining input to DXI-6 recognizes that other contraband weh at tools or weapone wight also be inportant $(0 \times 2-11)$. 
The abridgad logic tres, D-monkMx, hat roon tor developient of only one of the bove inpute to Dx1-6, epecifically, Dx2-10. The Inpute to and gate Dx2-10 are the elements of the phyelcal protection oyeter wich the edvereary wust defent: apecificajy, the varloue poestble nanuel, vituel bearches (0X3-7) and the various possible herdwace detectore thet might auplesent or aubseltute for manual, visual search (DX3-B). The adverancy'a options for defoating the search(ea) and detector(z) conplete the developient of the contraband anggling ovent (DXI-6). Options DX4-3, DX4-4, and DX4-5 are inpute to OR gate DX3-7. Optione DX4-6, DX4-7, and DX4-8 are inpute to OR gate DX3-8, One nore level of development can be found for DX4-6 and aX4-8 on the complete logle tree, D-BOUHDhr. 


\section{SYSTEM DESIGN / ANALYSIS TECHNIQUE}

\section{DESGN / ANALYEIS CYCLE}

Anelyate of the effectiveneas of the physical protection of nuclear facilities and anteriale is part of the eycle of design and analyeis ahown in Figure 12.

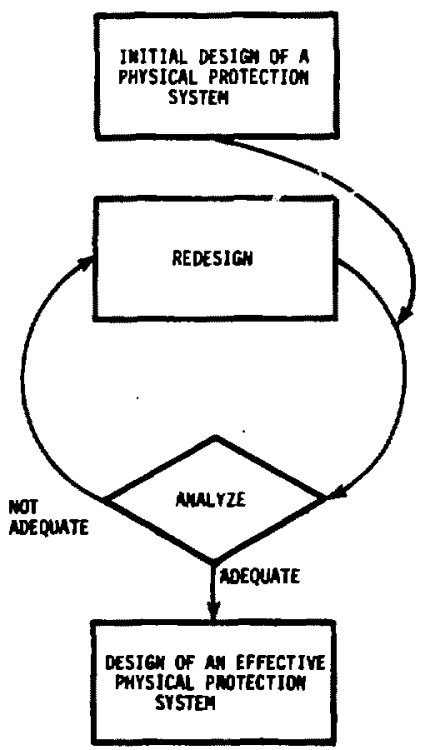

Figure 12. Deeign/Analyote Cycle

The cycle begine with the initial design of a PPS. The qualitative effectivem nose of the PPs is then anslyaed ggainet a range of threate. The reaulte of the anulyeis answere the queation, "Is the physical protection oyutem adequate or inadequate?" If the PPg 1 e found to be adequate, the deaign/analyoie cycle onde.

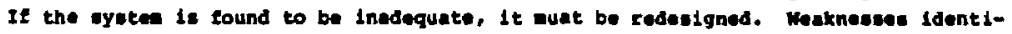
flad by the analyole aut be leproved. The dosign/analysis cycle is closed by anelyale of the redenigned ayctem. The cycle is rapeated until an adequately effective design is achieved. The credibility of the design of the Ppo 1 senhenced by the fact that total oyeten perforance is analyzed. 
Figure 13 introduce Information wich must be collected ans organized in the design/analyaie cycle. It al wo differentiates anong three types of loop in the overall cycle. The design and analysis of a physical protection systern for a nuclear facility involvea six basic stepas

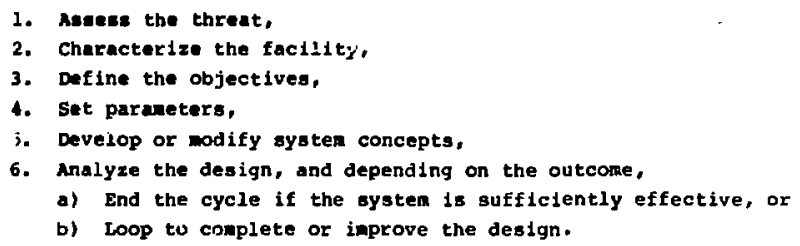

The first two steps (assess threat and chacacterlze facility) gather and organize Inforation, together with the third step (define objectives) they define the general design/analysto problea.

In the fourth step (set parametera), the general problen is aplit into several specific problems whose parameters have values that cover the expected range. Targeta are a phyaical protection parameter; all targets mult be considered before the denign/analyeit procese stops.

The fifth step (develop or wodify eysten concepts), solves one specific prob1on at a time. An effective syatein can be achiaved by iteration, at each step finding combinntions of system elements to provide pasitive measures for all four functions of the phyaical protection systen.

The aixth step (analyze the design), qualitatively analyzes whether the conceptual deaign consists of positive neasures. This design/analysis nethod is iterative after the analyais step. The conceptual design may need modification before it is judged capable of achieving its objectives (return to step 5 , systen concepts). Paraneter values must be changed until the conceptual design solves the whole prob16i in an integrated manner (return to atep 1, set parameters). It is possible that after any negative evaluatione the objectives nust be nodified (return to step 3 , define objectives).

\section{Simplifyine Deaten and Amalyals}

The phyaical protection problen can be illuetrated by logic trees. Logic tree PPG (Rigure 14) has end event "Defeat Physical protection syates" generated by an or gate. The adversary can defeat the physical protection systen by defeating any of 1t. four necesary functions: detection, delay, comenication, or response. This tree is aieply a logical etutement of the physical protection problen as viewed by the adversary. The adversary "uine" if any one of the events is accomplished, and the phyeical protection syetem "wine" if it prevente the adverancy from accompliahing all of the events. 


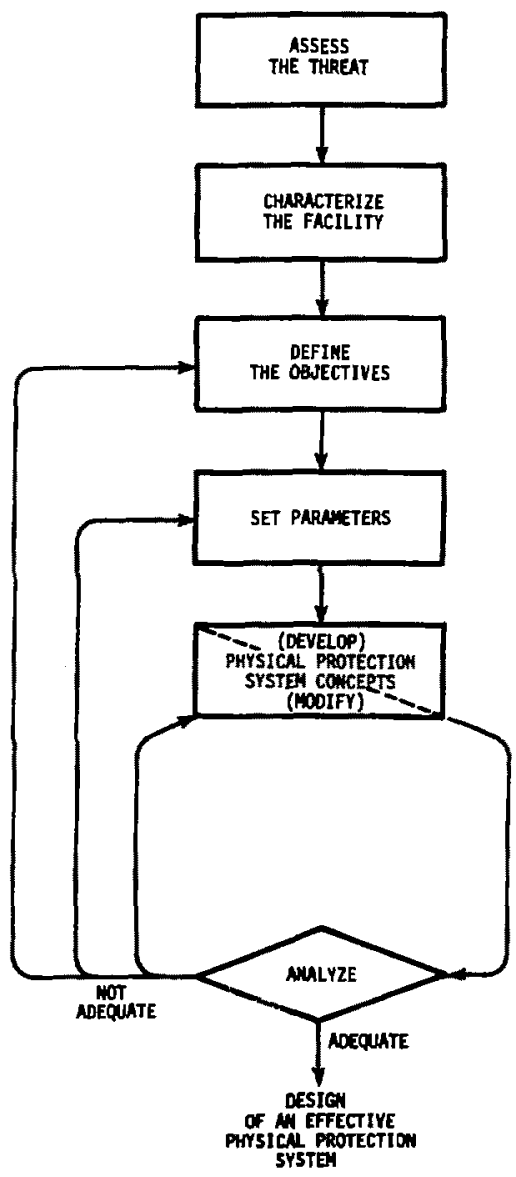

Figure 13. Deaign/Analysis Information and Loopa 


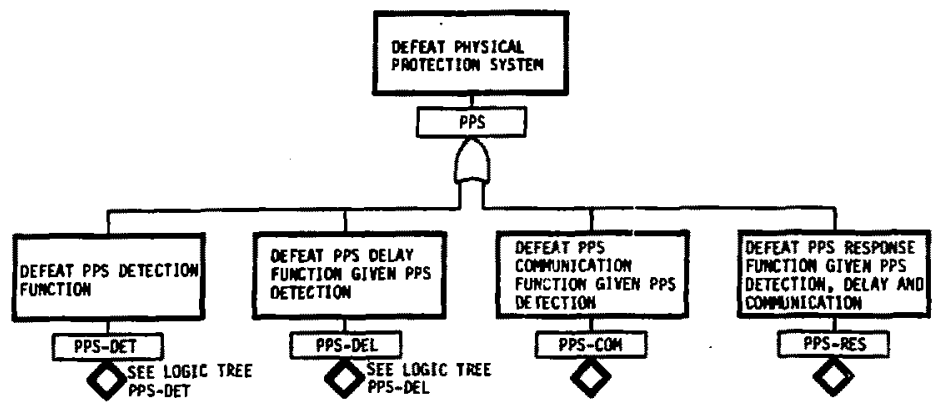

PIgure 14. Logic Tree PPS

Review of the information required about the advereary and the facility will convince the designer and enelyet thet thoy ere deeling with e very complex problen. The rone concept provides a focal point for the design and enelyeie of an effective phyeicel protection eyetem and helpe limit the problen to a eize that can be eslved.

The election of the zone depende upon the aite, the threet, threat tectice, and threat objectives. For en exieting eite, the doninant criterion for initial election of a zone way be to place the zone where wost of the existing detection and delay elenente, if any, are loceted. Inie naxieizee uee of exieting eleaents and operations, but may not eininize the operational and finencial lapact on the site.

significent analytic coplexity ie avolded by liniting coneideration to the phyoical protection eycten acting within the zone. In sone caees, thia einplification ie eufficient to ane the deeign and analysie proble volvable. If the phyetcel protection syeter is effective, the threat will be neutralized within the zone. quetione can be auked about any euppleantery physicel protection functione beyond the zonet detection before the zone is penetrated, delay beyond the sone, or reepone to intercept the attackere after they have departed from the sone. The protective force, for example, would certainly take advantage of detecting an advereary prior to sona penetration and would continue a bettle, if neceseary, bayond the zone. Safeguarde that act outeide the zone are not pert of the PPS end would unneceanarily complicate tha analyala.

The cole of the zone in a phyaical protection ayaten is introduced in logic treee PPg-DEY (Figure 15) and PES-DEL (FIgure 16). The end ovent of logic tree PPS-DET (Figure 15), "Dafeat PPS Datection Function," Ia generated by an wo gate and can be acconpliahed if the adversary dafeete both the zone detection function (2OME-DEP) and detection functions other then thoee deaigned into the aysten (DFT-1). Since the adyerary wut do both for euccese, it is eufficient for the 


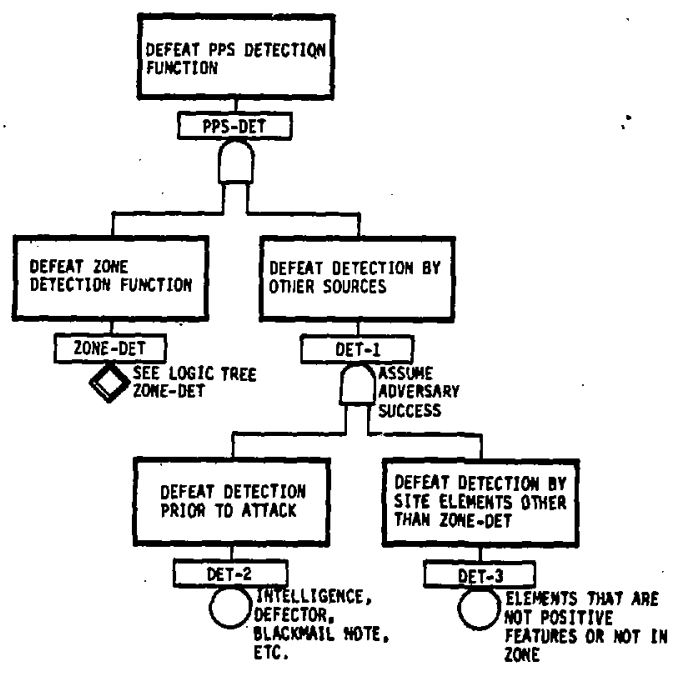

Pigure 15. Logic Tree PPS-DEr

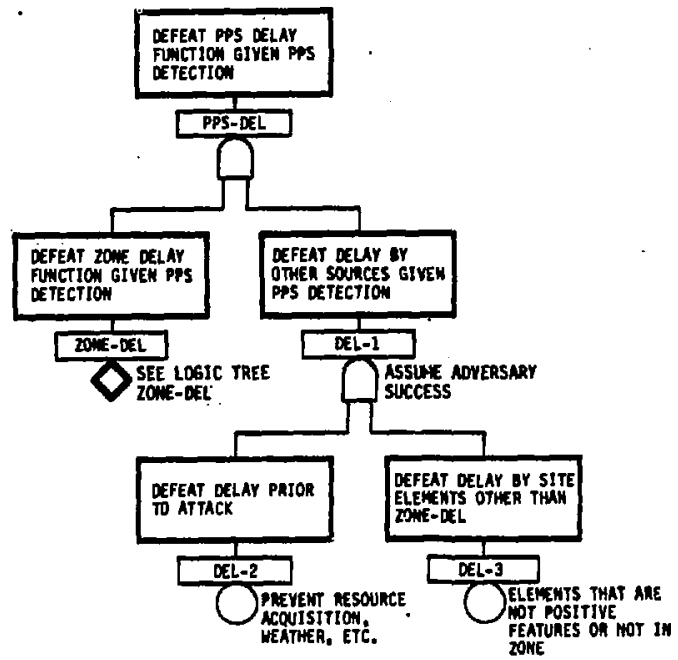

Figura 16. Logle 2Te PPs-DFL 
phywical protection syeten to prevent the advareary tron accomplishing zONE-DET. The physical protection myaten ia denigned to detect and halt attacks within the zone, w the analyais will evaluate event zONz-Der. Event DET-1 refers to factors that sre not part of the physical protection syatue design, so DET-1 will not be evaluated. Loglc tree PPS-DEL (Figure 16) aimilarly develope the delay function.

Timely comanication and responue that can intercept and neutralize the adversaries within the zone mult alwo designed into the system. For example, the response force must carry out its initial interception within the zone since that is where positive meanures exist to track and delay the adversary.

Development of the zone detection function is given in logic tree zONE-DET (Figure 17). The adversary may attempt to defeat detection while using force (DET-FORCE), stealth (DET-STEALTB), or deceit tactics (DET-DRCEIT).

Event DET-FORCE 18 bounded by event DET-STEALTH. This assumes that any attack using force tactics will be detected at least as easily as if the adversary had been using stealth (or deceit) tactics. As long as this assunption is true, the analyst can place a lower bound on the effectiveness of detection by examining only generic $\log$ ic trees for stealth and deceit tactics. The development of DET-STEALTH and DET-DECEIT is found on these logic trest. Similarly, the detection function of a physical protection syuten can be designed with the ald of only the generic logic trees for stealth and decelt.

A similar developnent of the zone delay function is given in logic tree zONE-DEL (FIgure. 18: The adversary nay attempt to defeat the zone delay by the use of force (DEL-PORCE), otedth (DEL-STEALTH), or deceit tactics (DEL-DECEIT). Delay events are all conditioned upon prevlous detection of the adversary. Stealth and deceit events assume that the delay associated with these tactics will be at least as long as the delay associated with force tactice. This assumption is generally valid then adversary detection has prevlously occurred and when the PPS has deaign features ouch as adversary tracking while in the zone. If this assumption is valid, the stealth and deceit generic $\log i c$ trees need not be used when evaluating the aystem delay tunction.

\section{DESIGN / ANALYSIS TECHNIQUE}

This design/analysis technique is qualitative and uses generic logic trees. Instructions for performing the six parta of phytical protection design/analysis follow (wee alwo Figure 13).

begin by defining the general problem. This requires collection of infornation about the spectrua of potential adveraaries (step 1), about the aita, (step 2), and about the ayatem objuctives (atep 3 ). Based on the objectives and the design of the physical protection syatem, identify the areas of the site where the wysten and the adversaries any interact. Then select the $\log i c$ trees needed to trace the interactions between syatem and advereary. 


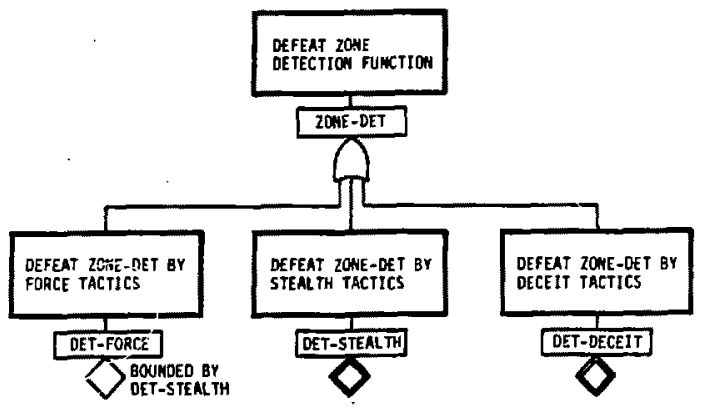

Pigure 17. Logtc Tree zONE-DEs

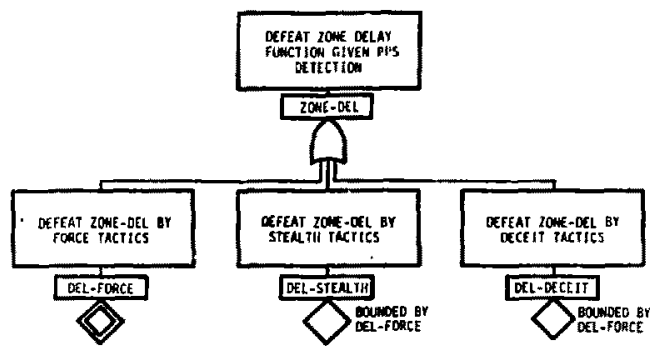

Figure 18. Logic Tree 20NE-DEL

Fourth, select a specific prablem for the design/analyais cycle. Threat and facility characteristics an be fixed as paraneters by the analyet or designer. It sinplifies the inediate problen but requires analyeis and deafign to be conpleted over several iteratione, changing the paranetere to cover their expected range, Paraneters may be assoclated with the threat, its plan of attack, and the facility. For example, wee Tables 4, "gome advarency Characteristica," and 5, "some Inportant Facility Characteristica." In particular, one ganeric adversary aut bo celected from the spectrum of potential adverearies. Wext chooge the rone and logic crees most appropr late to the selected adverancy'a attack. It is not eay to design a system that is prectical, economical, and effective againet a woll-trained, wellequipped threat consieting of several individuals. A suggested practice is to begin the analysis with an adverasy reted nost the wak ond of the threat apectrux. This eype of anelyals hes reletively few coplications and cen be done guickly. If thit analyele thows that the initial design faile to offer saticfectory partormance, relatively little of eort has been ueed to esteblish that there is a need for inprovement. Analyaie of redesigned byoten can teesonebly begin with the leat severe 


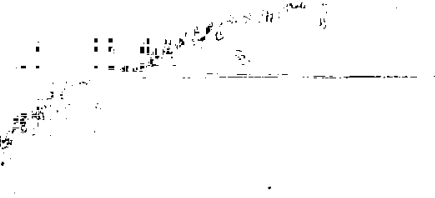

threat that caused fallure of the previous design. If the aysten is affective againet a wak threat, the wecond analysis con une threst fzon the strong end of the epectrua. If the design also posec this test, little effort has been used to test extrese of the threat spectrum. If the design fail the test of a strong threat, try a threat fron the middle of the spectro. A search strategy wuch as this can avoid a lengthy aeries of analyees where severity of threat is increased or decteased ateadily by enall anounts to cover the full apectrun.

Fifli, ather eccept aiven design of a physical protection syaten for analyrie, or ake a conceptual devign using logic trees. Based on threat asesesent, facility characterisation, and definition of objectives, and conetrained by parameter atting : a designer can develop or modify physical protection aystem concepta.

Elements that perfore the required functione of the system any be asigned to chosen location at the facility. Several option acy be devaloped. The cholce of which option to Inplewent will be ande after all optione have been analyzed. There are three design activities to perform:

1. Provide all of the neceasary physical protection functione to prevent the advereary' euccess.

2. Consider a variety of phyoical protection elements to oppose the adveraery at each tack. Include all existing features of the facility that aight be useful for phyeical protection.

3. Select the elemente to include in a phyeical protection aysten on the baces of cost-effectivenest and avolding exceseive redundancy. Recognize when one eleaent can thwart esveral tasks and also when the logic of the tree piratis an adveraary to be thwarted without requiring an element to thwart the succeseful conpletion of-every talk.

Sixth, perforn the qualitative analyais using logic tress. There are three questions to ask:

1. Does the physical protection systen include all of the neceasary functiona? If not, nawe the wiseing functions.

2. Do the functions operate against all atcacks that the eelected threat can wount? If not, identify which function are weok and the attacks by which they might fall.

3. Do the physical protection eleaente have positive aenures? If not, list the deficiencies. If better elesente are know, list them.

If the answers to these quetions are all "yes," return to the fourth atep (aet paraneters), otherwiee design modification or a change of bysten objectivea is required.

To welect another specific problew by making a new setting of paraneters for denign/analyeis requirea, for the sene adversary.

1. Belection of another tactic, a different tine, or different environmental conditione for the attack, or

2. selection of afferent operational state of the facility,

or it reguires selection of another adverary. 
The design/enalyaie cycle te complete when the deatgn of the phyatcal protection ayato to show to be potentially adequate after having been analyzed ageinst the wot werere attack wich can be wounted by adversaried within the asauned apectru. If the dedgn falle, the enelyat has the option of recurning the dasign to step 5 for improvenent, whth only those waknesese identifled mich were involved in the falluce, or elee analying further cases to find other possible weaknesees that wre not teeted by the case that firet cuused oyeten fallure. The latter procedure bbould make redesign wore efficient. If operationel impect, econonica, or sone other constraint precludes a design that is found to be potentially effective ogsinet the fuld threat opectru, return to step 3 and raduce the epectrum or other eyeten objectives and try agein.

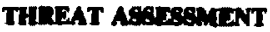

To anulyze or formulate phyeleal protection concepte, a threat spectrum nust be actured, deduced, or otherwise establiahed. To anke an informed choice anong phyelcal protection concepte, the relative effectivenees of each concept needs to be evaluated uaing this thres: spectrum. some adversary characteristlca are simmarized in Table 4 and discuseed below.

\section{Toble 4}

sone advereary Cheracterietice

1. Carcying cepacity for tools and wapons,

2. Facility accese (outeidere ith no uthorized accent, - plorees or visitors with accese, or outiddere in collueion vith employeet),

3. Inouledge of fecility (layout, operations, and phyelcal protection eyetenl.

4. Motivation,

5. Muber of adverearies,

6. Bkillo (nilitary and technical),

7. Epacial equipment (esti-contained breathing opparatu, otc.),

- speed of partoriating teske,

9. Tactles (dacelt, force. stealth, or eny cobiastion of these).

10. Toole (cuttin toreh. explonivas. Iader. lock pick. wire cuttere, etc.).

11. Irenaportetion (eltcraft, boet, goot, ground viniels, or

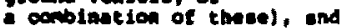

12. Wepons (autenatic ritle, club. hasa gun, elmotgu, etc.). 


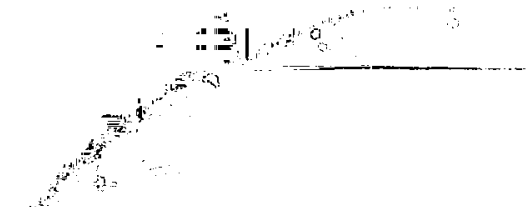

Inforation aust be collected to anewer three questions about the adversary:

1. Who 1: the adversary?

2. What are the adversary' capabilitias?

3. What are the variobles of the adversacy's plen of attack?

Adversaries can be separeted into three classes: (1) outinders, (2) insiders, and (3) outsiders in collusion with insiders. For each clase of adversary, the full range of tactice (decelt, force, stealth, or any combination of these) should be analyzed.

Important capabilities of the adverany include such itens as his knowledge of the physical protection systen, level of sotivation, skills that would be useful in the attack, apeed wth wich the actions that make up the attack are carcied out, and capacity to carry tools and wempons. Since it is not generelly poseible to teat and evaluate the capabilities of a known edversary, the analyat nust make asaumtions, These assuaptions can be based on published information about human performance and tested vulnerability of phyaical protection elenents.

Knowledge of the eystem can be gained fil any ways. Fences, lights, some sensore and assessemt devices, guard posts, and petrol schedules are anong the things thet can be directly saerved fron nutside a protected olte. Visitors may be able to observe some indoor syetcis elements such as door switches, space alarma, and perhape a security control center. Intiders would be able to gather extensive information over an extended period of tine. They may obtain aystem plans; they way be pert of the system. Obtaining exteneive knowledge of the system through the collution of insiders is a major benefit to outsiders. Even without deliberate, conscious collusion, the outsider ay gain wuch information fros conversation with insiders. Information nay be ayailable in public docuents. Finally, an adversary can benefit from general knowledge of comercial security practicea and harduare. The analyat should be cautious in assuning that any apect of the phyaical protection system would not be knom to an adversary.

The level of the adverary's motivation weend likely to be high. An attack on - nuclear facility is an unconventional act ascociated with gre _i hazards. It seems plausible that an unuaually strong motivation would be required to initiate the attack. To the extent that deterrence to initiating an attack is high, oice an attack has begin, it wll be difficult to discourage the adversary from continuing.

The skills ueful in the attack can be determined from the analyat's knowledge of the properties of the protection elementa. Lacking actual adversaries to examine, it is inpossible to catalog their skills. Inferences about the likely aize of an attaik force any be ade by the analyst fron a list of special skills that are not likely to be ponsesend by a single individual.

The speed with wheh any atep in an attack is carried out will vary. For exaple, where several teat: of the ane actlvity have been perfortad, wuch as cliabing over a particular type of fance, the resulte are a minieu tine, a maximum time, and an average tine. When these date are availuble, the analyat neede a ratonale 
for the selection of a particular ties within the range. In an advereary group not rated ior top perfocmance and easentially antrained, apeed would vary from on indirldual to mother and tron ow chek to onother. The aimpleat anduption wold aesign everege speed for all caeke. If the group of adperantes in assued to coneigt of Individuale selected for high potential performance and if they are wll-trained, the anelyat ay aesign maximu speed for all taske.

The capecity to cerry toole and wepone chould be entimated. For exanple, the analyet asy assuse that an advarenry on toot can carry an 18-kg (40-pound) losd in a biker" backpack. For a perticular attack, the analyat can keep track of the neceswary toolf and wapons. If the accunulated wight or volue is not portable, the carrying capecity of additional adverantes or vehicles is requtred.

The tools used by an attacker may include lock picks, laddera, cutting torchee, wre cutere, explosiven, and any others. rools nay be required to penetrate barriers, to dieable detection elemente, to jea comunications, or to comit sabolage. Wepone, If they ere used, range fron the very eimple to the very powerful. A club, a handgun, an autcatic rifle, a sotgun, etc., can be used to combat the respones of a phyalcal protection eyated. These toola can al wo bed to diable equipeent auch a lighte or carera.

Varieblee of the edverancy"e plan of attack include both chotces within his range of cepability and within the range of facility characterietica. Choices can be ade for the attack wong such capabilities and characteristice a environent and wether, the wode and epeed of travel, the nuber of adveraaries and their coles and capabilities; the operationsl state of the cacility, the path taken to reach the encget(a), the tine of day, the tools and wapone carried, and the tactic chosen far each attack task.

Environent and wather can be used by the adversery to his adyantege. Wildlife, if ble to nove tbrough wensor fields, way caune alachs. If thene nuisance alare occur frequently and " : Aifficult to asese, escurity pareonnel nay becone incenaltive, aking detection of an adverany lees likely. Wather ay provide an odvertary with eany opportunitles. Bevy rain, wos, tog, or duat can obucure an

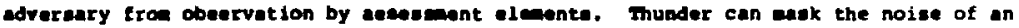
explosion. Violent storna ay caune a lose of comerctal power.

Mode of travel wy be by foot, bowt, ground vahicle, aircraft, or a conbination of thene. sped of travel nay be elgnificant after detection of the attack, wen a respones torce is eowing a quickly a poseible to intercopt the attackers.

Muber of advertarlen is - variable thet could allow for a diversionary ettack or epecialized tank weh a explosive dewolition, disablement of electronic equipant, ariver, atetle apeclalist, ete. A anall nuber of attackere may be preforable where etealth or decelt are the principel tactice used and avoldance of darsction le important. 


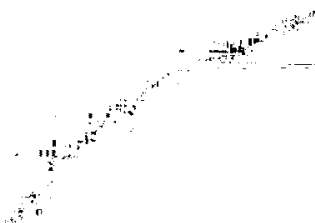

Cperational states of the facility include the work ahifte, the number of operational coployees and guarde working ach ahift, and the locatione in a facility were these individuale are ituated. Eargancy otaten vuch as a fire, criticality, - cediation leak, or anotber abnoreal condition any be used to advantege by the adversary and, In fact, the edveraary ary even couse in energency.."

Several pethe to the tergets of the attack may exist. The adversary would choose the path wi.ch he perceives as being the nost advantageous to his. Time of day ney al wo be an important factor. For exeple, darkneas provides cover for attackera, detection oystene noy not be operated in come locationa at all tines, and rast. hour traffic any degrede respones.

\section{FACUITY CHAMCTEIVATHON}

Information wust be collected about the aite se vell al about the advereary. To characterize a facility the analyet aut acquire and organize the information needed to perforn theft and eabotege target analysea, and to identify other phystcal protection concerns. The advereary noeds to know where to find his targets, how to reach thea, wat kind of lmpediments be wust overcoese long the way, and wat charecteriatice can be uered to his advantege. These are sumarixed in Table 5 . The anelyat sut know the save informetion to evaluate the effectiveneas of the physical protection ayatee as it interacts vith the odvereary.

Table 5

some Important Facility Characterietics

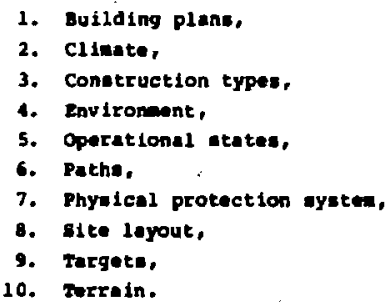

\section{DITIIION of CDUCTIVES}

The objectives of a phyoical peotection aytem nut be defined prior to developent and evaluation of eeaningful design concepta. The objectivee should relate to

I. Furpoes,

2. Performance,

3. Coste, and

4. Impect on other facility ayatemen,

The objectivee any be apactiled, in part, external to the dealgn offort. 


\section{Purpase}

The principal objective of a physical protection system describer its purpose. Generically, the purpose ts to protect nuclear naterials from theft or sabotage. Already identified are cour essential functions of physical protection fdetection, delay, compuitication, and response) and the defense zone where adversary and phys 1cal protection system interact. Analyot and designer nust transiorm the objective of target protection into one or more chotces of boundartes for a defense zone; initial boundary were the adversary to first to be detected and finsl boundary where his attack is to be terninated. Thts task is performed before the generic physical protection logic trees are examined, using information gathered and organized during threat assegsment and facllity characterization.

The rematning objectives are more specific to a particular facility. They can be used to guide the selection or evaluation of physical protection elements ag the logic trees are exanined, event by event.

\section{Performance Objectives}

Performance objectiver deal with two situations. Firat, the physical protec-m tlon systen must be highly likely to succeed over a specified range of such attuck paraneters as threat spectrun, tive, weother, torget(a), mode(s) of attack, etc. Second, the phyaical protection systen nuet have predictable perfornance as attacks increase in severity beyond the specified range of attack pacaneters. Theae performance objectives ace

1. Protection in deptin,

2. System Integration,

3. Predictable aysten perfornance, and.

4. Minimize tbe inpact of the fallure of ony one subeysten.

To achieve these performance objectives is to provide positive neasures in tbe physical protection syater.

"Protection In depth" iaplies that the performance of a physical protection syeten thould not depend upon only one "line of defene". It refere both to redundant implementation of a function at a given location and to backing up the function at one or more other locetions, If the beckups are inplenented with different technologien, the adversacy must buve additional knowledge, akille, and tools to defent the oystem. If a single berrier cannot eufficiently delay the adversary, "protection in depth" might do so by placing enough barriera in aequence along his path to aggregate the neceenary delay. If a eingle type of aeneor cannot he depended upon to respond to an intruding adveranry regacdlew of his method of intruaton, wore than one type night be uned at a given location. The types preferably would have complementary cepabilities. Furtheraore, intruaion acrone lenced boundary way call for alfferent enero differently placed than intrueton by tunnelling, or tron the air, or by an insider.

Gyetom integration is an objective wich should enhance aysten parformance, The essential functions muet not merely be included in the syate but they must also 
work together to achieve the denired result. For exaple, detection of the advereary requires that he be sensed and that his intrusion be properly assessed. The adversary aust rewein in the vicinlty of the seneor long onough after it is activated so that asesement can accur. This regulres integration of delay with detection. Furtheraore, the barrier wich impleanten delay should not provide cover for the advereary that could thuart effective asenesuent.

Predictable syatem perforance inplies that the assurance of aucceseful protection mut not decreas: abruptly if the severity of the attack increases alightly. an increase in the eeverity of the attuck aight involve use of more powerful and efficient tools, a foster sode of travel, weapons that are nore effective, or a greater number of adverwaries. The notion of a slight increase in severity is quantitative, not qualitaive in nature. For oxanple, if the adversary can choose among three categories of tnols--hand tools, power tools, and explosives--switchlng from power tools to explosives cannot be seen as anall increase in weverity merely because it 1s the next nore severe category of tools. The analyot nust be aware of how much more energy can be applied to the adveraury's taske by the change of tools and judge the increase in eeverity by that difference. Predictability of syoten perfokmance recognizes that aystem perfocmance will probably dograde somewhat as severity of attack increases, the degredation may even be nonlinear, but the syatem any not fall utterly to perform its functione if it is placad under a slightly greater strese by the attack.

To minimize the inpact of the failure of any one ubsyatem, contingency plans and redundency in the designad aystem are naceanary. Furthermore, no function may tall even if one element fails. It is unlikely that a complex syaten will ever be inplemented which does not experience eubsysten foilure. Causes of subsystem failure in a phyaical protection aystea are numerous and can range fron environmental factors (which ay be expected) to adversury action outside of the throut spectrun used in the systen design (not expected). While knowledge of the cause of a subsyaten fallure is ieportant in an attempt to restore the oyetem to normal operation, it is more inportant for contingency plens to be provided. These contingency plane will aininize the effecte of oubsyaten failure $\bullet 0$ that the syotem continues to operate effectively. Contingency plane may be carried out autonatically, $\bullet .9 .$, when one piece of equipent talls, redundant equipment sutcmatically begine to porform the function provioully performed by the disabled equipment. However, certain eubeystex fallures may require id from cources external to the facility in order to aininize the impact of the Eallure.

\section{Cont Oblucthres}

Cost objectives way be inposed upon a design project. However, they might not be explicit, in whlch case Interest is focused on cost-effectiveness evaluation of alternative designe that aoet performance goals. In either cese, it if neceeuary to estinate the cont of each effective syatem design. While the coet-effectivenese evaluation cannot occur until the design is complete and is not within the scope of this report, coet entinates can be prepared ae a deeign proceeds. The analyet must estimate sll oystea costis 
1. Procurement,

2. Invtallation,

3. Operation,

4. Heintenance.

\section{Inpact Objectives}

The last objective is to linit to an ecceptable level the inpact of the physical protection syaten on other facility ayatena. The soveral faciltty systens that may be inpacted are

1. Matertal accountability,

2. Material control, and

3. Operations.

The inpact of phyelcal protection on material accountability may be neutral or sonewhat favorabla. The two syateme do not intarfere, and there are scenarios for wich a phyalcal protection ayater can provian tinaly detection of theft but anterial accountability cannot (for example, a theft of a lerge quantity off-ahift when aaterial accountability is not operating). However, enterial accountability aystems should datect repated divaraion of anounte of nuclear anterial too anall to be detected by physical protection systens.

The lapact of phyaical protection on acerial control may be nautral or require atricter material control. Mterial control la underatood to be the aystan wich athorizes, regujates, and monitora the nopenent of nuclear material. Wherever the phyaical protection ayatea intercepts a movenent of nuclear wateriel, the propriety of that movenent in accordence with enterial control nuet be atiefactorily dewonetrated. Materiel control mut be eufficiently atrict to eneure that $1 \mathrm{t}$ will be very difficult to decelve the phyalcal protection oystem.

wong eeveral kind of impact on operetions that mey occur ere changes in

1. Morale,

2. Production conte, end

3. Bafoty.

An ecceptable level of inpact on operation thould be aininal, eince the effecte of Inpleanting phyalcal protection can be adveras. Parhapa vorale could be favorably lepeced if the benefite to soclety from enhencing the security of nuclear meteriale ere expleineds thite euet offut a tendency to reeent an inplied dietruet of fecility enployees.

Phyicel protection is an overhead 1 tee, wo it inheranty adda to the coet of the facility'a product. Ixapled are tine coneuning, non-productive phyaicel protection manures auch as eccese control and searchen tor contrabend. Economic force will drive eyeten design to echieve a mandetory level of phyeical protection ee inexpensively at poseible. 
safety can conflict with physical protection, ws wen a real fire or release of radioactivity requiras prompt avacuation of a building, but hoax fire or radioactivity alarm could be uned by an adverary to cover hia escape with stolen nuclear naterial. Mandatory safety regulations cannot be arbitrarily overidden by a physical protection aysten. Instead, the physical protection syaten nust conforn to afety regulations, though this night not preclude changes of traditional safety procedures for others that are equally effective but more nearly compatible with physical protection.

\section{DEFINE THE GENERAL PROBLEM}

The general problea is defined by establishing the threat spectrun, site attributes, and system objectives.

Threat spectrun nuet be anaigned an upper bound for the purpose of the design, whether the bound is derived fron threat analysis or is arbitrarily assuned for lack of predictive information.

Site attributes contribute to defining a general design/analysis problem by establishing the physical context in which the physical protection systew wust function.

Syeten objectives are needed input for application of the zone concept. Where should firet detection of a particular type of threat occur? how far toward the adversary's target or escape should the threat be allowed to proceed? Insiders and outeiders, theft and sabotage all require consideration.

Fron the system objectives, derive the corresponding defense zones. "Boundaries" are definitive characteristics of zones. The two boundaries, initial" (first detection) and "final" (tecuination of attack) wust be selected for aysten objectives to be changed into a useful zone concept.

\section{SELECT A SPECIFIC PROALM}

To select a specific problem, select one zone to study from all the sones that might be established. In general, everal logic trees are required to detai the interactions batween the adversary and the phycical protection syatem within one zone. The set of $\log 1 \mathrm{c}$ trees relevant to a zone can be claseified by action (penetrate a boundary, cross an area, enter a building, acquire apecial nuclear materiala, or cause a release) and by tactics (deceit, force, or atealth).

There is a relationahip between particular tactics and particular function. Delay is exanined on the force logic trees. Detection is exanined on the stealth and/or deceit $\log i c$ trees. Comunication and response are related to the ovent "Defeat Reinforcenents" on any $\log 1 \mathrm{c}$ tree.

Nerrow the problem further by welecting one logic tres to atudy from anong all the trees relevant to one zone. Each $\log 1 \mathrm{c}$ tres is comprieed of many events. 
Narcow the problem st11l further by exanining one event in the tree.

\section{DEVELOP OR MODITY PFS CONCLTS -}

Make a liet of any phyical protection elemente which aight block an adversory from acconplishing the event. The design should proceed to another event and potentially effective physical protection elenents chould be listed for the event. This process is continued until all prieary evente of the logic tree have been considered.

The designer akee aelection of theae liated physical protection elements that can be expacted to be positive measures, preventing the adversary fron accompliohing the event. The designer hopes to achleve a cost-effective gysten not nerely by choosing econonical elements fron the liat for axch ovent but also by taking advantage of redundancy ang the liats of elements for all events of the $\log$ ic tree and taxing advantage of the logic of the tree. The adverarary can be prevented from accompliahing any event thit is the output of an Alo gate by preventing hiw from accoplishing any one event that is an Input to the No gate. Thus a designer can choose anong all the element lists acsoclated with inputs to an AND gate for a feu that are most cost-effective. Hore than one elenent should be chosen to provide a truly politive nasura having defenme-in-depth and reliability. The attack icenario influences the decision about which elemente constitute positive neasure.

\section{ANALYZE}

Uaing the foglc trees to avaluate ayaten is a loglcally almple procedure. The difficult tak for the analyet is deciding whether the design of the phyaical protection ayaten has positive wesures thet can prevent an adversary from accompliahing a particular event. Making thet ducteion is beyond the ecope of this report. The $\log i c a l$ evaluation is preserted.

Every event in the goneric logic trees describes an action which an advereary muat perfor to achleve the end event of the tres. awalitutively avaluate each priary event in the tree. The inportant question 16, "Can the adversary accomplisb the evert?" The reatining anelyais 1: done quickly and follow slaple rulat. Exanine all evente that input to a gate. If the gate is an or gate, the adveraury need only accompliah one of the Input events to accomplich the event generated by the oR gate. If the gate 1 a an $A$ o gate, the edvereary nust accoplith overy input event to accomplieh the event generated by the awb gate. To keep track of the adveraery' accompliabments end fallurea, wark each event whlch cannot be accomplished. For exanple, place an " $\mathrm{x}$ " or " "w" edjacent to each unperformable ovent. When all event: at the botton level of the tree have been evaluated, all the neceevery information - has been generated to apply the loglcel rules to the gater at the next higher level of the tree. Complete one level before soving up to a higher level. Continue until the gate wich generates the end event has been evaluated. The proceas is 111uatrated in Figure 23 for the logic tree grahra-bounahy. 


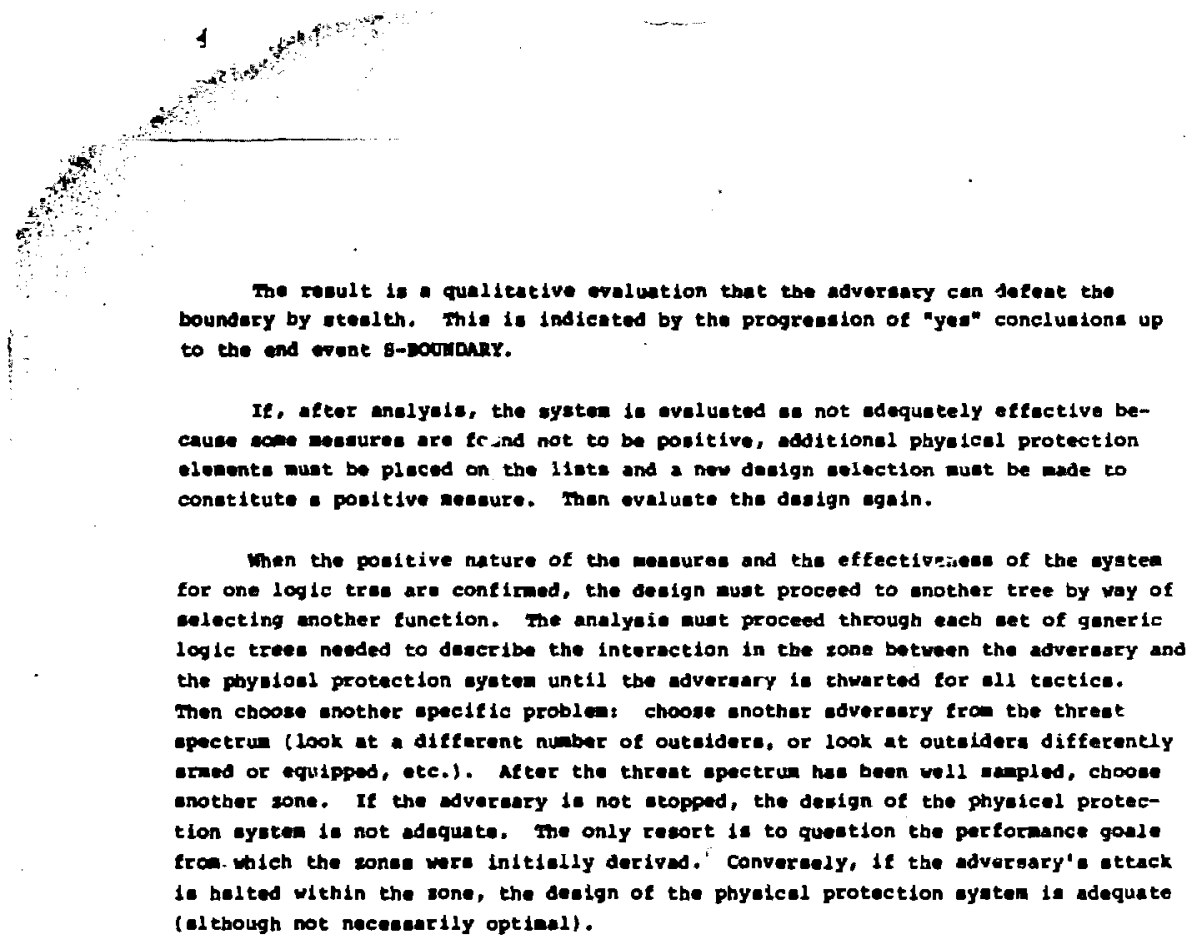

\section{ANALYSIS TECFNIQUE EXAMPLBS}

\section{Deties the Genorit Problem}

wo exaples ore given of defining the general problem becauge the ecope of this ectivity is too lerge to be demonerated in a fou rorde.

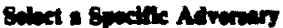

To desonetrate the eacond part of the anelyaie technique, a particular edvereary is selected from the threet epectrua. In thie inetence, the choice has been made arbitrerily to woke the example einple, lat the edverasy be a eingle outeider woes goel if eabotage of a nuclese power reactor that wuld caues an unacceptable releace of nuclear meterisl beyond the elte boundery. Aasue that the edveraery

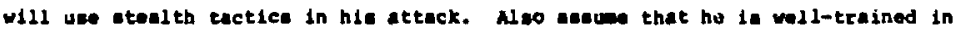

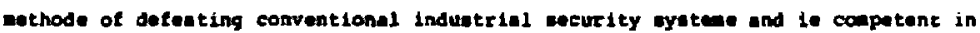
the uee of explosivee to eabotege equipent.

\section{Solvet a Evadile Zone}

Given the eite depicted in Figure 19, asewe that the cone if a boundary region cloesly coneined to the alte perineter, a depicted in Figure 20 . The perieotor is arived by a eingle tence and one portal location at wicb there are eperate festures for vehicle and pedeetrian acoese to and froe the elte. The objective of this whe 10 to prevent any adverary crom penetrating the lence or portal. In other words, the edvereary is not to be allowd to enter the pover reactor site. 


\section{Salact a Saceilic Lode True}

For the sone aelected, only $\log 10$ trees for panetration of a boundary need to be analyzed. Three ganeric $\log 1 \mathrm{c}$ treed are applicable for the thin, ingly fenced zone: DECEIT-BOUMDARY, FOACE-BOUNDARY, and STEALTH-BOONDARY. All three trees should be analyred because an wdveraary is free to une whichever tactic seens to him nont advantageous. As a minimum, the stealth and deceit trees would be used to evaluate the detection function, and the force tree wold be used to evaluate the delay function. Only the evaluation of detection againet stealth tactics is preaented to 1lluatrate the athod. Pigure 21 is the simplified generic logic tree STEALit-BOUnaRY, which descrlbes how the adversary might penetrate the boundary fin this exapple, the zone) by stealth. S-BOUkMAR to the same event as DET-STEALTH in Pigure 17.

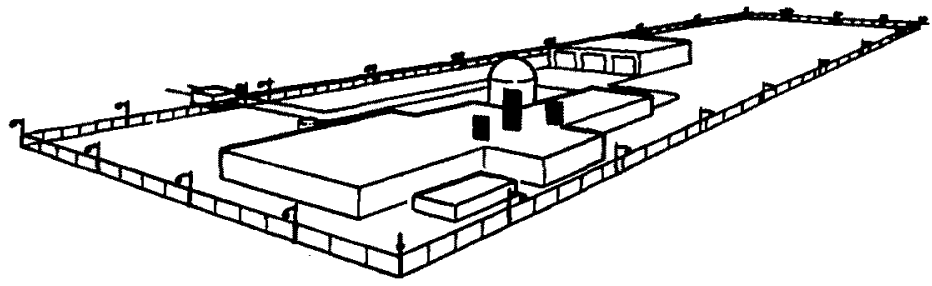

Figure 19, An Hypothetical Powr Reactor site

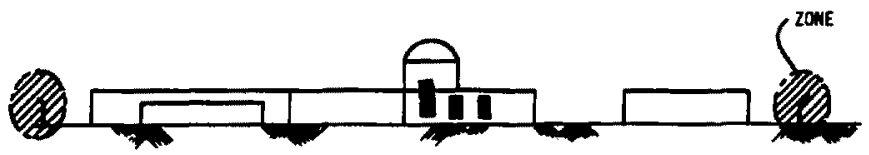

Figure 20. Exanple of a zone

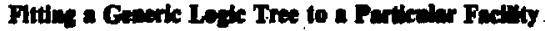

The deaign of a physical protection syaten for a particular facility will not, in general, heve all the elemente ieplied by the generic logle treet. Before the facility cen be enelyied, the tree aust be odified to accurately descrlbe the facility and 1te physical protection syoted. Using figure 21 , asene thet the phyeical protection ayatem design being analyred includer only one fonce. Reep event 83-1 (outer tence) but delete (crone off) evente s3-4 (Inner fence) and s3-2 (area betwen fences). Ascume that no providion has been ade in the design to delay underground or atr attecke end thet the single fence is the only barrier in the design. Delete 83-3 (other berrlers). The result is that ald gate s2-2 has only two Inpute, 83-1 (outer Eenee) and sx3-5 (defat or bypane censors). Bince the Initiel boundary of ane te the coneern in this caee, prevlous detection le not 


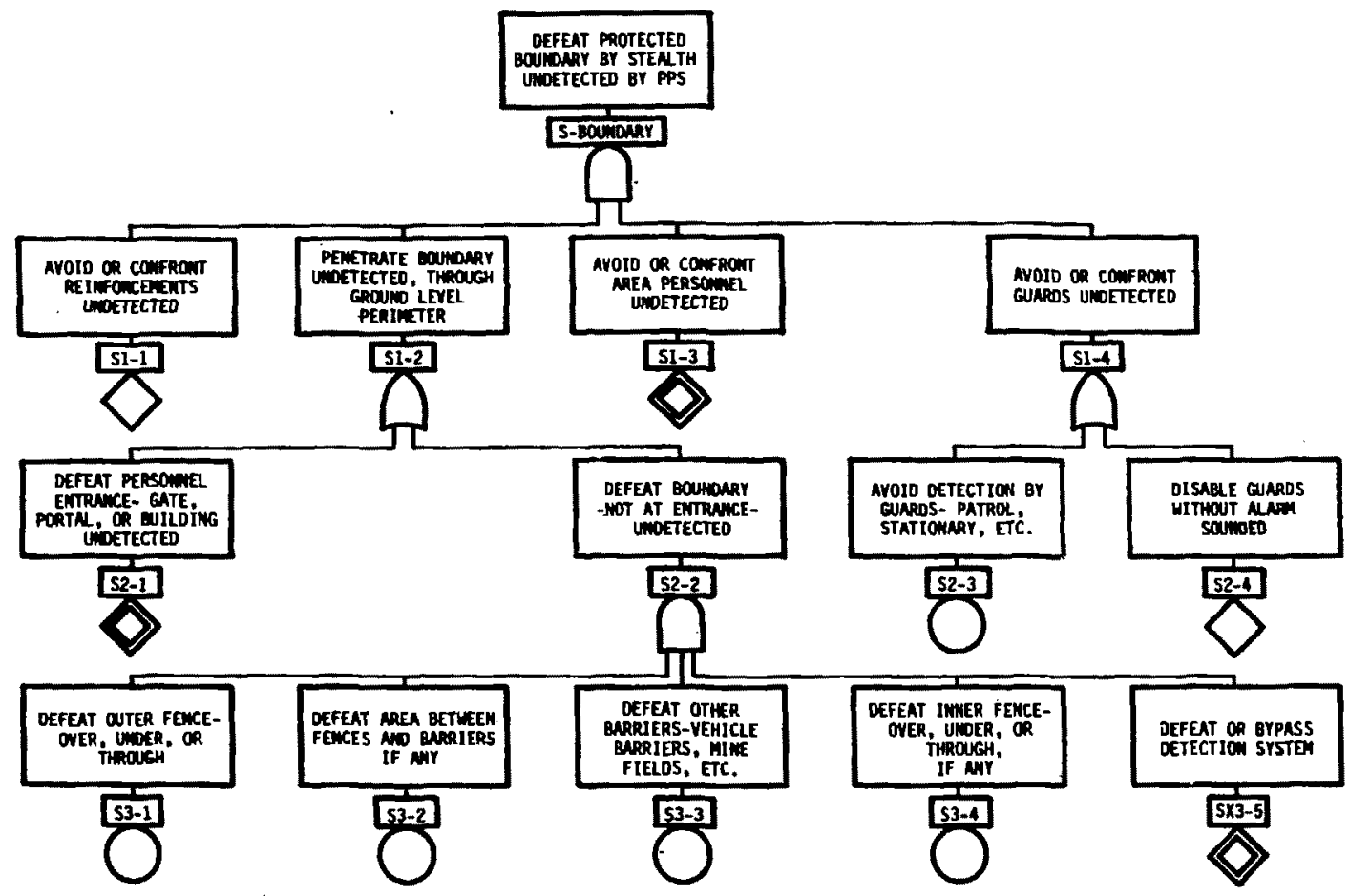

Figure 21. STEALTH-BOUNDARY, Simplified 
assuned, Aloo, delete sl-1 (avold or confront reinforcenents). Figure 22 is the modified STEALTH-BOUNDARY logic tree. Modify gimilarly each logic tree needed to analyze the zone.

\section{Describing or Duigaing the Syotem}

Before a logic tre's can be analyzed to see if a physical protection systen can prevent an adversary from accomplishing the end event, it is necessary to note the elements on the logic tree adjacent to each event which they might prevent. Figure 22 showg an example of detection elements that could act at the singly fenced boundary of the power reactor site. The gelection, mixing manpower and relatively simple technology, is representative of basic industrial security. The single fe.lce is described only as "chain link" (S3-1). At the portal (S2-1), it is assumed that guards rust activate a turnatile for access by pedestrians. Access by vehicles has been onitted in this example. The fence along the perineter of the site is patrolled by guards (S2-3) approximately every 30 minutes. If guards see an intrusion, they can report it by radio (walkie-talkie, s2-4). Site personnel are trained to report susplcious artivity and alarn boxes are provided for signalling (51-3). pinally, no sensing hardware is installed along the fence (sx3-5).

It is possible for this procedure to be used either by an analyst, associating actual or planned physical protection elenents with a logic tree, or by a designer, speculating about what elements could prevent an adversary from accomplishing events. In a design process, the association of physical protection elements and events produces lists of possible parts of a physical protection system. The designer might then choose wich elements are nost cost-elfective to define the systen.

\section{Evalantine a Syctem}

For the physical protection elements given as an exanple in figure 22, 1evel 3 (the botton level of the tree) is where evaluation begins. The results of evaluation are shown in Pigure 23, Arbitcarily, the primary events will be evaluated fron left to right, so event $53-1$ is examined firte.

S3-1: Defeat (outer) fence - over, under, or through, Recall that this example has only one fence, so "outer" fence is an irrelevant description. Exarination of the Barrier Technolosy thandbook (SAND77-0777, see Tahles 3.6-I, 3.6-II, and 3,6-III therein) will show that a chain link fence, no natter how elaborated with bacbed wire or tape, can be penetrated by going through it with ajds as simple as gloves, boltcutters, wirecuttera, or sone conbination of these, in approximately a half minute or less. The fence can be penetrated in less than a half minute by going under it with the ald of one or two additional adversaries using gloves or one or two long (3-metre) pieces of plpe. The fence can be penetrated in less than a half minute by going over it with the ald of gloves, hooks, carpet, or some combination of thege. An adversary can accomplish event s3-l quickly and with only a minor burden of toole.

Sx3-5: Defeat or bypass detection systen. There 18 no sensing hardware along the fence in the example, so the event 1 s trivial, and any adversary can "accour plish" it. 


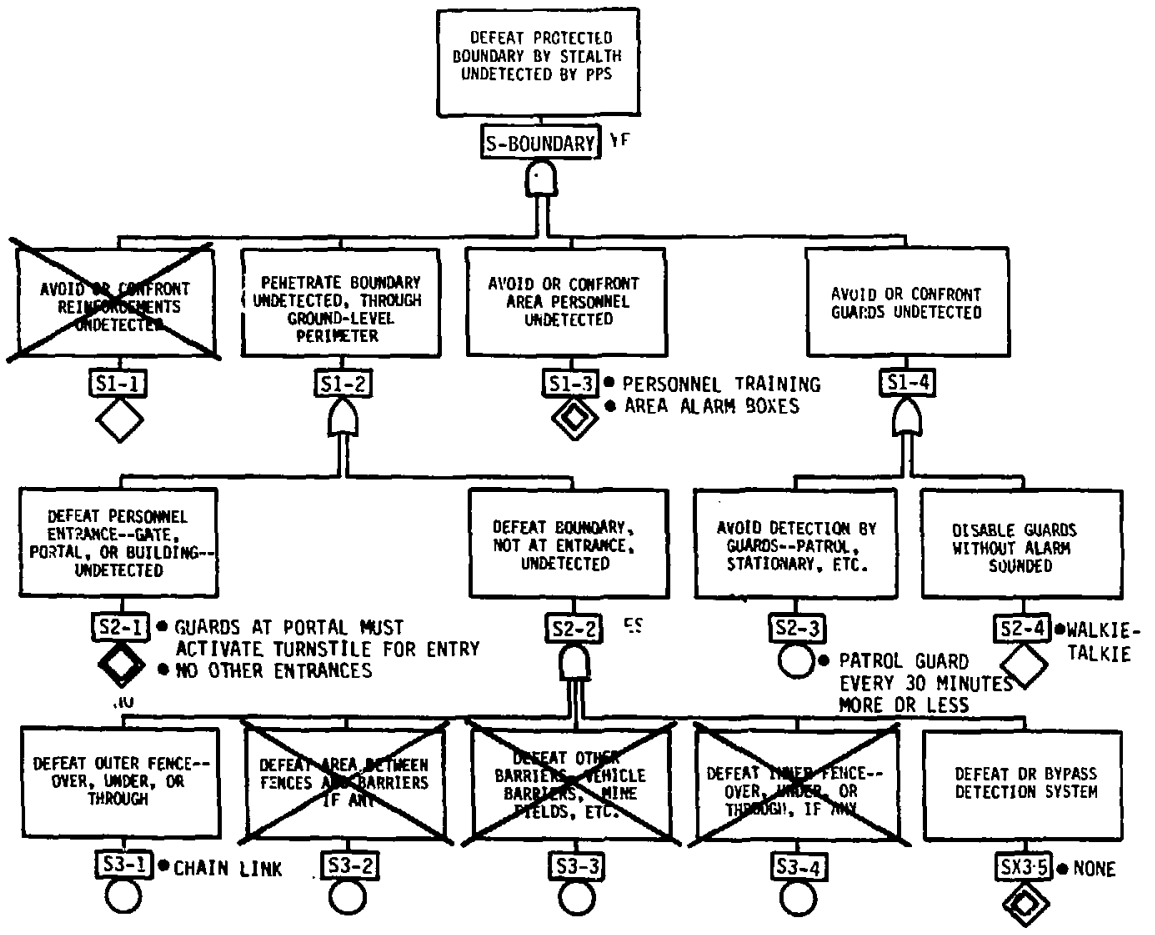

Figure 22. Gener1c Logic Tree Fitted to site Boundary 


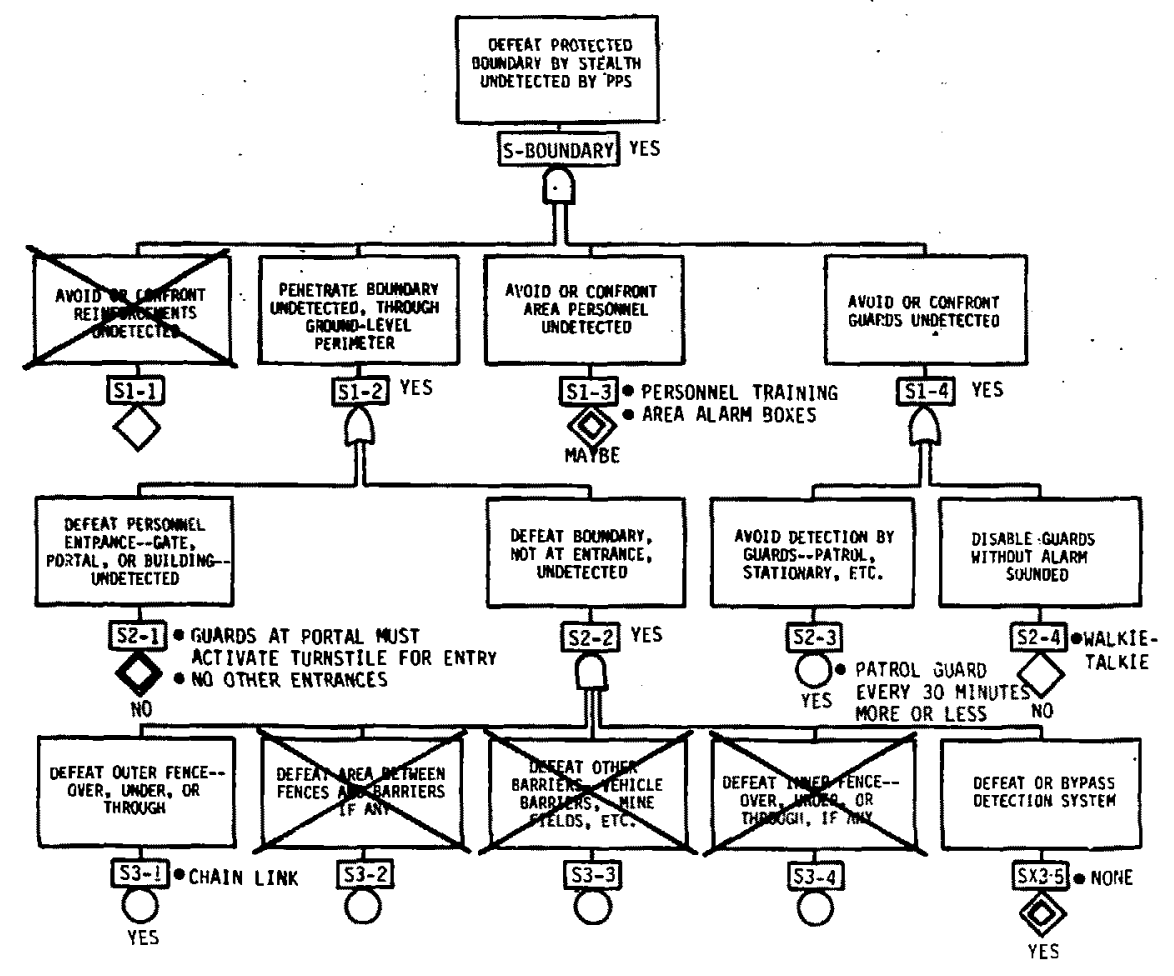


An adveraary can accomplich both $53-1$ and $5 \times 3-5$, so he can accompliah s2-2 wich 1s generated from then by an AND gate.

Next the analyat evaluates the primary events at level 2 of the logic tree.

52-1: Defeat personnel entrance -- gate, portal, or bullding -- undetected. This event is evaluated to demonetrate the technique, but the anolyet should be aware that the previous evaluation of $52-2$ has made 1 t unnecessary. Since $52-1$ and S2-2 are inputs of an $O R$ gate that generates event $\$ 1-2$, and because analysis has already shown that an adversary can easily acconpliab $\$ 2-2$. It follows thet the adversary can easily accompliah $51-2$ whether or not he can accompliah s2-1.

an adversary using stealth tactics to penetrate a gate or portal intends not to be detected. The adversary will try to etay out of range of any ansing elements or to tamper with then so no alorm is generated as he penetrates the gate or portal. In this exanple, guards at the single entrance mus activate a curnetile to allow entrance or exit. The adyersary's problem is to pass the turnstile without being detected by a guard. Assume that the guard can have the turnatile continuously under visual and aural observation, and assume that the adversary aust elther mechanically alter the turnatile or climb over it. Hechenical elteration of the turnstile would involve partially dieantling it, probably with the aid of power tools. If seen or heard, either action would be self-evidently improper. Inough supporting data is lacking, it seems that guards would be effective detectors in the situation visualized in this exapple. Thus, the adversary probably could not accomplish event s2-1, (1,e., could not get past the turnetile by stealth, undetected).

52-3: Avoid detection by guards -- patrol, etationary, etc. In this exaple, a patrol of one guard completes a circuit of the aingle fence approxinately every 30 minutes. The analyst should aake use of the inforation gathered for walution of 53-1, penetration of the single fence. No watter how the advercary ohooces to get artass the fence, he can do it in a half ainute or lovs. Iy inopection of Figure 1), it appears that the adveraary can be out of aight of the patrol guard for opproximately 15 minutes, assuning that the fence crosing is ade were the fence is nearest the reactor building and on the side opposite the entrance gate or portal. It seems ressonable to conclude that the adversary can apposch the fence, use a half minute for the crossing, and reach cover ang the resctor structures before the patrol guard can see the area where the crossing wa nade. The odverary can accomplish s2-3.

S2-4: Disable guarde without alarm sounded. The guarde have walkie-talkie radios for communication of alarms. There are guards stationed the gate or portal and there is one guard on patrol. An alert adveraary ahould be able to avold the patrol guard as described for event s2-3. An intelligent adversary ahould be able to avold the gate guarde merely by keeping cover betwen hinesle and them. If the adversary accidentally confronts a guard, no matter who is more surpriged, it seeng that the guard can souno some sort of warning over his cado, Thus the adversary cannot accomplish s2-4. 
An edversary cap accoplish 82-3 but not s2-4. Thene two events generate event 51-4 through an of gate. Thu s1-4 en be accopliehed because s2-3 can be accompliahed, regardleae of whether $32-4$ ean be accoaplished.

Next evaluate the prinaxy events at lovel 1 of the $\log i c$ tree.

S1-3z Avaid or confront area porsonnel undetected. Area perwonnel are workers who have operstions 1 or adainistrative dutien a opposed to aecurity duties. They are trained, howver, to leok tor posetble intruders and to report posmible intrusions by using one of the alarm boxed placed near the fence land throughout the nuclear facility). Awsing that the edverasy can choose a place and time for crossing the fence that jill not inewitably bring his into close contact with area personnel, and allowing the adverwary tine to hide until any parsonnel who wight cone near have departed, it apean plausible thet detsction by area personnel can be avolded. If an accidentel confrontecion oceurs, the employes has a relatively modest chance of being near enough to sn alarw box to sound an alakm unlese he overpowr: or eseaper from the edvereary. An adveracry aight, under particular circustances, be detected, Dut an alert, Intelligent advoreary aese able usually to accomplish 81-3 by ovolding aren pereonnel. The analyet nuy annotate this event with "Myes" or "yesp" as a reminder of the relatively lorge eleant of chance in the outcone of the event, but the enelyeis will treat the ovent as if it were einply annotated with "Yas." In other words, the butden of proof of effectiveness 11 tes with the phyejcal peratection cyster.

Since sl-3 was the only prinary event on level 1 of the logie tree, the analyet now evaluetes the ond event 8-coumanx, Events 81-2, 81-3, and s1-4 all can be accoplished by the adverany, and this aetefles the requirement inposed by the awD gate for the accomplishment of s-bouman. In thite exuple, the logic of the tree acting on the walutions of the primary ereate lead to the concluaton that the advereary can defent the proteated boundary by otealth undatected by the phyaical protection syeten.

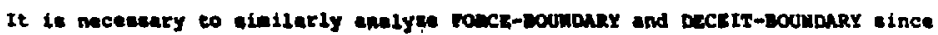
the adversary hat the option of vilng any tactle. Only if all adverany tactice fall has the phylieal protection gyeten auceesded. 


\section{APPENDIX A}

Abridged Geweric Phycical Protection Logic Trees 


\title{
ABRIDGED GENERIC PHYSICAL PROTECTION
}

\author{
"AREA" GENERIC LOGIC TREES
}

There are three generic logic trees: one each for crossing the area by stealth, force, and deceit tactics. The prinary events of each tree can be divided into two groups: (1) how the adversary gets across the area and (2) how the adversary renains undetected (stealth and deceit trees) or overcomes any opposition that he encounters wile he traverses the area,

Physically, the terrain to be crosed is a distributed barrier whose paraneters include, at least, its extent (length of path to be travelled) and the dijificulty of travel (rate of travel along the path). Thus, the primary event for tram versing the area relateg to the distributed barrier that must be overcome.

One question to ask In a gualitative evaluation of the logic tree is, "Can the adversary overcone the barrier(s) to crossing the area?" The specific terrain is important, but terrain suitable for efficient site operations will require only ordinary skills and equipment of the adversary. For the stealth and deceit trees a gecond question is, "Is it likely that the adversary can avoid, disable, or deceive the detection elements without an alarn being generated?" For the force tree a second question 1s, "Is 1t likely that the adversary can overcone any opposition that he encounters?"

If a quantitative evaluation is needed, one guestion is, "How much time will the adveraary need to overcome the distributed barrler?" This time, the delay provided by the barrier is a function of the length of the path travelled and the speed with which the terraln can be travelled using the reans assuned for the adversary. The other quentitative question 1s, "what is the probability that the adversary w1ll be detected as he traversea the area?"

\section{STEALTH-AREA}

Figure A-1 showg a simplifled voraion of the generlc logic tree, STEALTH-AREA. There are 6 primary events $(51-1,51-3,51-4,5 x 1-5,52-1,52-2)$. These can be divided Into two groupe. One group concernu the adversary's need to get across the area $(S 1-1)$. The other group concerns the adveraary's need to renaln undetected while he traverses the area $(51-3,51-4,5 \times 1-5,52-1,52-2)$.

The logic tree assunes that the area 1s homogoneoun. Thus, thore is one basic event (51-1) for traveraling on area. The event does nut describe the nature of the torrain. It 1e the analyot's job to characterise the terrain from site-mpecific infornation. If the terrain is not virtually honogeneous, adjacent areas can be defined, each of which has esentially hougeneous characteristica. 
Two kinds of elenente detect area traversals, One kind surveys the area from a fixed position (Sx1-5, S2-1, s2-2). Guarda atationed in observation towers (S2-1, $52-2)$ and radar $(s \times 1-5)$ are examples.

The second $k$ ind of element is mobile within the area (51-3, 51-4, 52-1, 52-2). Guards on patrol are one example $(s 2-1, s 2-2)$.

Operations personnel way be traversing the area at the sane time and in the same region as the adversary, and they aay aee $h$ ta (s1-4). If the population of the site is large, so all workers are not known to one another, and if the adversary is dressed within the expected variation for site workers, he should not acouse suspicion. Especially if there is cover warby, the adversary nay be able to avoid a direct meeting with an employee (S1-4) which could lead to a confrontation over credentials wich the stealthy adversary is presuned not to have.

Reinforcenents for the becurity force (5l-3) would be called only after detection. The time between notification of the securlty force and its arrival might be long enough to prevent the force fron intercepting the adverary during the area traversal that gave rige to the detection. However, this event night be relevant given detection at a previous boundary or area.

Having exanined all primary events on the implified logic tree, note that the logic by which they generate the ond event is the ane as for the STEALTH-BOUNDARY tree. The adveraary must traverae the area and he nust avoid detection while doing so. This is the fundamental logical statement made in the logic tree. All other detail merely elaborates on the possibilities. The fundenental logical statenent is made by AND gate S-AREA. The Input for area traversal cones fron event si-1. All four other inputs $(51-2,51-3,51-4,5 x 1-5)$ supply requirenents for avoiding detection.

One other development appeara on the tree. Event S1-2, "Avoid or confcont guards undetected atates in option. The necessary loglc is an OR gate, S1-2, with inputs s2-1 and 52-2. This same sort of option ie inplied for s1-3 and s1-4, both undeveloped eventa. Their developments would bave the sane logical form as the development of $51-2$.

\section{FORCE-AREA}

Figure A-2 showe a simplified veraion of the generic logie tree, PORCE-AREA. There are flve prinary evente $(F 1-1, E 1-3, F 1-4, F 2-1,(2-2)$. These can be divided into two groups. One group concerne the adversary' ned to travarae the area $(E 1-1)$. The other group concerne the advereary's need to overcone any opposition that he encounters whlle he traverees the area (F1-3, F1-4, E2-1, F2-2).

Every event but one on BrEALRA-RREA has a counterpart on FORCE-AREA. The exception is sx1-5, "Defeat or bypass detection syatem." By definition, when using the force tactic the adveraary expecte to be detacted, so the rorce trees have no evente that require the adversary to take action againet the detection syetem. 


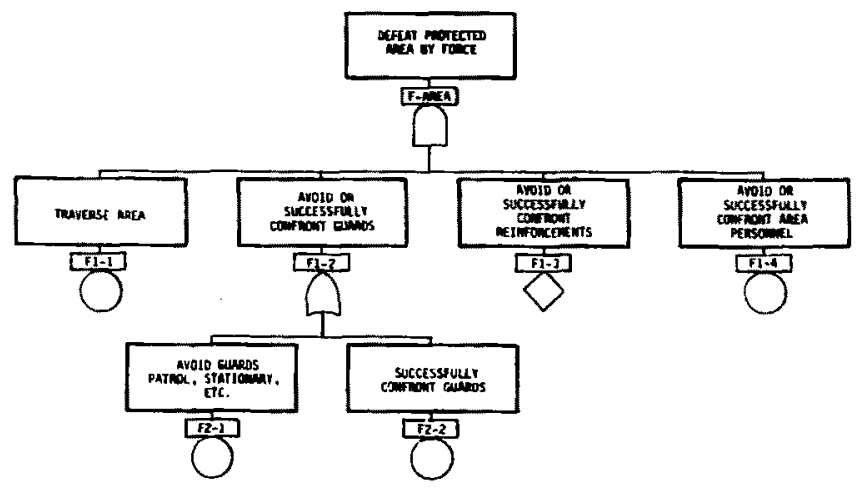

Figure A-2. FORCE-AFFA LOgic Tree 


\section{DICEIT-AREA}

Figures $A-3$ and $A-4$ show a teplified version of the generic logic tree, DECEIT-AREA. There are 16 primary eventa (D1-1, DX1-3, DX1-6, DX2-1, DX2-2, DX2-3, DX2-6, DX2-7, DX2-8, DX3-1, DX3-2, DX3-4, DX3-5, DX3-6, DX4-1, DX4-2). They can be divided into two groupg. One group. concerns the adversary's need to get across the area $(D 1-1, D \times 4-1, D \times 4-2)$. The second group concerns the adversary's need to remain undetected while he traverses the area (DX1-3, DX1-6, DX2-1, DX2-2, DX2-3, DX2-6, DX2-7, DX2-8, DX3-1, DX3-2, DX3-4, DX3-5, DX3-6).

The logic tree assumes that the area is homogeneous. Thus, there is one basic event (DI-1) for traversing an area. The event does not describe the nature of the tercain. It is the analyst's job to characterize the terrain from site-specif ic information. If the terrain is not victually homogeneous, adjacent areas can be defined, each of which has essentially hooogeneous characteristics.

There is aloo the possibility that an additional adversary inight take pact in a scenario, making a two-man adversary toan to defeat a two-man rule. Basic event DX4-1 specifies that the second man of the two man team is an adversary. Undeve1oped event DX4-2 is the defeat of the area by the second man using deceit. The analyst is told to review the logle tree D-AREs for the second man.

Detection of area travermal by an adversar; using deceit seems unlikely. It is barely concelvable that the adversary might arouse suspicion of area personnel, or that spot checkn of persons in the area might be made, either case leading to a recheck of the adversary's identity and authorlation to be in the area. The adversary's need to defeat detection by acea peraonnel is covered by developed event DX1-3. The events related to defeat of an 1dentity credential check (DX2-1, DX2-2, DX2-3) are identical to those on the loglc tree DECEIT-BOUNDARY. The events related to defeat of an authorization check (DX2-6, DX2-7, DX2-B) are analogous to those on the logic tree DECEIT-BouNDARY. Though there is no obvlous need or mechanism to Initlate a two man rule within an area. it wold be necessary to maintain one initiated at a previous boundary. Consequently, the subtree covering the adversary's need to traverse the area despite the tro-aan rule 1s duplicated fron the logic tree DECEIT-BOUNDARY. The prinary evente that concern detection avoidance are $0 \times 3-1$, $D X 3-2, D \times 3-4, D X 3-5$, and DX3-6. Pinally, there is a possibllity that the adversary would need to avold, deceive, or defeat a response to detection that occurred during the area traversal or at an earlier tine in the attack (DX1-6, an undeveloped event).

Having examined all primary eventa on the simplified logic tree, note that the logic by which they generate the end event is the same as for the STEALTH-BOUNDARY tree. The adversary must traverwo the area and he must avoid detection while doing 8o. Thla is the fundanental $\log 1 \mathrm{cal}$ statement made in the logic tree. All other detall merely elaborates on the posibilitios. The fundamental statement is made by the AND gate D-AREA. The input for area traversal coned from event Dl-1. All other inputs (DXI-2, DX1-3, DXI-4, DX1-5, DX1-6) supply requiremente for avolding detection. 


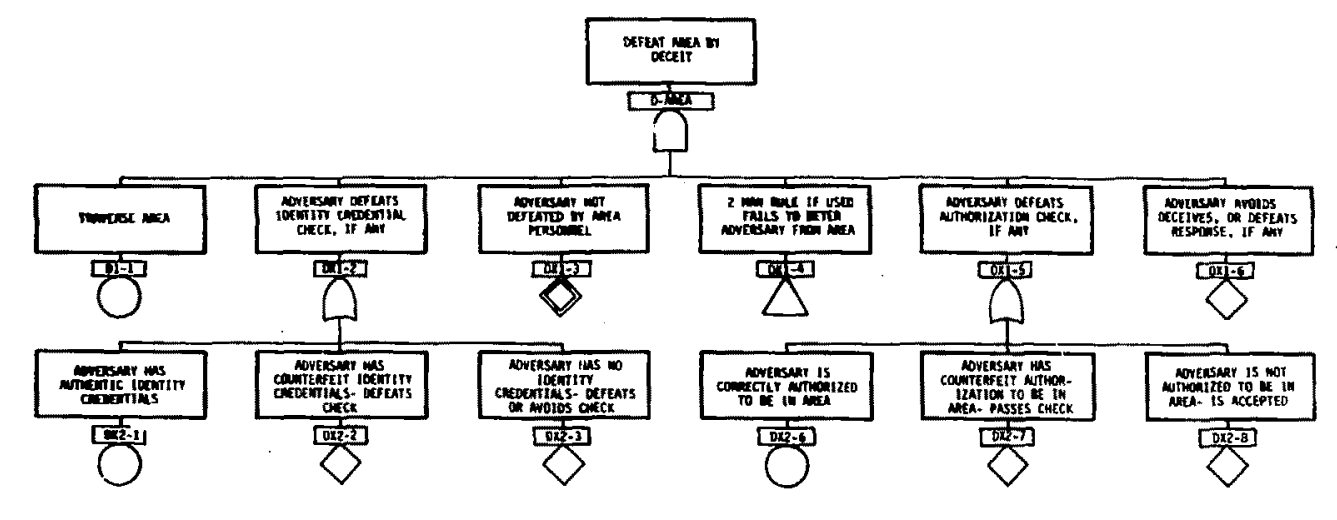

Figure A-3. DECEIT-AREA Logic Tree 


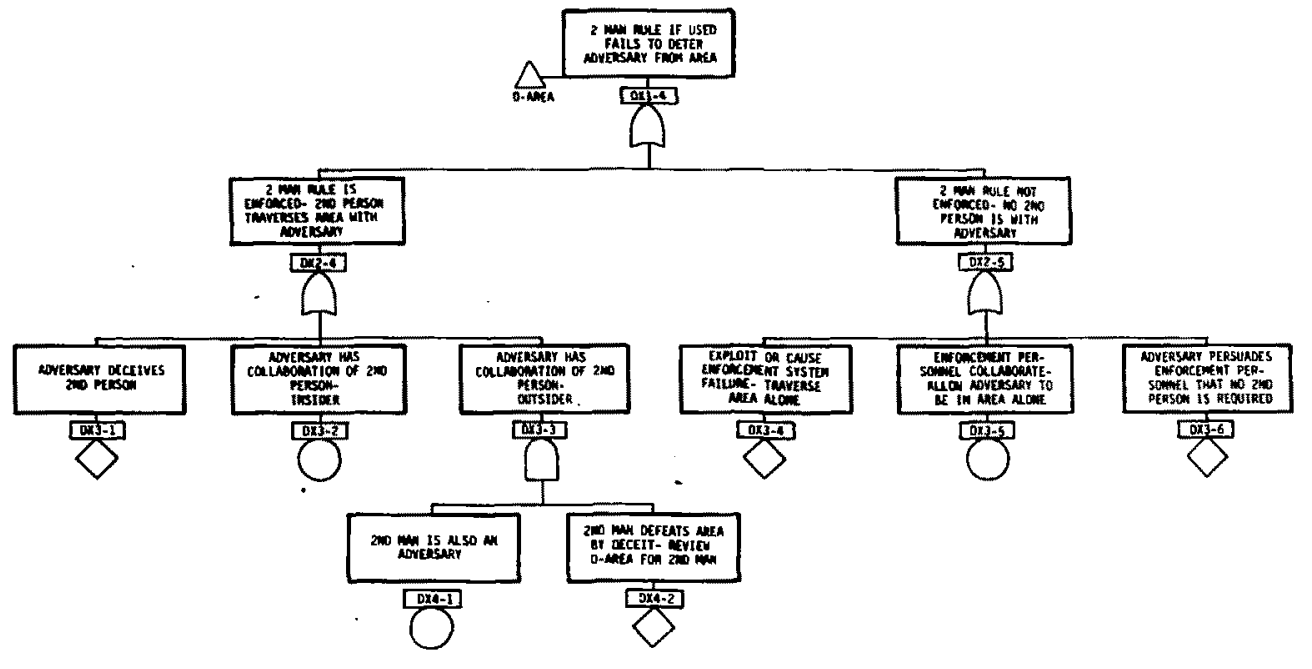

Figure A-4, DECEIT-AREA, Two-Man Rule Logic Tree 


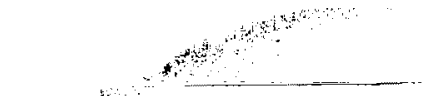

The types of Identity credentials which an adversacy might use (0x2-1, Dx2-2, DX2-3), expressed in terms of the degree of the adversary's detectability, complete the development of $D \times 1-2$ as inputs to an OR gate.

The types of authorization which an adversary might have (DX2-6, DX2-7, DX2-8), expressed in terns of the deqree of the adversary's detectability, complete the development of $0 \times 1-5$ ag inputs to an OR gate.

The adversary's options for defeating a two-man rule (DX3-1, DX3-2, DX3-3, DX3-4, DX3-5, DX3-6) constitute the development of DX1-4 as inputs to or gates, for ease of reading this portion of the $\log i c$ tree, $0 \times 3-1, D \times 3-2$, and $D \times 3-3$ are grouped as inputs to OR gate DX2-4. Event DX2-4 merely labels its inputs as all dealing with options in which a second man does traverse the area with the advergary. Events DX3-4, DX3-5, and DX3-6 are grouped as inputs to OR gate DX2-5, Event DX2-5 merely labels its inputs as all dealing with options in which a second man does not traverse the area with the adversary. The two label* events, Dx2-4 and Dx2-5, are inputs to of gate DXl-4. Finally, DX4-1 and DX4-2 are pseudo-events lequivalent to comments) pertaining to event DX3-3. They remind the analyst of two concurrently relevant things: that the second man can also be an adversary and that this additional advergary must be analyzed using the full tree, D-ARER. SO, DX4-1 and DX4-2 sre inputg to AND qate DX3-3.

\section{"BUILDING" GENERIC LOGIC TREES}

There are two generic logic trees: one each for entering or leaving a building by stealth or force. The prinary events of each tree can be divided into two groups: (1) how the adversary enters or leaves the building, and (2) how the adversary remains undetected (stealth tree) or overcomes any opposition that he encounters while entering or leaving the building.

One question to ask in a qualitative evaluation of the logic tree it, "Can the adversary overcome the barrier(s) to entering or leaving the building? for the stealth tree a second question is, "Is it likely that the adversary can avoid or disable the detection elements without an alarm being generated?" For the force tree a second question is, "Is it likely that the adversary can overcome any opposition that he encounters?"

If a quantitative evaluation is needed, one queation $1 \mathrm{~s}$. "How much tine will the adversary need to overcome the barrier(s) to entering or leaving the building?" The other quantitative question is, "What is the probability that the adversary will be detected as he enters or leaveg the building?"

\section{STEALTH-BUILDING}

Pigure A-5 shows a simplified version of the generic logic tree, STBALTHBUILDING. There are 10 primary events $\{s 1-2,51-4,52-1,52-2,52-4,52-5,53-1$, $5 \times 3-2, s 3-3, s \times 3-4)$. These can be divided into two groups. One group concerns the adversary's need to get into or out of the building (s2-1, s2-2, 53-1, 53-3). The 


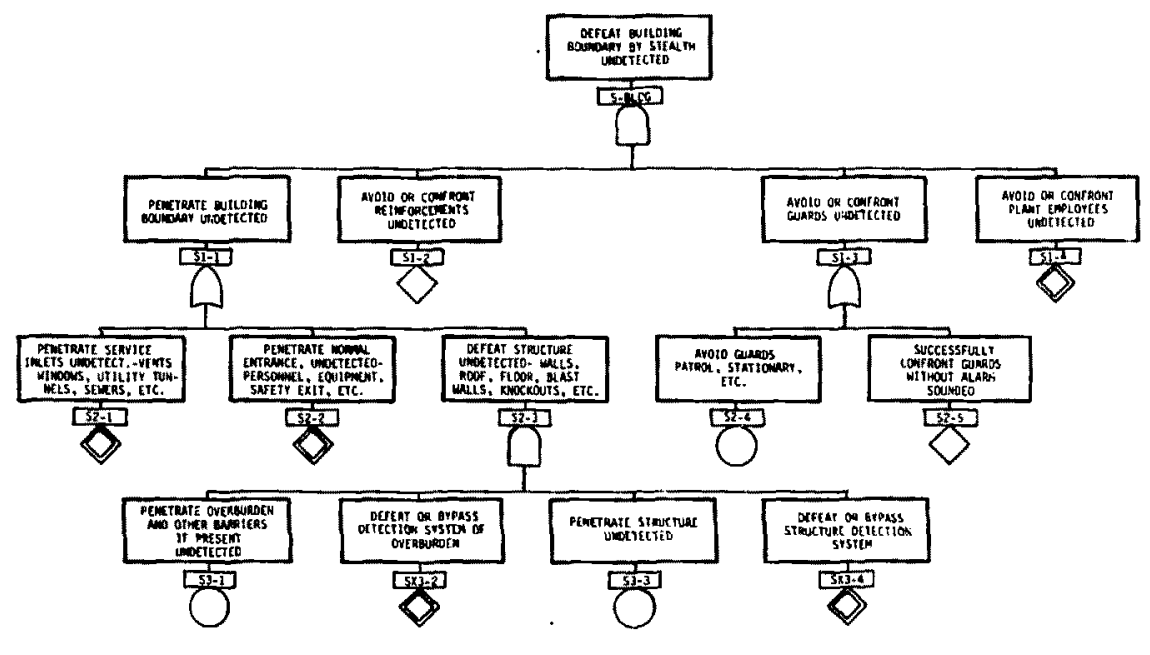

Figure A-5. STEALTh-BUILDING Logic Tree 
other group concerne the adveraury's need to renain undetected while entering or leaving the building (51-2, s1-4, s2-4, 82-5, sx3-2, 5x3-4).

The $\log i c$ tree assumes the bullding, as a boundary, has two parta. In one part, entry or exit is accomplished normally, 1.e.. through a personnel or equipment entrance, a cafety exit, etc. (wee event s2-2), in the other, entry and exit are prohibited, i.e., everywhere other than a personnel or equipnent entrance, safety exit, etc. (see evente s2-1, s3-1, s3-3). Thege two parts of the boundary should present different problene to the advernary.

A few, but not all, possible types of normal entrances are named in event s2-2. It is the analyst's job to supply these elenenta from the design which he is evaluating. However, s2-2 is a developed event; it is further developed on the complete generic logic tree, STEALTH-BurLorNG. That development is ignored in this discussion.

There are entrances that are not normally uned by personnel but which could be penetrated by the adversary. Some of these possibilities are named in event s2-1 (service inlets: vents, windows, utllity tunnels, sewers, etc.). It is the analyst's job to supply these elemente from the design which he is evaluating. However, s2-1 is a developed event, it is further developed on the complete generic logic tree, stealph-BurLDING. That developent is ignored in this discussion.

The other means of entering or leaving a building that is unconventional is to penetrate the structure of the building (see event s3-3). The structure may be protected by an overburden of earth or other moterial (see event $53-1$ ). It is the analyst's job to supply from the design which he is evaluating, the details of overburden composition and penetrability and of building atructural features and penetrability.

Two kinds of elements detect entering or leaving a building. One kind is associated with the building itself, its entrances and atructure (5x3-2, sx3-4). No examples are named on the simplified logic tree.

A second $k$ ind of element is mobile and operates anywhere along the periphery of the building, either inside or outside $(s 1-2,51-4,52-4,52-5)$. Guards on patrol or stationed in observation towerg are one exanple (s2-4, s2-5). These would be a trained part of the physical protection system. If they alone could not be positive neanures for detection, they nay reinforce the other kinds of detection elements to produce positive neasures.

The two events that nane guards as detection elementa list two way that an adversary may not be detected, He can avold being seen by the guarda (\$2-4), or, if he to seen, he may be able to prevent the guards from sounding an alarm (S2-5). While the latter method of avoiding detection may be forceful cather than stealthy, it represent: an action reguired of the adversary if he is to continue his attack by itealth, undetected, after he accidentally confronto a guard. In general, the advereery should be able to conceal himself and observe the movenent of the patrol. 
The adversary could weit unt1l the patcol leaves the vicinity of the place where the building is to be astecked before beginning the attack. It may be difficult for the adversary to know whether or not he is being seen fron an observation tower or to prevent the sounding of an alara if he knows that he has been seen.

Operations personnel may be nearby when the adversary makes $h$ is attenpt to penetrate the building and may see a susplcious action ( $1-4)$. The adversary may have difficulty avolaing operations personnel: his attention may be concentrated on the physical work of his penetration attenpt, and the building itself fas well as any other bulldings that might be nearby) can expose che adversary and operations personnel to one another suddenly and at relatively close quarters. Confrontation would be an unintended camplication of an attack by gtealth, and it might increase the chance of being seen by a guard in an observation tower.

Reinforcenents for the security force (S1-2) would be called only after detection. The tine between notification of the security force and its arrival should be carefully compared with the expected task time for penetration that renains after detection of the penetraticn. Whether the securlty force could intercept the adversary during the penetraclor attempt is strongly dependent on site details and the adversary's scenario. This event may be meaningful with respect to penetrating a building after detection had prevlously occurred.

Having examined all primasy events on the implified logic tree, the logic by which tbey generate the end event is exanined next. The adversary nust penetrate the building and he nust avoid detection while doing so. This is the fundanental $\log$ ical statement made in the $\log i c$ tree. All other detail merely elaborateg on the possibilities. The fundanental logical statement is made by AND gate S-BLDG. The input for penetrating the building comed fron event sl-1. All three other inputs (S1-2, s1-3, 51-4) aupply requirements for avoiding detection by the elenents that can operate anywhere along the periphery of the building, regardless of were the penetration if made. The elements that detect only at entrances, noral or unusual, or only at building structure away from entrances nust be associated with those optional locations for penetrating the bullding.

The operational penetration locations are inpute $52-1,52-2$, and $52-3$ to $O R$ gate s1-1. Fenetrating the bullding through a normal entrance or exit (S2-2) is a developed prinary event. Penetrating the building through one of the service inlets (e.g., vents, windows, utility tunnels, sewers) is alco a developed prinary event (S2-1). But penetrating the building away from a normal entrance or gervice inlet (S2-3) is generated by an awD gate which zepeato the fundanental logical statoment of the $\log i c$ tree. Penetrating the building away from a normal entrance or aervice inlet reguices that two basic eventa (s3-1, s3-3) be performed. These two eventa are Inputs to AHD gate s2-3. Avolding detection during penetration is represented by two developed events (5x3-2, sx3-4), both of which are Inputs to AND gate s2-3.

One other development appears on the tree. Eyent s1-3, "Avold or confront gund: undetected" states an option. The necessary logic is an on gate, sl-3, with 
Inputs s2-4 and s2-5. This wove cort of option is inplied for s1-2 and s1-4, both doveloped events. Their developenta would have the ane logical form as the development of $\mathbf{s i - 3}$.

\section{FORCE-PULDHNG}

Pigure A-6 show a simplified version of the generic lagic tree, FORCEBUILDIng. There are eight prinary events (F1-2, F1-4, P2-1, F2-2, F2-4, F2-5, F3-1, F3-2). These can be divided into two groups. One group concerns the adversary's need to penetrate the building $(\mathrm{F} 2-1, \mathrm{~F} 2-2, \mathrm{~F} 3-1, \mathrm{P3}-2)$. The other group concerns the adversary's need to overcone any opposition that he encounters wile penetrating the bullding (F1-2, F1-4, F2-4, E2-5). Every event but two on stehLTh-BuILDING has a counterpart on ForCE-BuILDING. The exceptions are sx3-2, Defeat ar bypass detection system of overburden," and sx3-4, "Defeat or bypass structure detection gystem." By definition, when using the force tactic the adversary expects to be detected, so the pORCE trees have no events that require the adveraary to take action against the detection aysten.

\section{"ACQUIRE SNM" GENGIC LOGIC TRESS}

There are three generic logic tree titled AcouIRE SNH: one each for acquiring SNH by etealth, force, and deceit tactics. The primery avente of each tree can be divided into two groups: (1) how the advereary gets epecial nuclear material into his possession and (2) how the adversary remains undetected (atealth or deceit trees) or overcomes any opposition that he encounters while the swh is acquired.

When using any ACQUIRE SkM tree it is assuned that the adversary is almost in the presence of the SNM. If the SMM is stored in a vault, the advereary has arrived at the vault. If the SNM is in a pipe, the adverary is in a place where he has access to the pipe. If the SNM is in a process line, the adversary is in the presence of the process line, for example, at a glove box containing sky. Thus the prinary events for acquiring SNM relate to barriers that enclose the sNy in close proxinity or that have to do with properties of the SNM Itaelf.

One quention to ask in a qualitative evaluation of the logic tree is, "Can the adversary overcome the barrier(s)?" For stealth and deceit trees a second question is. "Is it likely that the adversary can avoid, disable, or deceive the detection elementa without an alarm being generated?" Por the force tree a aecond question is. "Is it likely that the adversary can overcone any oppoaition thit he encounters?"

If a quantitative evaluation is needed, one question ia, "How much tine will the adversery need to acquire SNH?" The other quantitative question is "What is the probability that the adverary will be detected as he acquirea sMH?" 


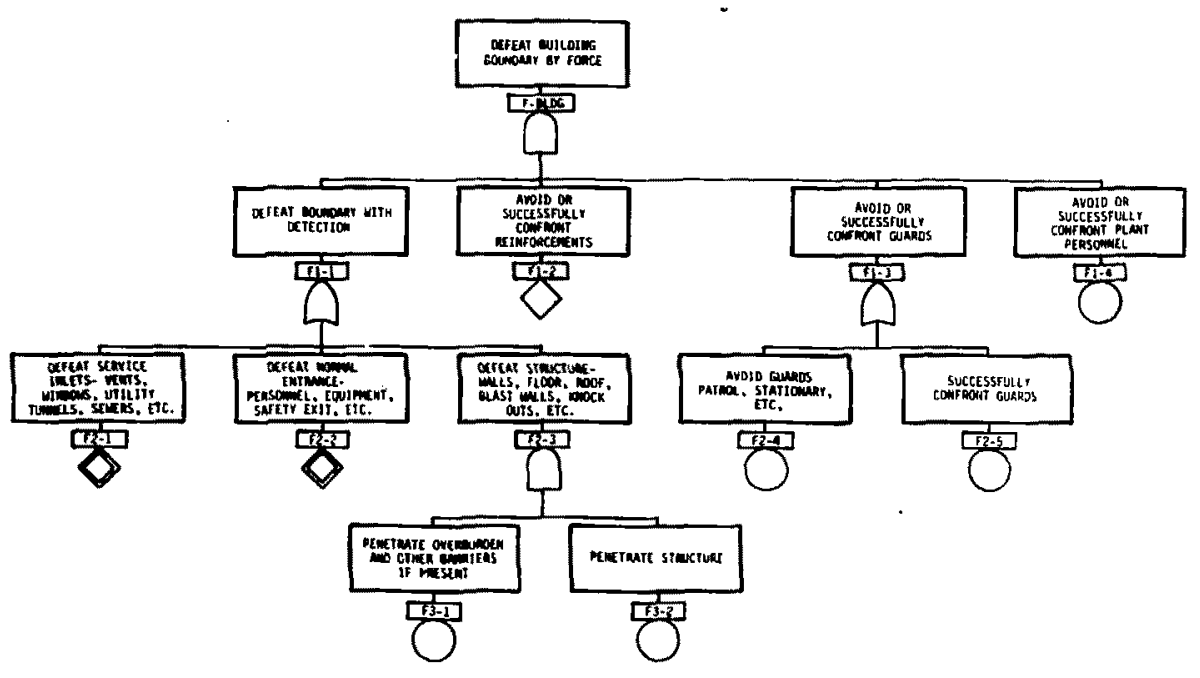

Figure A-6. FORCE-BUILDING Tree 


\section{STEALTH-ACQUINE SNM}

Figure A-7 thowe a amplified version of the generic logic tree, STFALTHACQUIRE SNM. There are 10 prtary evente $(51-1,51-3,51-4,51-5,5 \times 1-6,52-1$, s2-2, sxi-1, sx3-2, sx3-3). Thene can be divided into two groups. One group concerns the adversary's need to get the epecial nuclear material into his possession $(51-1,52-1,52-2)$. The other group concerna the adveraary's need to remain undetected while acquiring the SNM (s1-3, s1-4, s1-5, 5x1-6, sx3-1, sx3-2, 5x3-3).

The $\log$ ic tree astumes that acquiring SNy is a single process having as many as three steps (aee events s1-1, s2-1, s2-2). Each step is a primary event, and the description of each step includes exaples of physical protection aysten elenents and site specific characteristica that wust be supplied by the analyst from the design wich he is evaluating.

Locating and recognizing the SNM is the adversary's first step, 51-1. Assuning that the adversary has information sbout his target, this is a trivial task. The analyat wuet take care not to double count the task time with those of other events on STEALTH-ACOUIRE SNM and other logic trees that contribute to the same result as basic event $51-1$.

Defeating the conatraints imposed by the ctorage location of the SNM is the adversary's second step, 52-1. This means penetrating whatever physical protection barriers surround the storage space. For example, the sNy may be stored in a vault which the adversary must enter. SkM ay be flouing through a pipe which the adversary must tap, and the pipe may be encloaed in a chase which must be penetrated. SNM may be in a process line, for exaple, encloaed by a glove box to which the adversary would need access. $52-1$ is an undeveloped event.

Collecting the 5HM is the adverwary's third step, s2-1. This mears selecting the SNM to be taken and repackaging it a neceasary. Savaral of the factors that might influence SNM collection are liated in the event description. Composition of the SNM, for exanpie a liquid, a metal, powder, will affect the kind of package in which it might have been tored or in which the adveraary night wish to store it for removal from the site. The aize, wight, and shape of the container(a) in which the site stores SNM aight be inconvenient for an adversary to pick up and carry with him. If repackaging is neceseary, additional time is necessary for the task, and possibly special packages must have been acquiled somewhere and carried to the lacation of the 5NH. The analyet must decide whether these target characteristics are an effective impediment to the adversary. Gecause of the variety of posaible SNM targets, their characteristics, and the varip. ' he adversary's scenarios, s2-i is an undeveloped event.

Three kinds of elenent: detect acquisition of SNM. nne kind renses properties of SNM itsele and is located permanently in the imadiate vicinity of sNM with the purpose of detecting unauthorized movenent of SNM (5x3-1, 5x3-2, 5x3-3). No examplee are named on the simplified logic tree. 


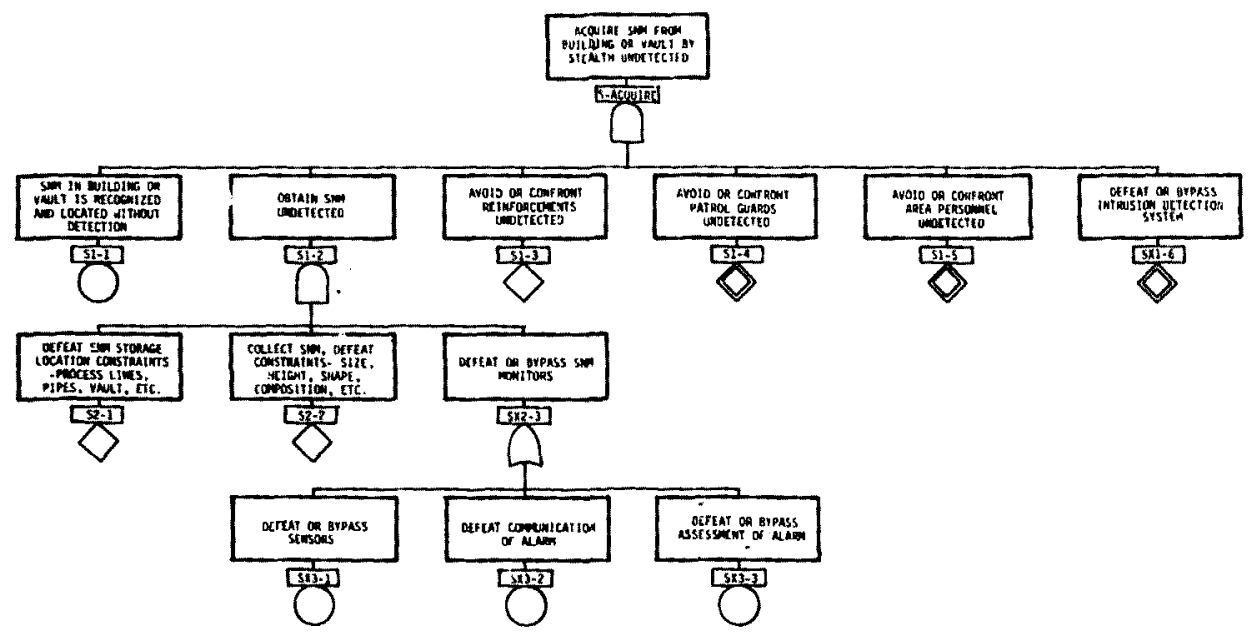

Figure A-7. STEALTH- $\Lambda$ CQUIRE SNM Logic Tree 
The second kind of element uaes fixed sensors to signal the penetration of an unauthorized person into an area where $5 N M$ is being proceased or stored (SX1-6). No examples are named on the simplified logic tree.

The third kind of element operates anywhere within the material access area (sl-3, Sl-4, S1-5). Guards on patrol are one example (S1-5). These would be trained as part of the physical protection syster. If they alone could not be positive measures for detection, they might reinforce the other kinds of detection elements to produce positive measures.

The event s1-t that names patrol guards as detection elements 1 ists two ways that an adversary may not be detected. He can avoid being seen by the guards, or, if he is seen, he may be able to prevent the guards frof sounding an alarm. While the latter method of avoiding detection may be forceful rather than stealthy, it represents an action required of the advergary if he is to continua his attack by stealth, undetected, after he accidentally confronts a guard. In general, the adversary may be able to hide until the patrol guards have passed and then have use of the period until the patrol is repeated to acquire SNy.

Gperations personnel may be nearby when the adversary acguires SNM and see his activity (sl-5). Depending upon the work schedule of a particular site, the adversary may be confident of avoiding accidental observation. Confrontation would be an unintended complication of an attack by stealth, and it may increase the chance of being observed by other operations personnel or patrol guards.

Reinforcements for the gecurity force (sl-3) would be called only after detection. The time between notification of the security force and its arrival might be long enough to prevent the force fron intercepting the adversary duriny the acguisition of SNM that gave rise to the detection, but one cannot generalize about this. Thus, this event may have relevance during acquisition of sNy. The analyst must carefully consider the scenario and the physical protection system to decide this question. This event may instead be meaningful with respect to detection during a prior step of the scenario such a crossing a boundary, traversing an area, or entering a building.

Having examined all primary events on the simplified logic tree, the logic by which they generate the end event is examined next. The adversary must acquire SNy and he must avoid detection while doing so. This is the fundamental logical statement made in the logic tree. All other detail merely elaborates on the possibilities. The fundamental logical statenent is made by AND gate S-ACQUIRE. The input for acquiring SNM comes from events $s 1-1$ and $51-2$. All four other inputs (Sl-3, s1-4, Si-5, sxl-6) supply reguirements for avaiding detection.

Event $51-2$ is $\log i c a l l y$ cedundant, being merely a collective label for its inputs $(52-1,52-2,5 \times 2-3)$. Events s2-1 and s2-2 deal with acquiring SNM, Event 5x2-3 supplies reguirements for avoiding detection of the SNM itself while it is being acquired. 
Only one true developaent appears on the tree. Event sx2-3, "Defeat or bypass SNM monitors" is developed Into the three aspects (sensing, comnunication, and assessment) of a detection system which state the options for causing fallure of detection. The necessary $\log i c$ is an $O R$ gate, $5 \times 2-3$, with innutg $5 \times 3-1,5 \times 3-2$, and s.3-3, all basic events.

\section{FORCE-ACQUIRE SNM}

Figure A-8 shows a simplified version of the generic logic tree, FORCEAcQuIRe. There are six primary events (FI-1, F1-3, F1-4, P1-5, P2-1, F2-2). These can be divided into two groups. One group concerns the adversary's need to get the special nuclear material into his possession (Fl-1, F2-1, F2-2). The other group concerns the adversary's need to overcome any opposition that he encounters while the SMM is acquired $(F 1-3, F 1-4, F I-5)$.

Four events on STEALTH-ACOUIRE have no counterparts on FORCE-ACOUIRE. The exceptions are 5x1-6, "Defeat or bypass intrusion detection systen;" 5x3-1, "Defeat or bypass sensors;" 5x3-2, "Defeat comunication of alacm;" and 5x3-3, "Defeat or bypass assesment of alarn." By definition, when using the force tactlc the adversary expects to be detected, so the FORCE trees have no events that reguire the adversary to take action against the detection systea.

\section{DECEIT-ACQUIRE SNM}

Figures A-9 and A-1D show a elmplified veraion of the generic logic tree, DECEIT-ACOUIRE SH. There are 20 peimary events $(\mathrm{Dl}-1, \mathrm{D1}-3, \mathrm{D1}-5, \mathrm{D2}-1, \mathrm{D2}-2$, $D \times 2-4, D \times 2-5, D \times 3-1, D \times 3-2, D \times 3-3, D \times 3-4, D \times 3-5, D \times 3-6, D \times 3-7, D \times 3-8, D \times 3-10$, DX3-11, DX3-12, DX4-1, DX4-2). These can be divided into two groups. One group concerns the adversary"s need to get the special nuclear aterial into his possegsion (D1-1, D2-1, D2-2, DX4-1, DX4-2). The other group concerng the advergary $y^{*}$ need to ramain undetected while acquiring the SNH (D1-3, D1-5, DX2-4, DX2-5, DX3-1, DX3-2, DX3-3, DX3-4, DX3-5, DX3-6, DX3-7, DX3-8, DX3-10, DX3-11, DX3-12).

The $\log$ ic tree assunes that acquiring sky is a single process having as many as three ateps (see eventu, D1-1, D2-1, D2-2). Each step 1s the exact duplicate of a corresponding step on the $\log 1 \mathrm{c}$ eree STEACTH-ACouIRE SNA: DI-1 duplicatea S1-1, D2-1 duplicates S2-1, and D2-2 duplicates 52-2. The reader is referred to the section "STEALTH-ACQUIRE SMM" for explanation of these events.

If in imadiate proxinity to SNM a two-nan rule is initlated or continued fron prior Initiation, the adversary should not be allowed to operate alone. An adversary could try to defeat the phyelcal protection system by having another, collaborating adverwary act as the second wan of the two-man tean (banic event DX4-1). In this case, the second adversary as vell as the firat must be analyzed for his abil1ty to defeat the $\log i c$ tree D-AcouIRE (undeveloped event DX4-2).

Four kind: of elemente detect or try to prevent acquisition of sw. One kind cenae propertiez of SNM 1 teif and is located permanently in the lamediate vicinity of SNH with the purpose of detecting unautborized movenent of SNM (DX2-4, DX3-1, 


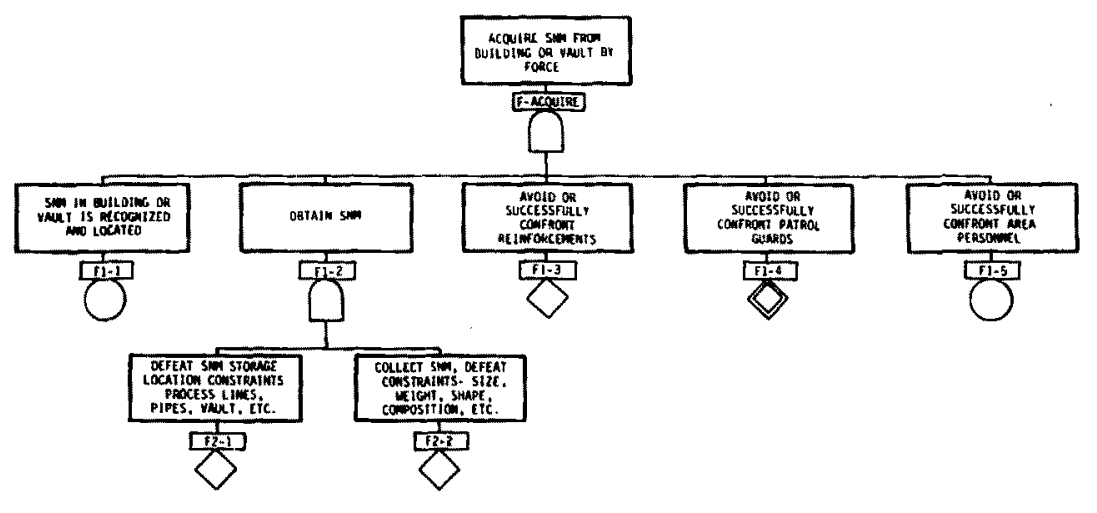

Figure A-8. FORCE-ACQUIRE SNM Logic Tree 


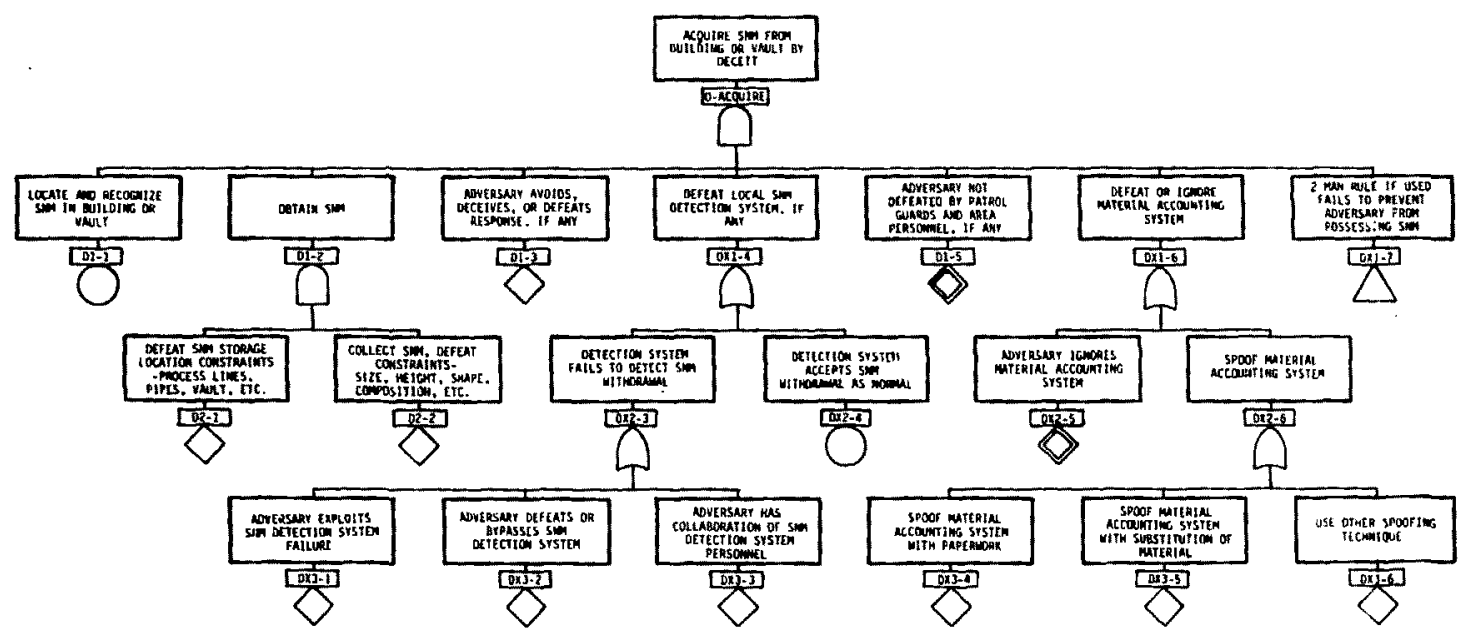

Figure A-9. OECEIT-ACQUIRE SNM Logic Tree 


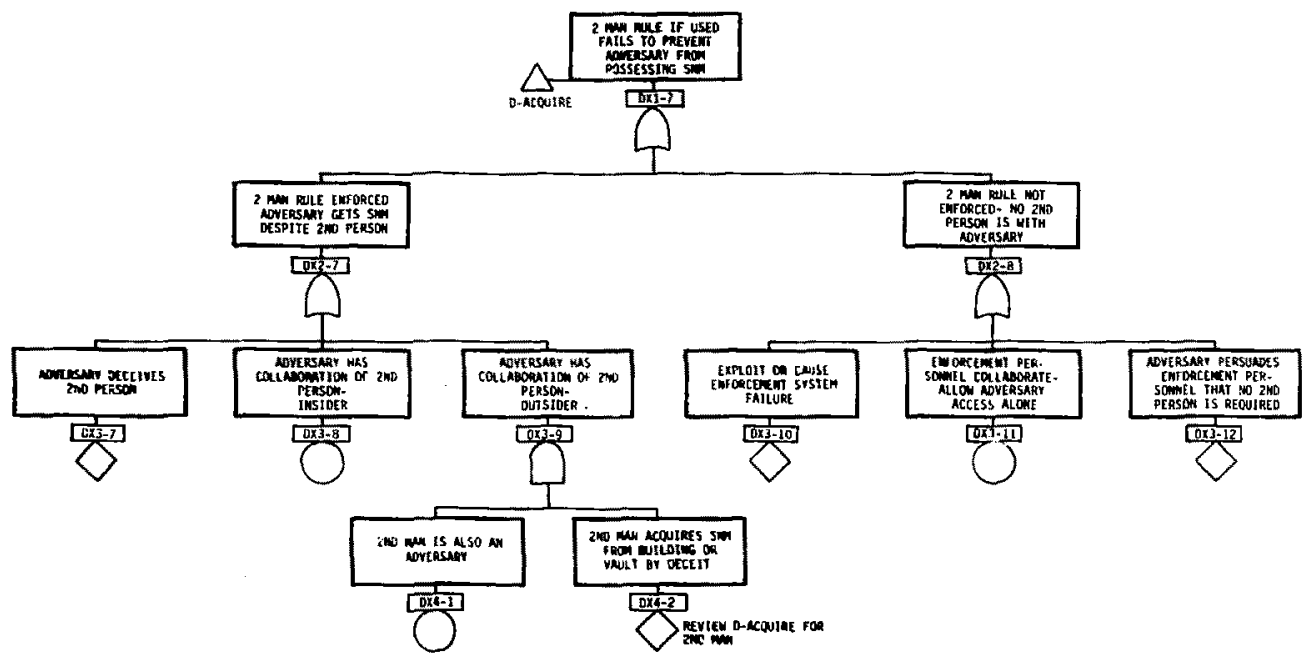

Figure A-IO. DECEIT-ACQUIRE SNM, Two-Man Rule Logic Tree 
DX3-2, $0 \times 3-3)$. Unique to the decelt toctic is the possibility (basic event DX2-(1) that the adveraary will be able to conduct a nornal tranastion to acquire SNM and only afterward try to retain unauthorized possession of it. If the adversary will not risk the detoction of the sNy that he acquires, he can exploit a fallure of the SNM detection symten (undeveloped event $D \times 3-1$ ) that he sonehow learns about, he can defeat or Iypass the swy detection system (undeveloped event DX3-2), or he might have the collaboration of key personnel of the SNH detection system to either defeat the systed for the adversary or ignore its alarms (undeveloped event DX3-3).

A second kind of element is the material accounting system (DX2-5, DX3-4, DX3-5, DX3-6). If the adversary does not need to keep the loss of sNM hidden longer than the reaction time of the material accounting system, he can ignore it in his SNH acquisition mcenarlo (developed event 0x2-5). However, if the adversary plans to hide the loss of SNM for an indefinitely long tine, he right attempt to spoof the material accounting systea either by tampering with the records of the system (undeveloped event $\mathrm{DXJ}-4$ ), or by aubetitution of other caterial for the sNM (undeveloped event DX3-5), or perhap: by mone other technique (undeveloped event DX3-6).

A third kind of element operates anywhere within the material acceas area $(0 l-3,01-5)$. The deacription of evente $51-3,51-4$, and $51-5$ from STEALTH-ACQUIRE SNH is also approprlate for these deceit events.

The fourth and finel kind of elenent is a two-man rule whose purpose is to prevent unauthorized acquieition of SNy (DX3-7, DX3-8, DX3-10, DX3-11, DX3-12). The subtree covering the adversary's need to traverse the area despite the two-man rule is duplicated from the logic tree DEceIT-BOUNDARY. The prinacy events that concern detection avoidance are $\mathrm{DX} 3-7, \mathrm{DX} 3-8, \mathrm{DX} 3-10, \mathrm{DX} 3-11, \mathrm{DX}-12$.

Baving exanined all primary events on the simplified logic tree, the $\log 1 \mathrm{c}$ by which they generate the end event ie examined next. The adversary aust acguire 5NM and he nust avold detection while doing 00 . This is the fundamental loglcal statement made in the $\log 1 \mathrm{c}$ tres. All other detall merely elaborates on the possibilities. The fundamental logical atatement is ade by AND gate D-ACoUre. The inputs for acguiring SNM come from evente $D 1-1$ and $D l-2$. All five other inputs (DI-3, DXI-4, DI-5, DXI-6, DXI-7) wopply requitenents for avoiding detection.

Before SNM can be physically acquired it must be located and recognized (bastc event $\mathrm{Dl}-1$ ). This should not be difficult for a well informed adversary, eapecially an insider. This event essentially is a reference to the prior part of the scenario that brought the adveracy into close proxiaity to the say so that it could be "recognized." The analyet must be caceful not to double count time to accomplish DI-1 that has already been counted in the analysis of other $\log 1 \mathrm{c}$ trees.

Event D1-2, "Obtain SNM," is logically redundant, being merely a collective label for its inpute (D2-1, D2-2). Evente D2-1 and D2-2 deal with acquiting SNM. They can be regarded as inputa to AND gate D-ACoOIRE. 
There are three real developments on the tree, but they contain logical redundancles. The adversaky has several options for the defeat of any local sny detection syatem: inputs to OR gate DXI-4 are DX2-4 (the SNH detection system accepts the acquisition of SNM as an authorized transaction) and DX2-3 (the SNM detection syatem fails to detect withdrawal of any SNM). However, event $0 \times 2-3$ is merely a collective label for events $\mathrm{D} \times 3-1, \mathrm{D} \times 3-2$, and $\mathrm{D} \times 3-3$ which are inputs to oR gate DX2-3, but could logically be direct inputs to or gate DX1-4.

The second development is of the adversary's options to defeat or ignore the material accounting system: inputs to OR gate DX1-6 are DX2-5 (the adversary ignores the material accounting system) and Dx2-6 (the adversary spoofs the material accounting system). However, event DX2-6 is merely a label for events DX3-4, DX3-5, and DX3-6 which are inputs to or gate $D \times 2-6$, but could logically be direct inputs to OR gate DX1-6.

The adversary's options for defeating a two-man rule (DX3-7, DX3-8, DX3-9, DX3-10, DX3-11, DX3-12) constitute the development of DX1-7 as inputs to or gates. For ease of reading this portion of the logic tree DX3-7, DX3-8, and DX3-9 are grouped as inputs to OR gate DX2-7. Event DX2-7 merely labels its inputs as all dealing with options in which a second man does cross the boundary with the adversary. Events $D \times 3-10, D \times 3-11$, and $D \times 3-12$ are grouped $A B$ inputs to oR gate $D \times 2-8$. Event DX2-B merely labels its inputs as all dealing with options in which a second man does not cross the boundary with the adversary. The two "label" events, DX2m7 and DX2-8, are the inputs to OR gate DX1-7. Finally, DX4-1 and DX4-2 are pguedoevents (equivalent to comments) pertaining to event DX3-3. They remind the andyst of two things that are concurrently relevant: that the second man can also be an adversary and that this additional adversary nust be analyzed by the full tree, D-ACQUIRE. So, DX4-1 and DX4-2 are inputs to AND gate DX3-9.

\section{"RELEASE" GENERIC LOGIC TREES}

There are two generic $\log 1 \mathrm{c}$ trees titled RELEASE: one each for releasing SNM by stealth and force tactics. The primary events of each tree can be divided into two groups: (1) how the adversary accomplishes the release of SNM and (2) how the adversary remains undetected (when using stealth tactics) or overcomes any opposition that he encounters (when using any tactics), at least until the release has been inltiated.

A RELEASE generic $\log 1 \mathrm{c}$ tree is to be used only when the adveraary has reached the location where he can employ a release mechanism. If his ecenario requires that he acquice SNM and bring it (or have it brought by someone elas) to the location of the releage mecbanism, the analyst should uae the appropriate AcourRe shm tree, and also the necessary Boundary, ARE, and BurfDrwg trees to follow the acenarlo to the point where the release mechanisn itself can be employed. 


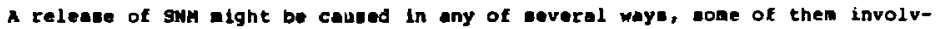
ing eeveral tergete, or vartous environnentel preconditione. Though a RELEASE logic tiee 1t more copplex than bet generic trea, it only alludea to release nechanisms rather than analyzing than in deteil.

One question to as in a qualitative evaluation of the logic tree is, can the adversary initiate his chogen relezbe mechanin and satisy all ita preconditions?" The adversary neede to be well infocted about release nechanisos, the achievability of preconditions, and be suitably Bkilled and equipped. For the STEALTH-RELEASE tree a second queation ib, It it likely that the adverary can avoid or disable the detection elenents without an alaci being generatedr For the PoRCE-RELEASE tree, a second queation 1a, Is lt likely that the adveraary can overcone any opposition that he encounters?"

If a guantitative evaluation is needed, one queation to ask is, How much time wil the adverbary need to accopplith the takk for release of SNM or to eatablish that the precondition have been aet?. Thie time is relevant for analysis only if it occura during the attack. The other quantitative question ia, what 19 the probability that the adverary will be detected a he attempto cause a release of SNH?

\section{STEALTH-RETEASE}

Figute A-11 hows a alaplified version of the generic logic tree, STEALTHRELEASE. There are 14 primary ovent (s1-2, s1-4, s2-1, s2-2, s2-3, s2-5, 52-6, s2-7, s3-1, s3-2, s3-3, s3-4, s3-5, sx3-6). These can be divided into two 'groups. One group concerns the adverancy' need to acconpliab the raleage of SNM (S2-3, s2-5, s2-6, s2-7, s3-1, s3-2, s3-3, s3-4, s3-s). The other group concerns the adveraary's need to rewain undetected, at leat until the roleage has been initiated $(s 1-2,51-4,52-1,52-2,5 \times 3-6)$.

The $\log 1 \mathrm{c}$ tree asumed that reluase of Sw can be accomplished in several wys. The released SNH can be propagnted offaite by alr (airborne release, see events s2-3, s2-4, s2-5, s2-6), or by other weans (examples cited in the deacription of event s2-7 are rolease (nto groundwater or wastowter). The releane can be accompliahed by woking on the smiteelf after acquiring it ("Direct involvement with SNM", see evente s2-4, s2-6, s2-7) or by cauring one or more syater faults that will eventually reault in an Say release ("Indirect involvesent with SNM," see events S2-3, s2-5, s2-7). The releage can be accomplithed by the use of explosives (wee event, 52-5, 82-6) or without explouives (see events s2-3, 52-4), Both cases night be approprtate for developent under event s2-7. These teveral methode of causing a release of SWH hould present different problens to the adversary.

The elemence of the phyaical protection oyaten that are tha last defenes againet releace of SXY are not nened in events 62-3, the developent of s2-4 (1.e., 53-1, s3-2, s3-3, 63-4, 53-5, 8x3-6), s2-5, 82-6, or s2-7. It it the analyat'. job to eupply theee element, fro the design wich he te evaluating. However, evente s2-3, s2-5, and s2-6 are developed eventes thuy are further doveloped on the complete generic logic tree, Brabri-RELengt. Thet developant ie lgnored in this discusetion. 


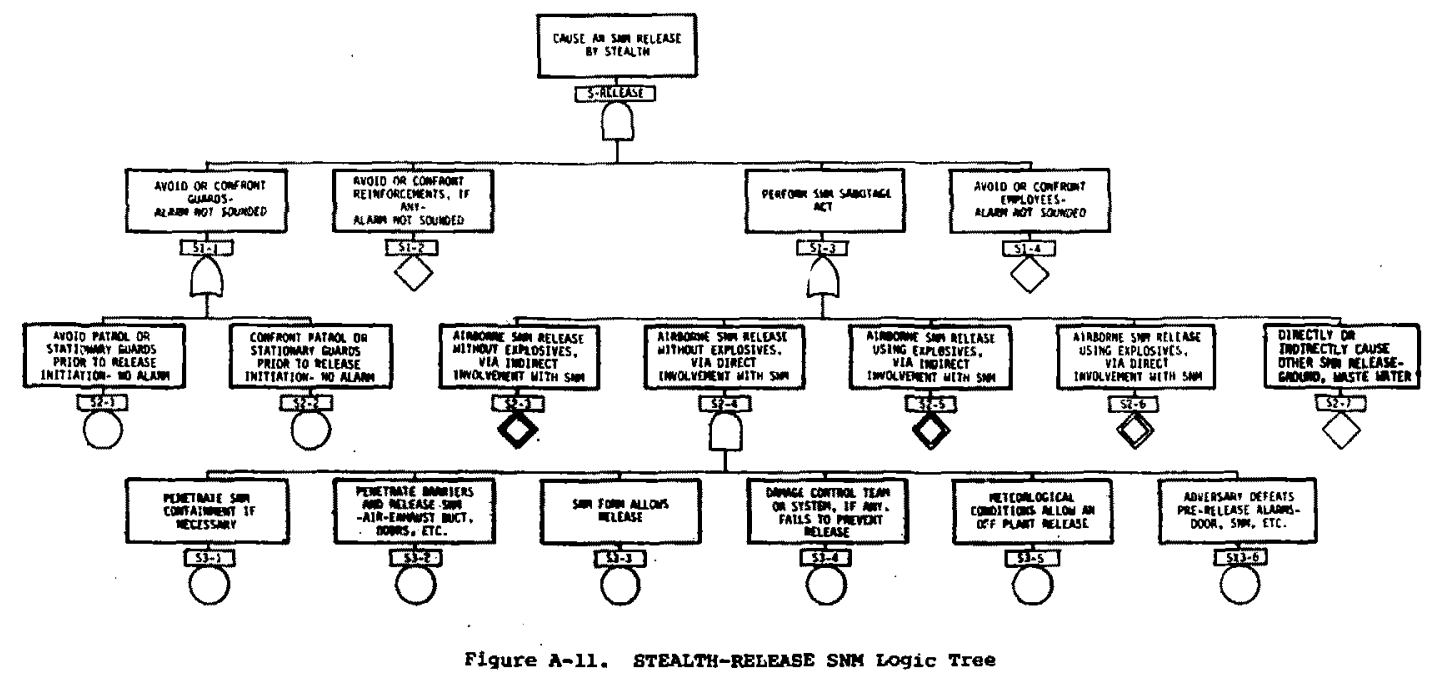


The maximun development has been retained in the abridged logic tree from the complete generic logic tree STEALTH-RBLEASE only for event s2-4, "Airborne SNM release without explonives via direct involvement with SNM." The release is represented as a nuber of events all of which sust occur for the adversary to be successful. First the adversary must ot least breach the containment of the SNM whether or not he finds it necessary to take possession of the 5NM (53-1). Then the adversary must penetrate any barriers between the no-longer-contained sNM and the atmosphere (S3-2). For example, high-efficiency particulate air (HEPA) filters might be breached so that the ventilation systen could be used as the release mechanisn. But for this scenario to succeed, it is necessary that the SNm be in the proper form, for example, a fine powder, so that the ventilation system will in fact be able to pick up the SNM and inject it into the outside atmosphere (53-3). For sowe releage mechanisas that do not use explosives for sNy dispersal, it may be possible for a danage control operation to either prevent or 1 imit the incipient celease if it is discovered early and the release mechanism works slowly enough

- (53-1). Even if an adverbary succeeda in releasing sNM to the atmosphere, the release might not reach offsite unless meteorological conditions (e.g., wind velocity and direction) are favorable (53-5).

Two kinds of elements detect an attempt to release SNM. One kind would be associated with release mechanism in locations where the attempt could be detected before the releate is achieved (sx3-6, basic event). Examples named in the event description detect use of doors that give ccess to a release mechanism, and the presence of SWM in the vicinity of a release mechanism where it would not be expected or permitted. The analyst mut identify the posaible release mechanisms so that he nay asaesa how thoroughly the phyaical protection systen provides for prezelease detection. One cannot be assured of distinguishing a release attenpt fron a theft attempt by which sensors are activated. Adequate assessnent la necessary.

The second $k$ ind of element is personnel that can see or encounter the adversary attenpting to achieve a releste of $\operatorname{sim}(51-2,51-4,52-1,52-2)$. Guards on patrol or stationed in observation towers are one exaple $(52-1,52-2)$. These would be a tralned part of the physical protection syeter. If they alone could not be positive neasures for detection, they may reinforce the other kinda of detection elenents to produce positive measurea.

The two events that name guards al detection eleaents list two ways that an adversary night not be detected. Be can avold being seen by the guards (S2-1), or, if he is seen, he may be able to prevent the guards from sounding an alara (S2-2). While the latter method of avoiding detection may be forceful rather than otealthy, it represents an action required of the adversary if he is to continue his attack by tealth, undetected, after he accidentally confronts guard. The adversary may be able to hide until the patrol guarde have passed and then use the period until the patrol is repeated to relgase SHM. It any be difficult for an adversary to know whether or not he is being coen from on observation tower (assuning that the SNM is being released from an outdoor location) or to prevent the counding of an alacm if he knowe that he has been seen. 
Operatione pereonnel any be neurby when the advereary arts to release GNM and see the actions (\$1-4). Depending on the work achedule of a particular site, the advertary ay be confident of avoiding accidentel obeervation. Confrontation would be an unintended complication of an attack by atealth, and it mey increase the chance of being oberved by other operetions personnel or guarda.

Reinforcenenta for the atcurlty force (S1-2) would be called only after detection. If the time between notification of the security force and its arrival is long enough that the adversary cannot be intercepted before release of sNM is initiated, only a dane control teas or system renains to mitigate or nullify the adversary's success. Thus, this event is Important during release of SNH. This event nay instead be neaningful with respect to detection during a prior step of the scenario such as crossing boundary, traversing an area, entering a building, or acquiring SNM.

Having examined all primary events on the simplified logic tree, the logic by which they generate the end event ia examined next. The adversary must initiate the release of SNy and he must avoid detection at least until this is accomplished.

This is the fundamental logical atatement made in the logic tree. All other detail merely elaboratea on the postiblities. The fundanental loglcal statenent is made by MD gate S-RELEASE. The input for intiating the release of SNM coned fron event s1-3. All other Inputs ( $\left.51-1, s_{1-2}, s_{1-4}\right)$ mupply requlremente for avoiding detection by personnel who may encounter the adveraury where he lo attempting to initiate the release.

Intiating release of SNM (S1-3) in generated by an OR gate whose inputs (S2-3, $s 2-4, s 2-5, s 2-6, s 2-7$ ) are the optional wethode of performing a sabotage act on SNM. All of these options but one (52-4) are developed events. The option of "Airborne SNM release without explosives, via direct involvenent with SNM* is generated by an AND gate which repeats the fundarental $\log 1 \mathrm{cal}$ statement of the logic tree. The input: for initiating the release of SNM come from events s3-1, s3-2, s3-3, s3-4, and s3-5. The other input, sx3-6, is the requirement for avolding detection by hardware systems before the release is initiated.

One other development appears on the tree. Event sl-1, "Avoid or confront guards -- alara not sounded, " atates an option. The necessary logic is an on gate, S1-1, with inputs S2-1 and S2-2. The sane Bort of option is impl led for s1-2 and si-4, both undeveloped events. Their developments would have the same logical form as the development of $\mathrm{s} l-1$.

\section{FORCE-RELEASE}

Figure A-12 hows a simplified version of the generic logic tree, FORCERELEASE. There are 13 primary event: (F1-2, P1-4, P2-1, P2-2, F2-3, F2-5, F2-6, E2-7. $3-1, F 3-2, F 3-3, F 3-4, F 3-5)$. These can be divided into two groups. One group concerns the adversary's need to initlate release of SNM (P2-3, F2-5, F2-6, F2-7, F3-1, F3-2, F3-3, F3-4, E3-5). The other group concerne the advereary's need to overcone any opposition that he encounters while initiating release of SNM (F1-2, P1-4, P2-1, F2-2). 


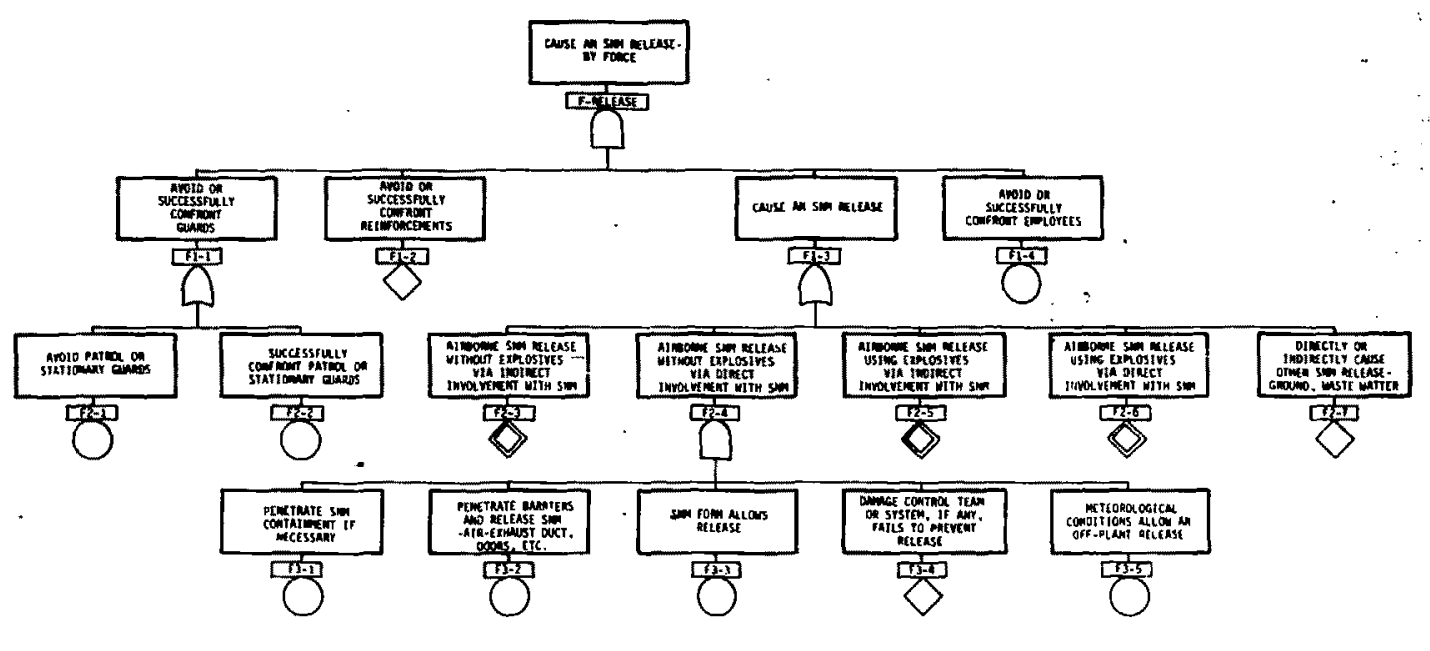

Figure A-12. FORCE-RELEASE SNM Logic Tree 
One event on sienLtH-RBLEAgs hes no counterpart on ronce-Rethast. mis exception is sx3-6, "Adveriery defente peereleave alerne -- door, sim, etc." By definition, when using the force tactic the idversary expects to be detected, wo the IORCB tres: heve no events thet require the advereary to take action againet tbe detection aycen. 


\section{APPENDIX B \\ Complete Generic Physical Protetion Logic Trees}




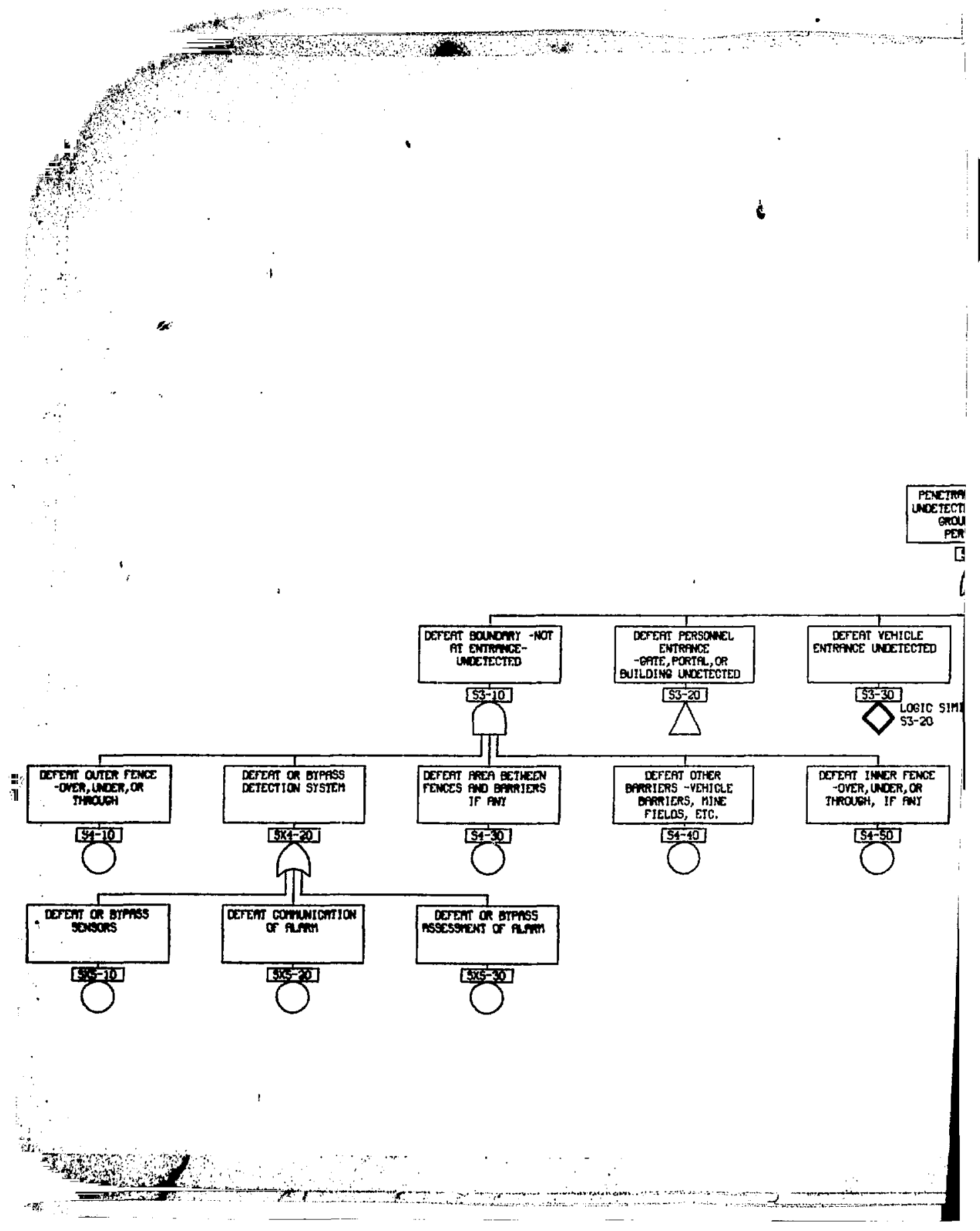



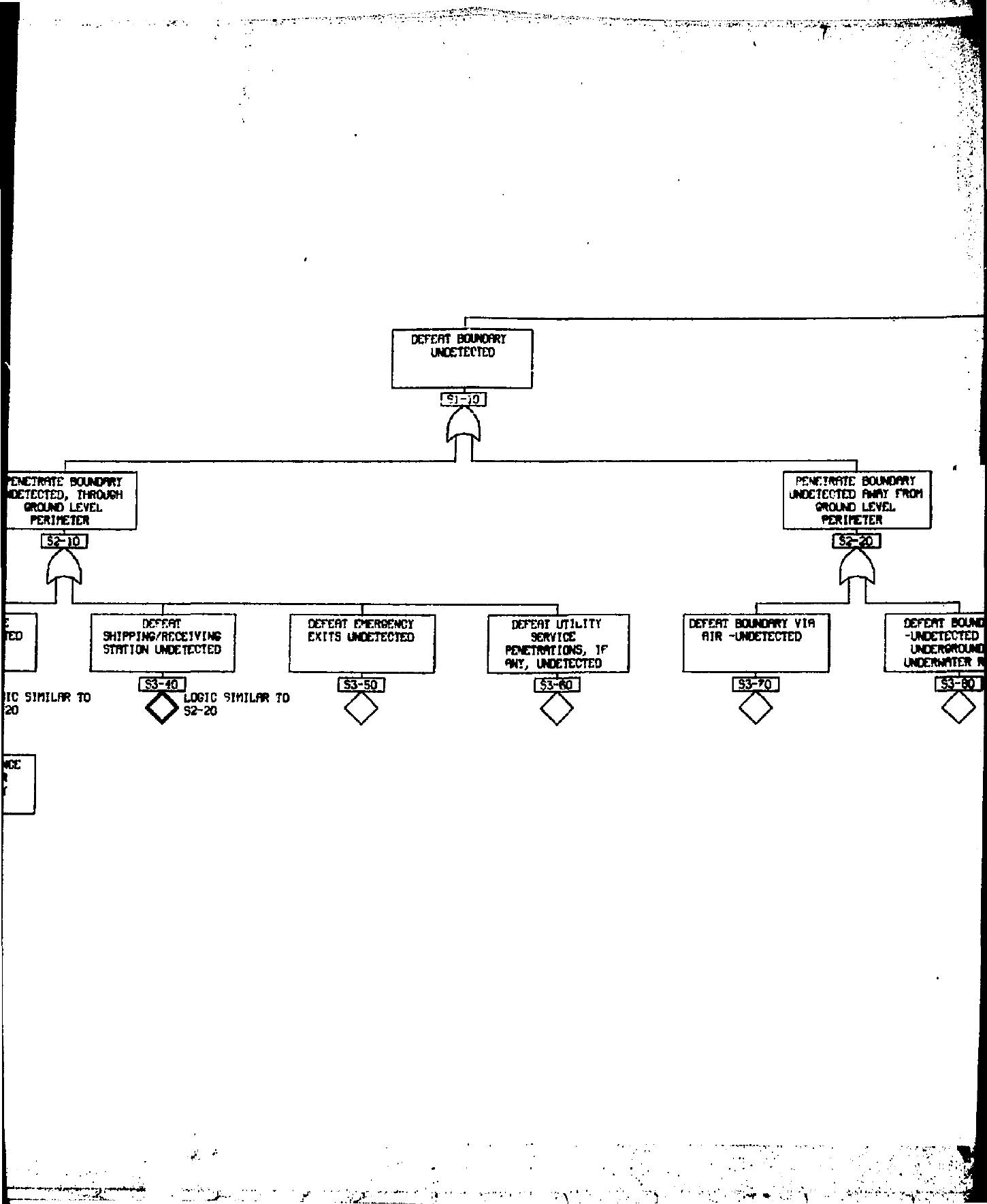

Defrent Bour -1NDxtectod Moctininter $\sum^{3-60]}$ 

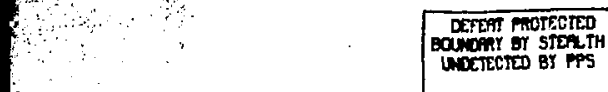

acuroper of STEA th

IMETECTED BY PPS

5-pitar

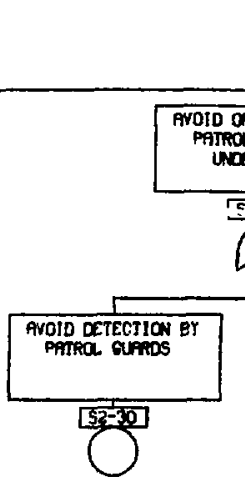

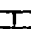

on contrort

unerected
1

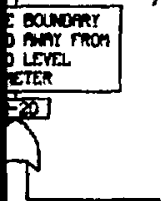

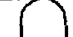

Dxpant Eouning

-UAPEIECTEO VJA

vipatindund of

Litantide RoJIE

AYolo or corront FEIHORERENTS UIDE?ETED
AYOTD or coirforrt SthtIOWAR GUANS LITETECTED - IN TOERS, ETC.

S3-60

DISFaL SITtIarer WINAS HI THOUT RLFW sowneo

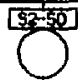

, 52-60 

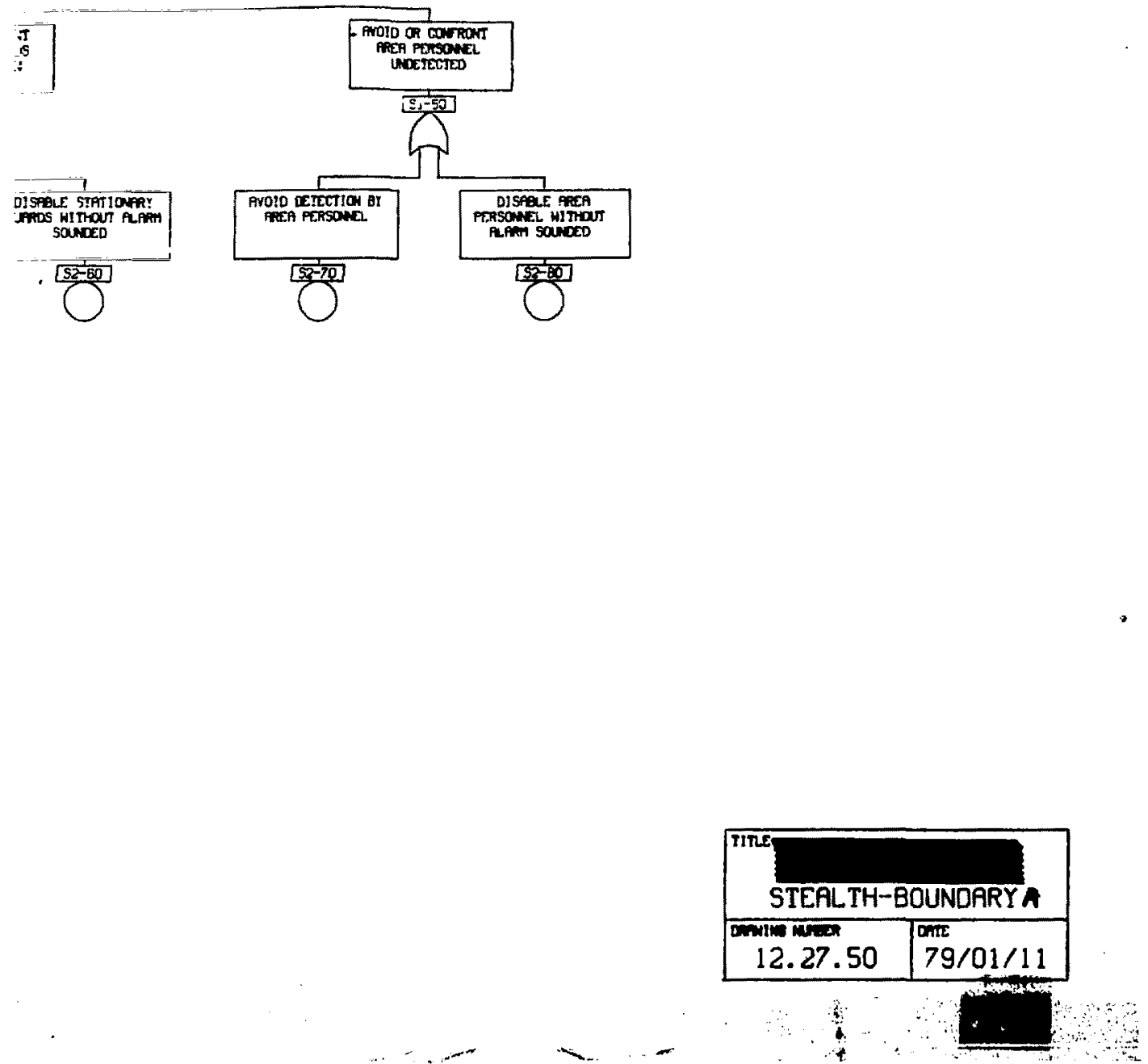
$\infty$ 
CO THROAFH PERSONT:

EMThance Uactr.CTEO
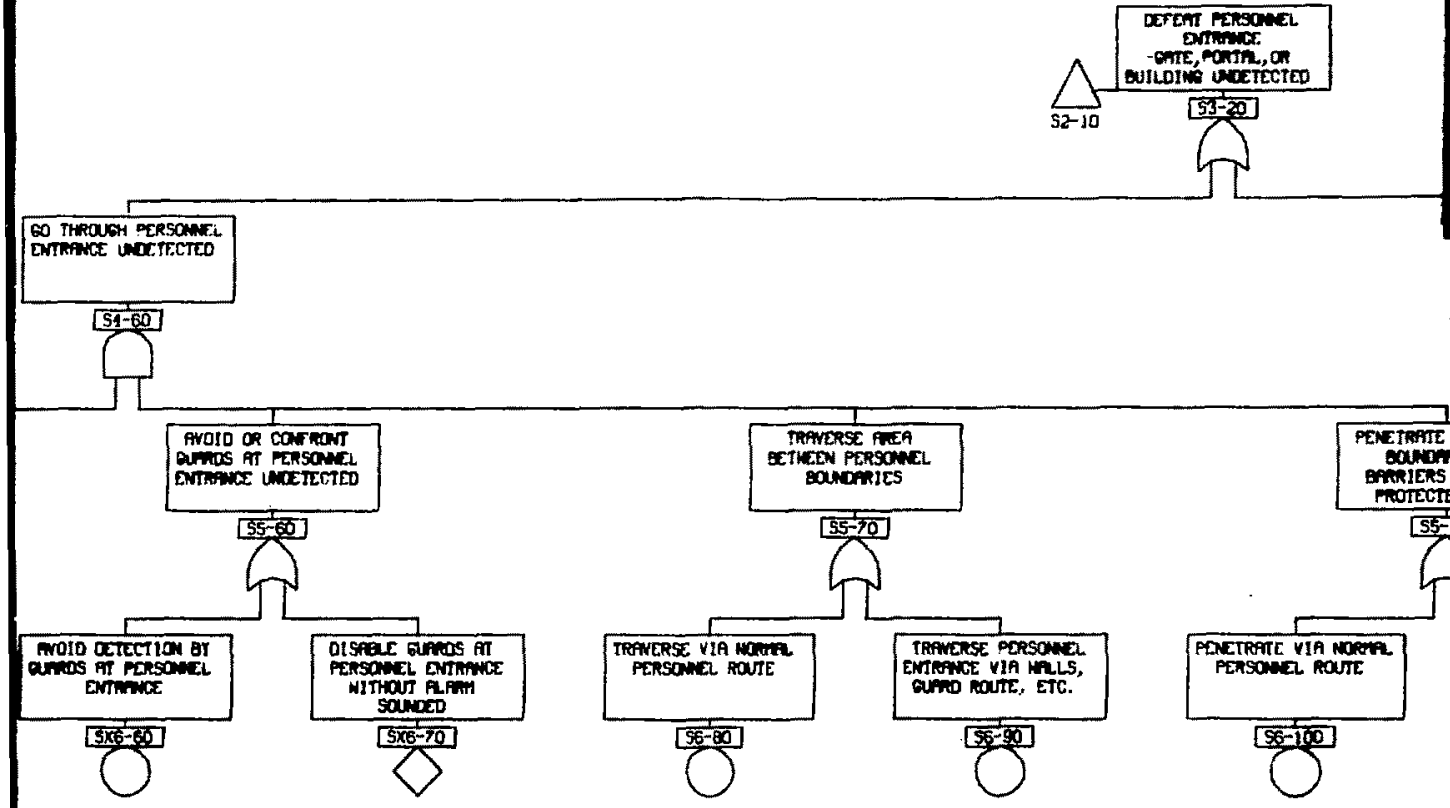


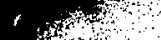

$x^{2}$

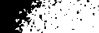

,

sis:

ini, on

Detectex
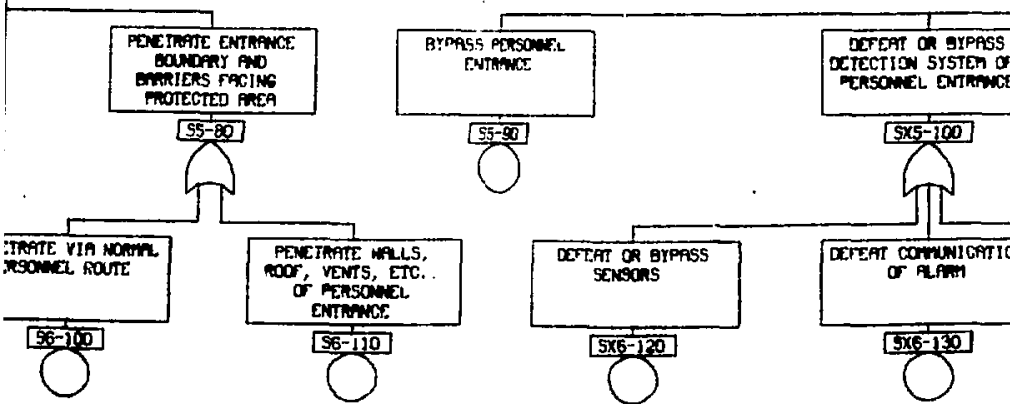

DFFAI OT GPass

ENTthuce

octection SYSTEm or

BTPASS PEASOTY

ENTARESE VIA ONER on

UNOR UNETECTED

mises FacIm

MIECTED FAEA
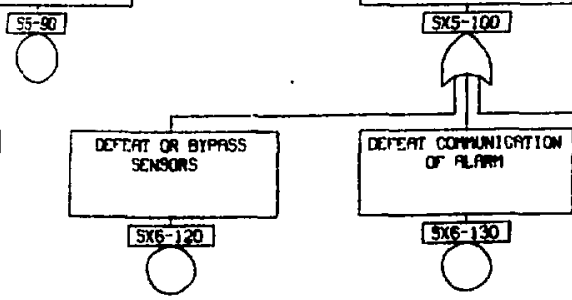

OFFEA of BYPASS ossesstevi or Aurem
ENTANACF:

S6-190

$5 \times 5-110$ 
aren an brmos nowssingt of furw

\section{5xk-10}

aroin on corront

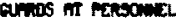

EMTive vatected

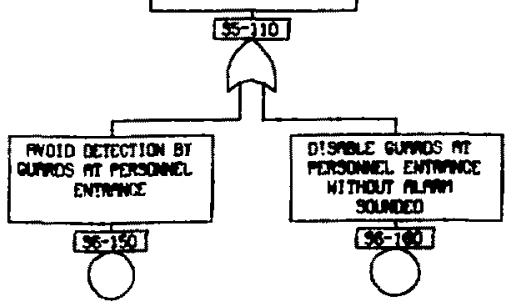

\section{$\operatorname{Tr} 8$}

STEALTH-BOUNDFRY B

Crmin Tim

12.27 .50 ant

$79 / 01 / 11$ 
$5 y$

4 trin

A

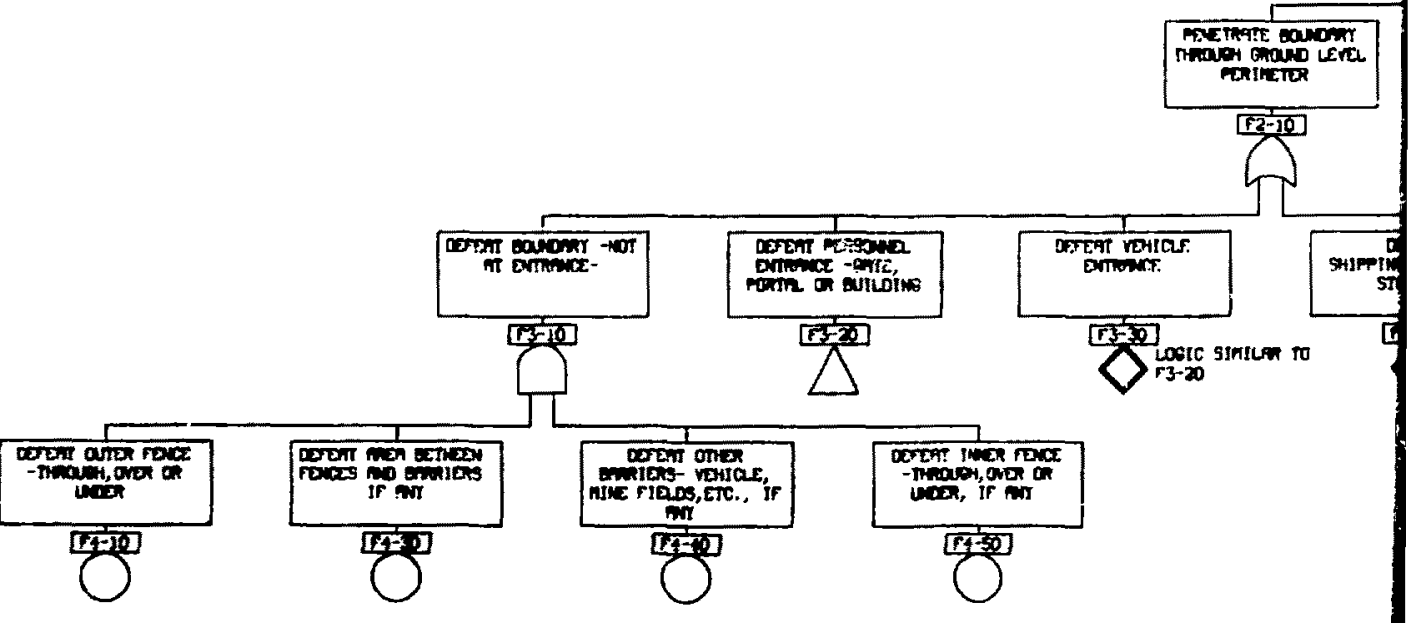




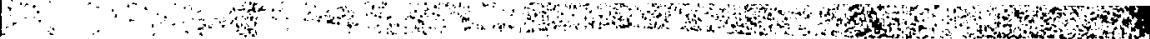

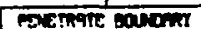

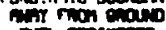
Ler motreter

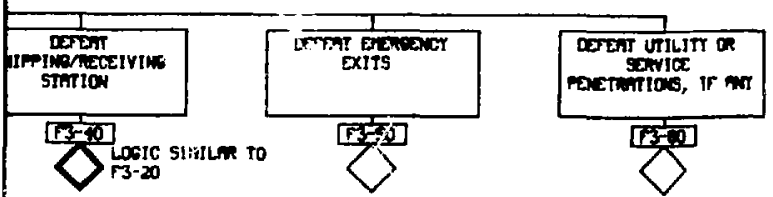

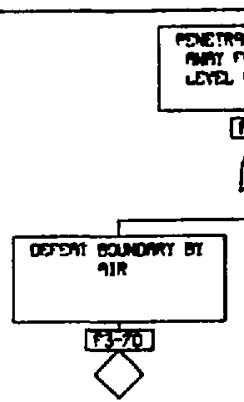
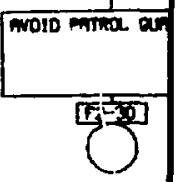

woun exingr vin visting of

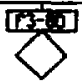




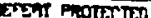

sovom ar Fons:

\section{F-क्षका

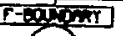

$\overline{x y}$

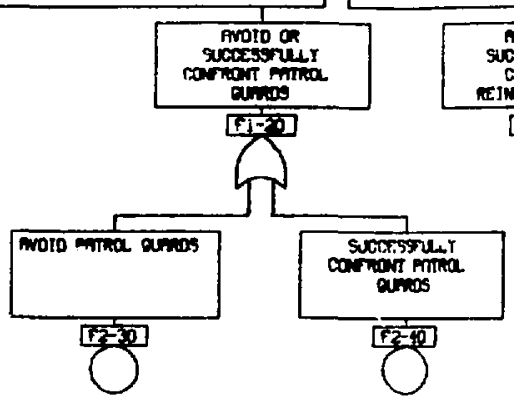

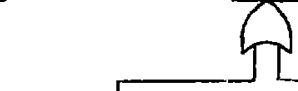

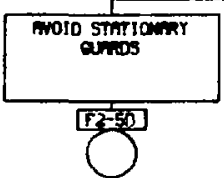

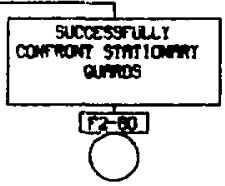

\section{AnI corting vIn

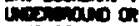

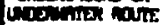

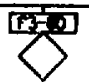




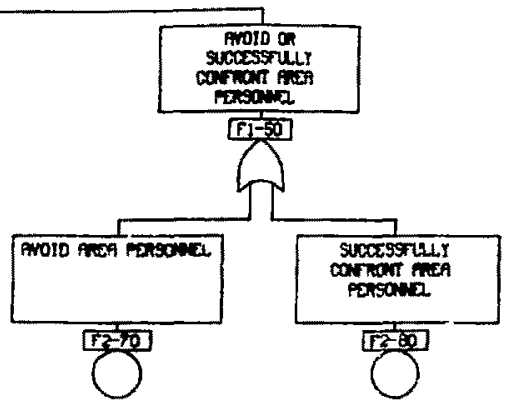




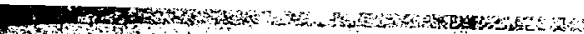




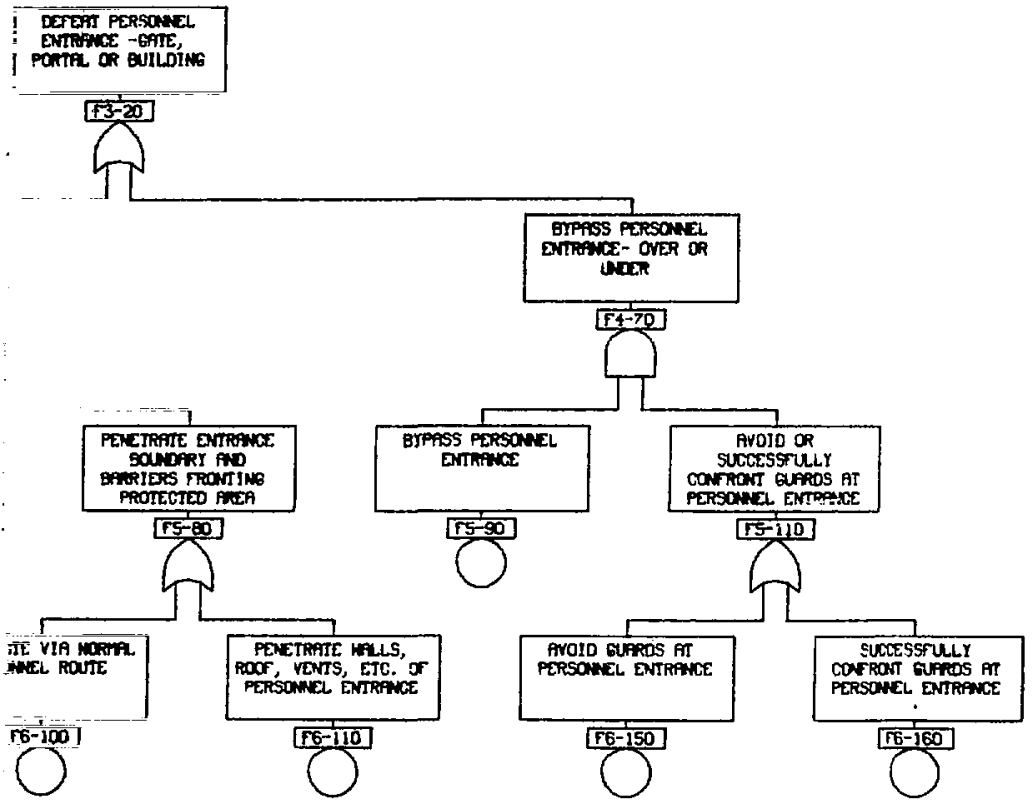




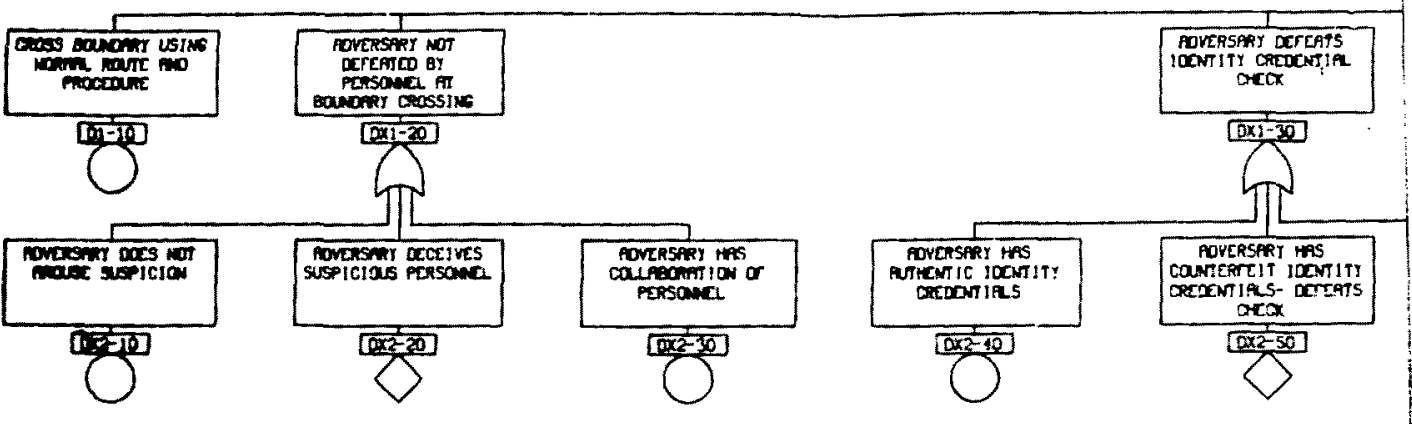




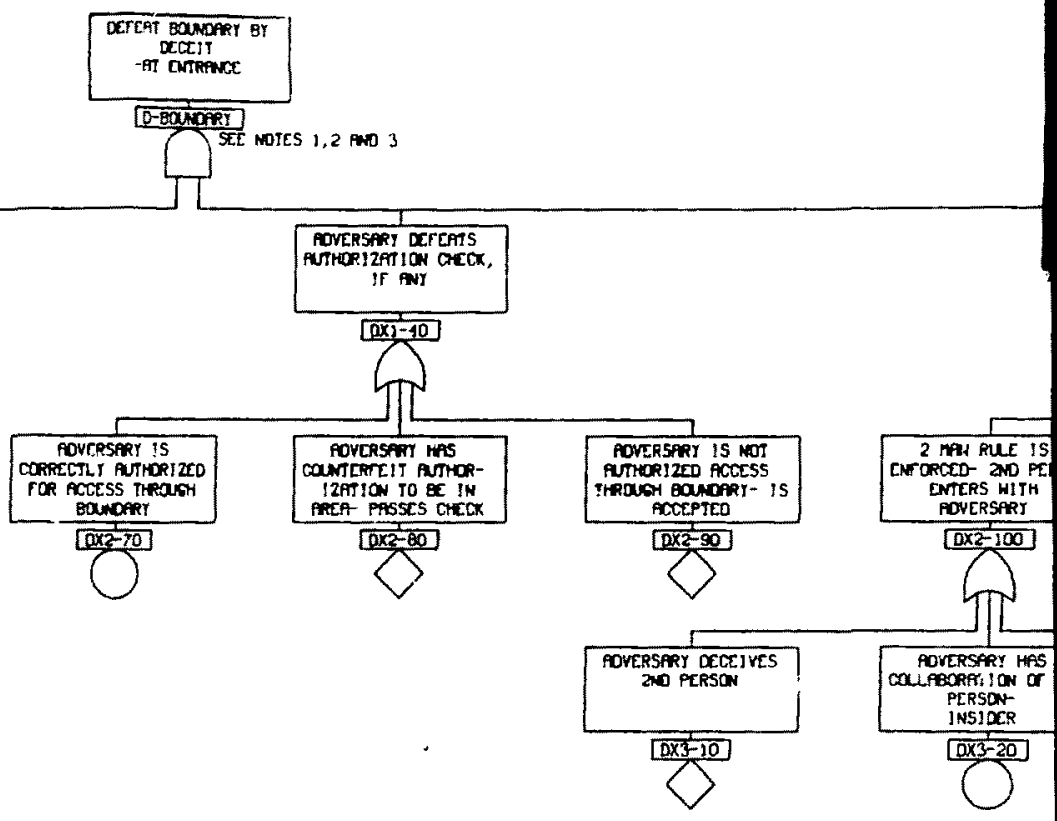




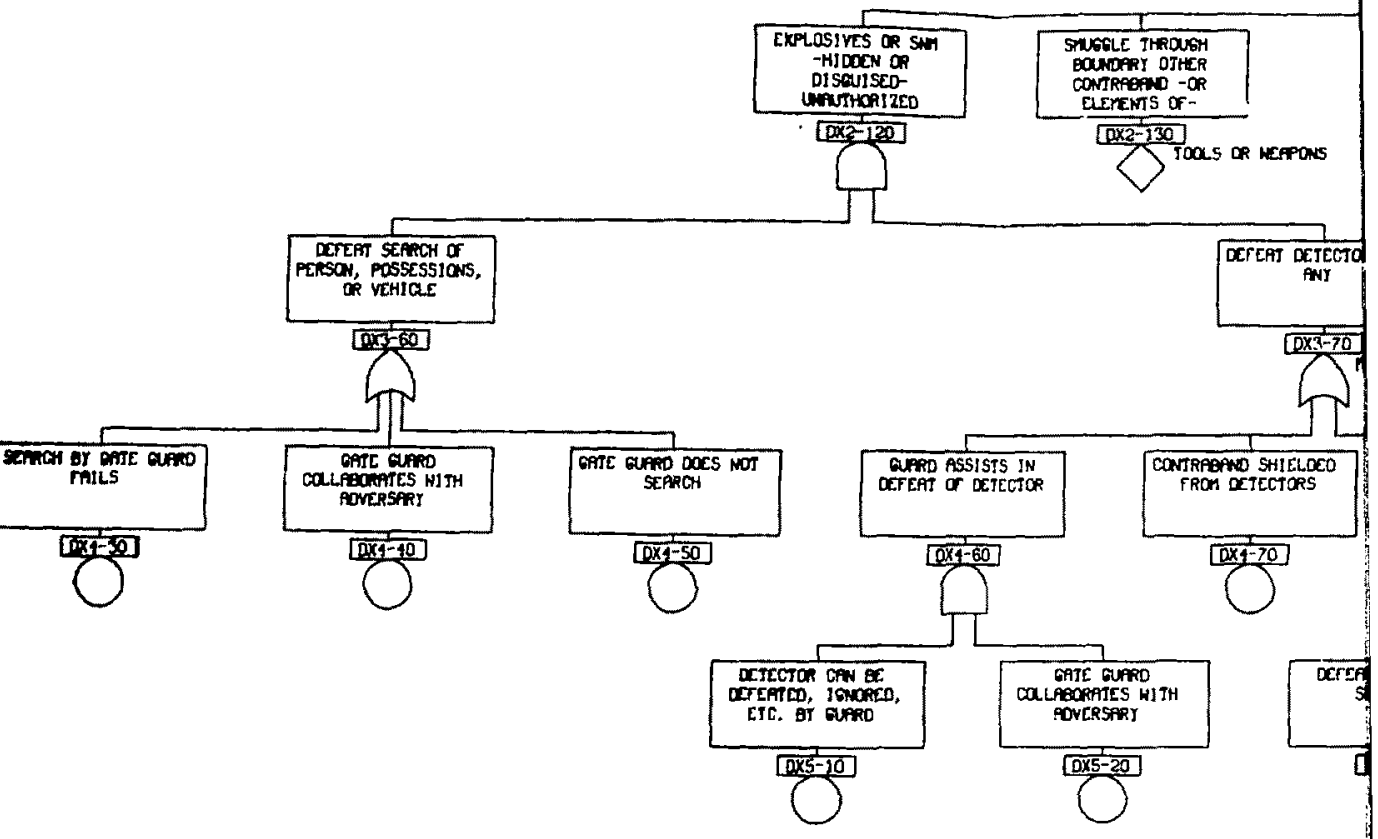




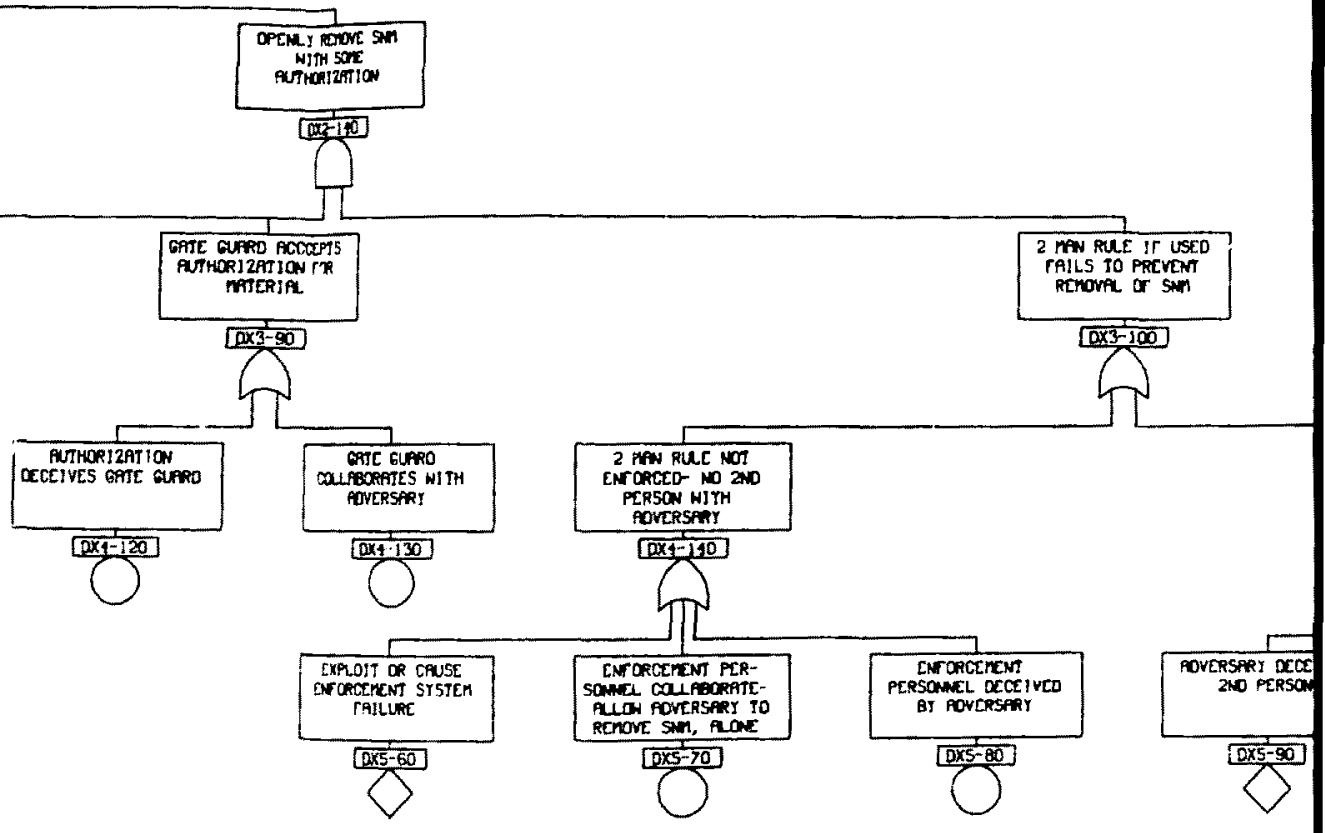



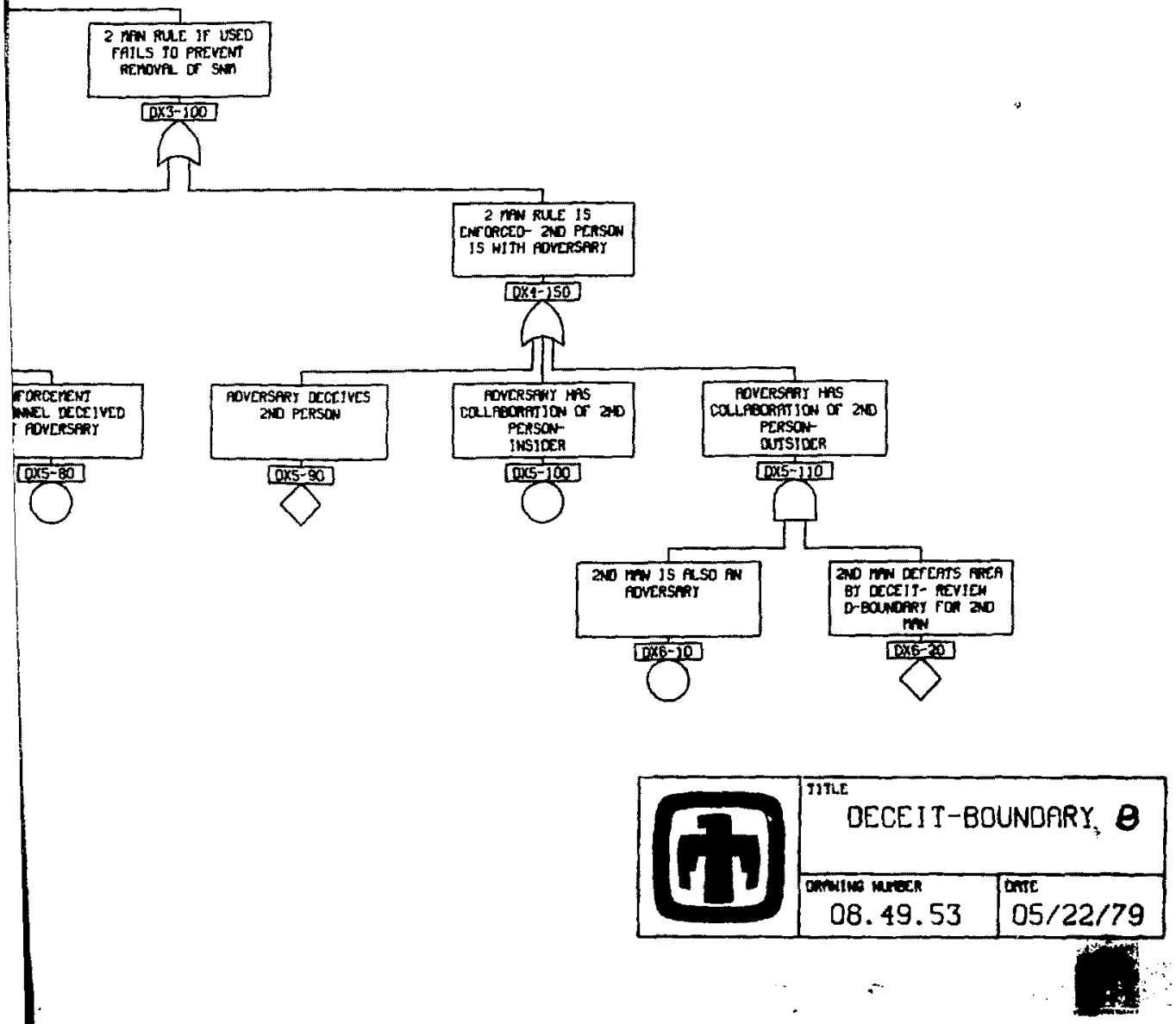

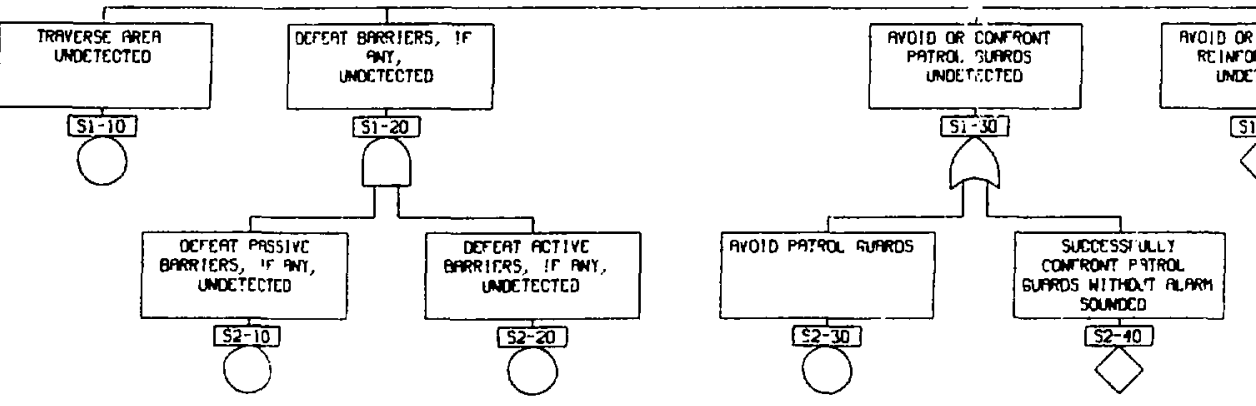

mer

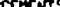

DrEAT PAS51YC DERS, IF AWT S2-10 () frolo

G)

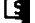





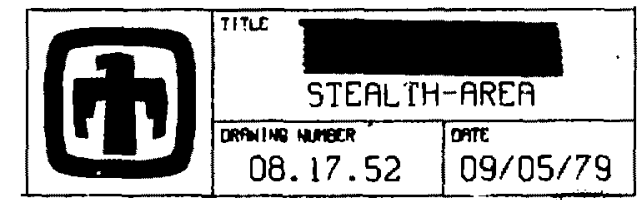




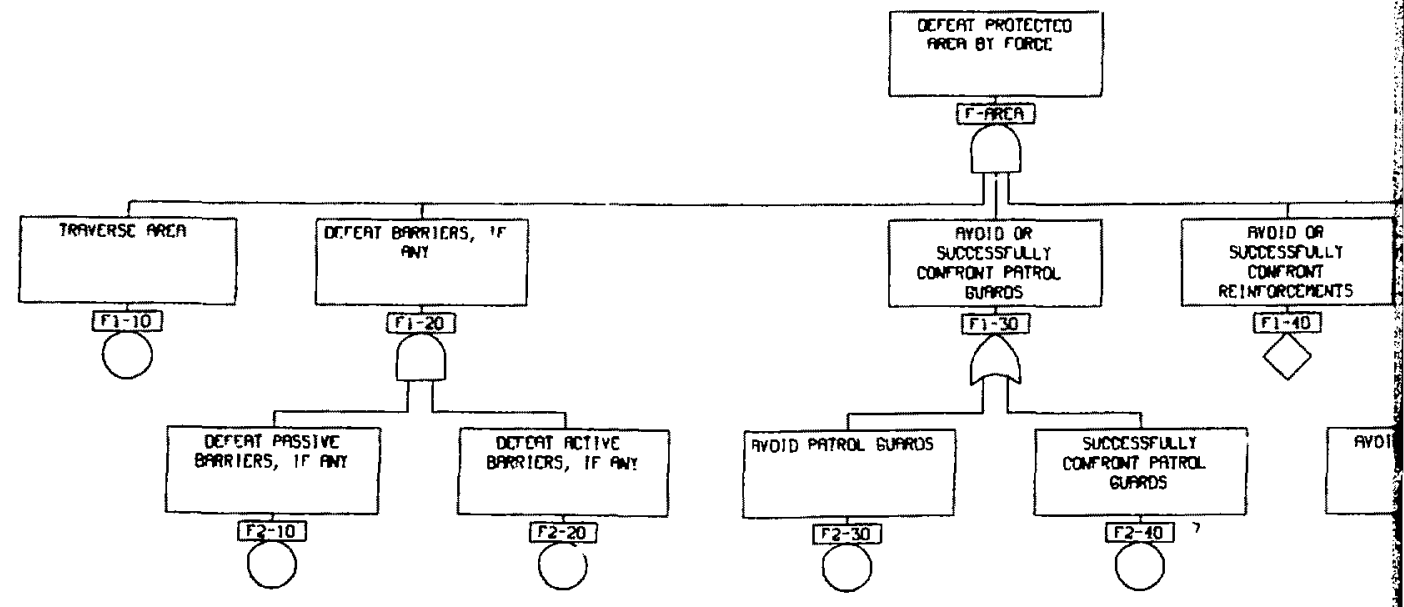




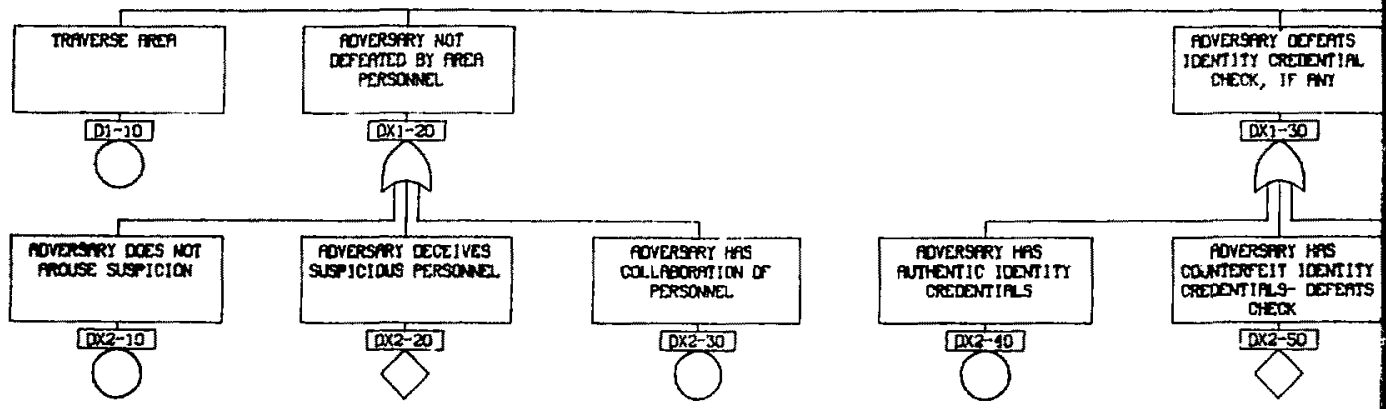




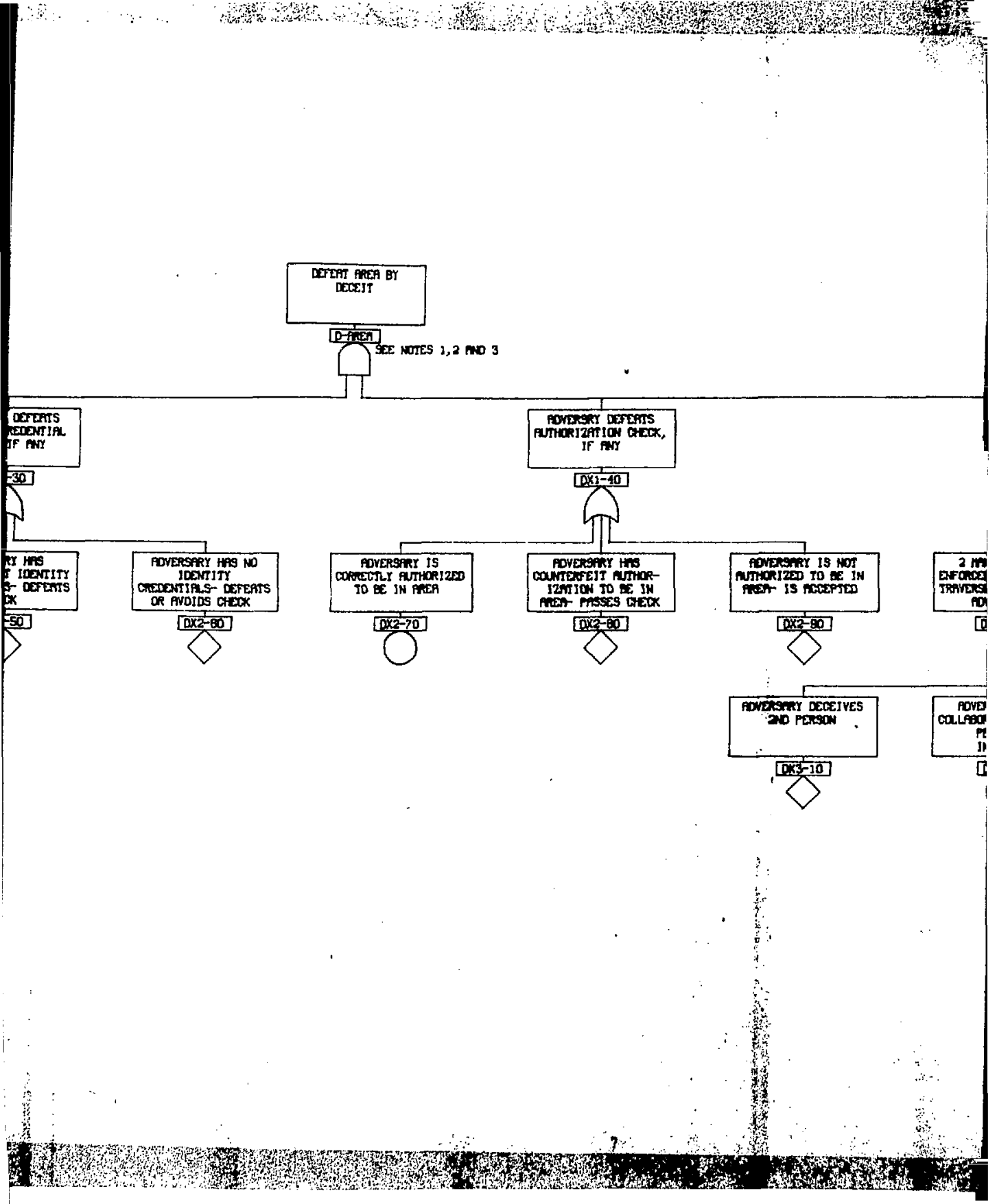




\section{$2 \mathrm{mw}$ hate If 4000 Patls to deter. foversent frem fres}

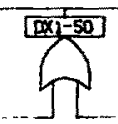

FOVEDSTI ANDIDS

arceives, on asstirs Resratise, If ANI

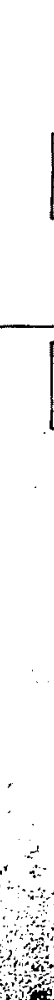

$2 \mathrm{mw}$ kUt 15

aroncoso- 20 POSSON

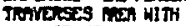
novistomy

$0 \times 2-100$

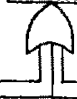

FDVERSFIY TIS

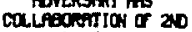
pressot IHSIDX: [a3-20].
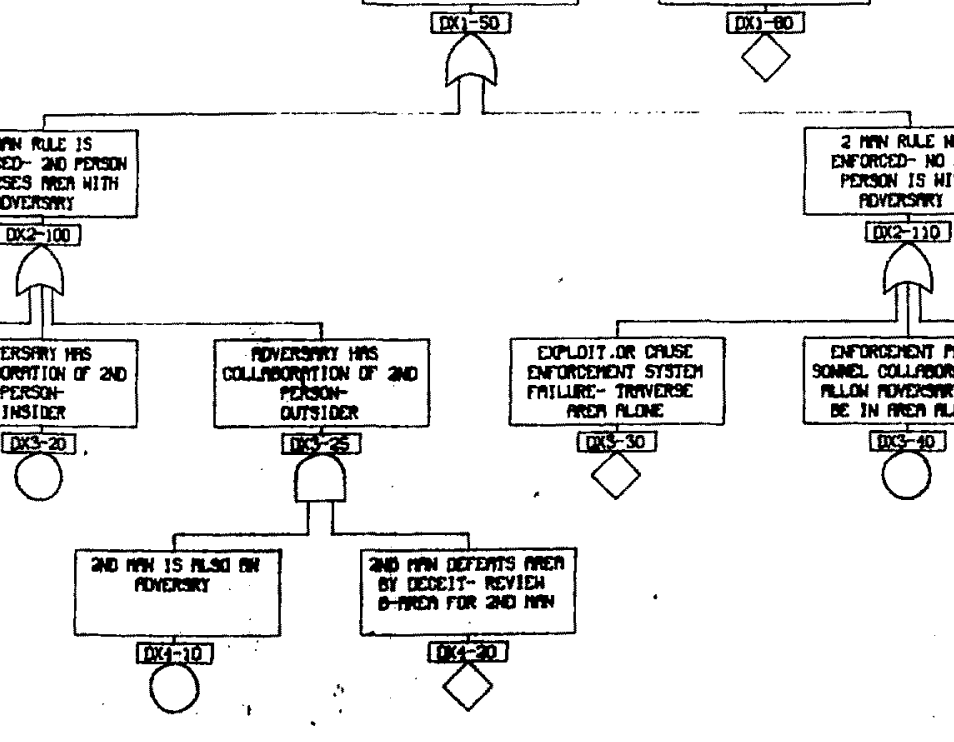

\section{$25 \mathrm{mw}$ oxrents men \\ or cescit- kxyles}

-rion ror zo men

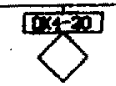

2 IN RUE NOT aronced- 1020 corosin

[0.2-120

Domasis ratserics aransarent ressave Int 1020 Foscon is mentreso

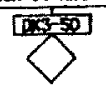




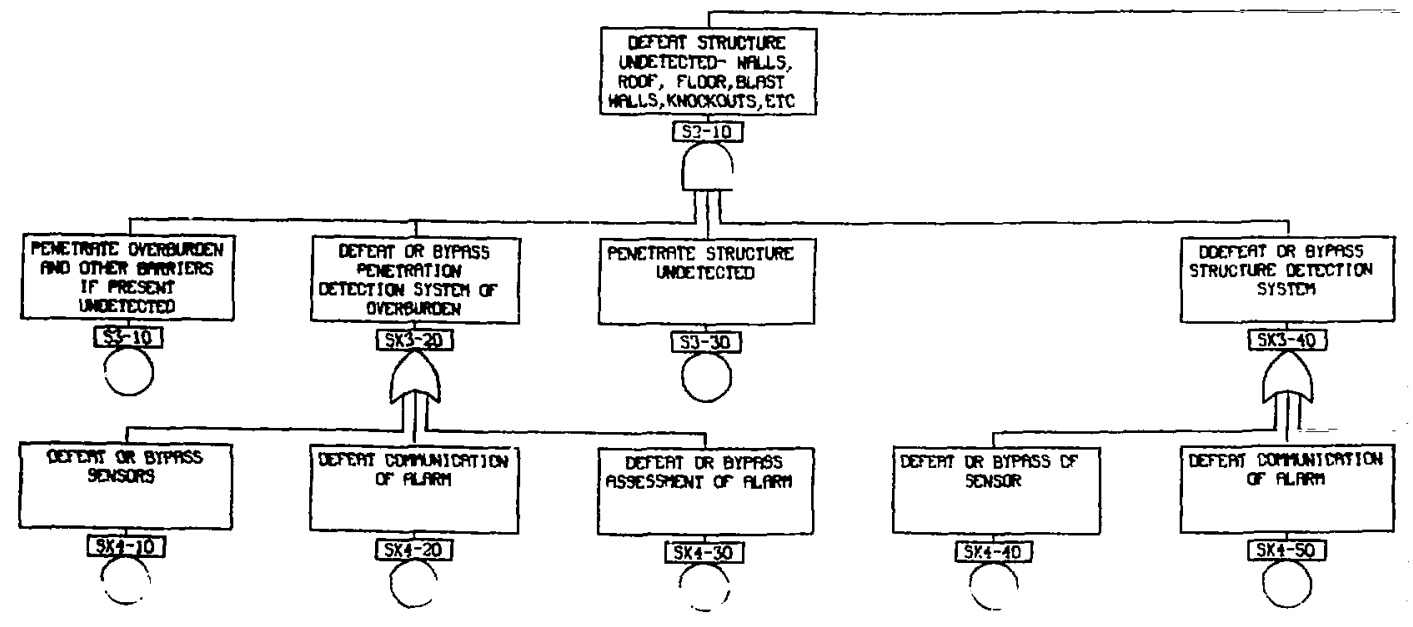




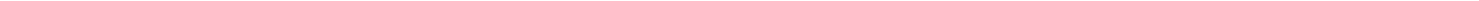



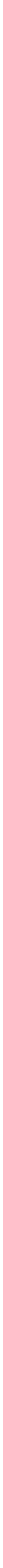
DEFEAT BUILOIK

GOUOARY BY STERLTH

UNCETETED

\section{5-8106}

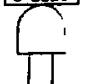

PENETRATE SERVICE IN

LEIS WDETECT. -VENTS

HIMDOUS. UTILITY TUN-

NELS, SENZRS. ETC.

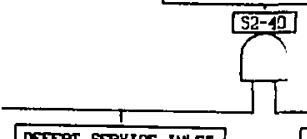

DEFEAT SERVIFE IKLCT

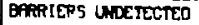

$53-120$

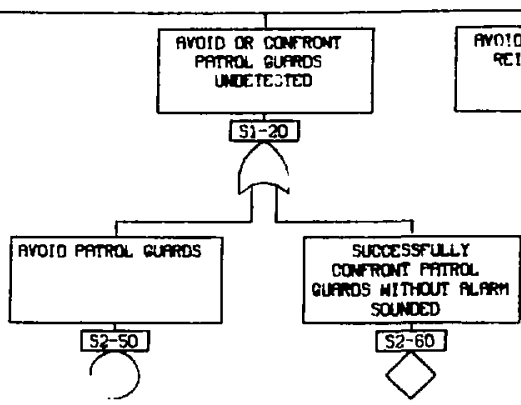

DETRAT SERYICE IMLET

SWI moNI TORS

DirtinICATION, OR

ASSE5STENT
(SX3)

$5 \times 3-130$
Avo!g of carroNt STRT IOMFY BURRIS UnCETECTID

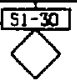

\section{$51-40$} 4
$5 \times 3-140$
AVDIo Stat towny aurnos

s2-70
SUGEEs: Grios NITH son-1<smiles>C1CCCC2CCC2CC1</smiles> 

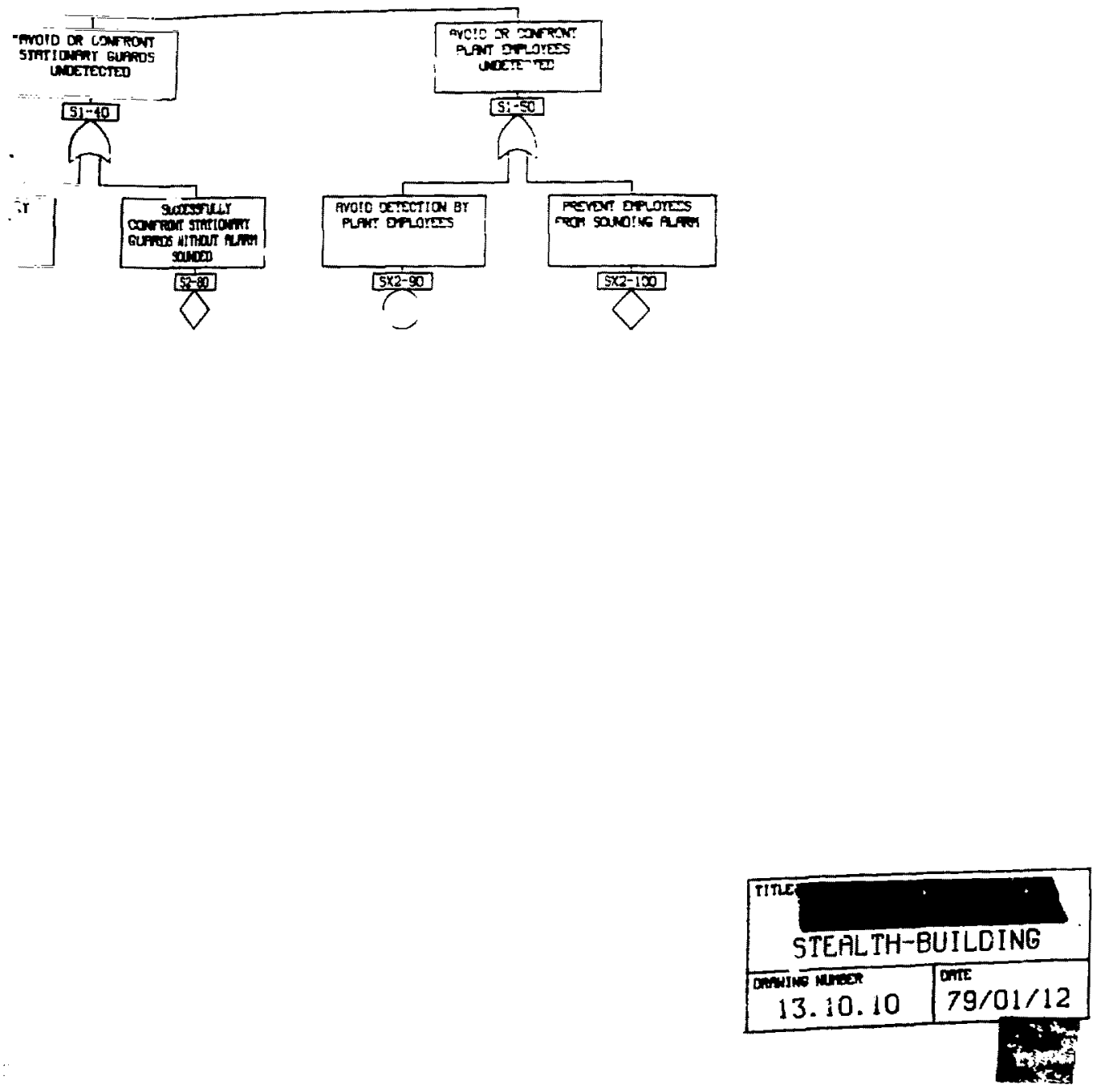


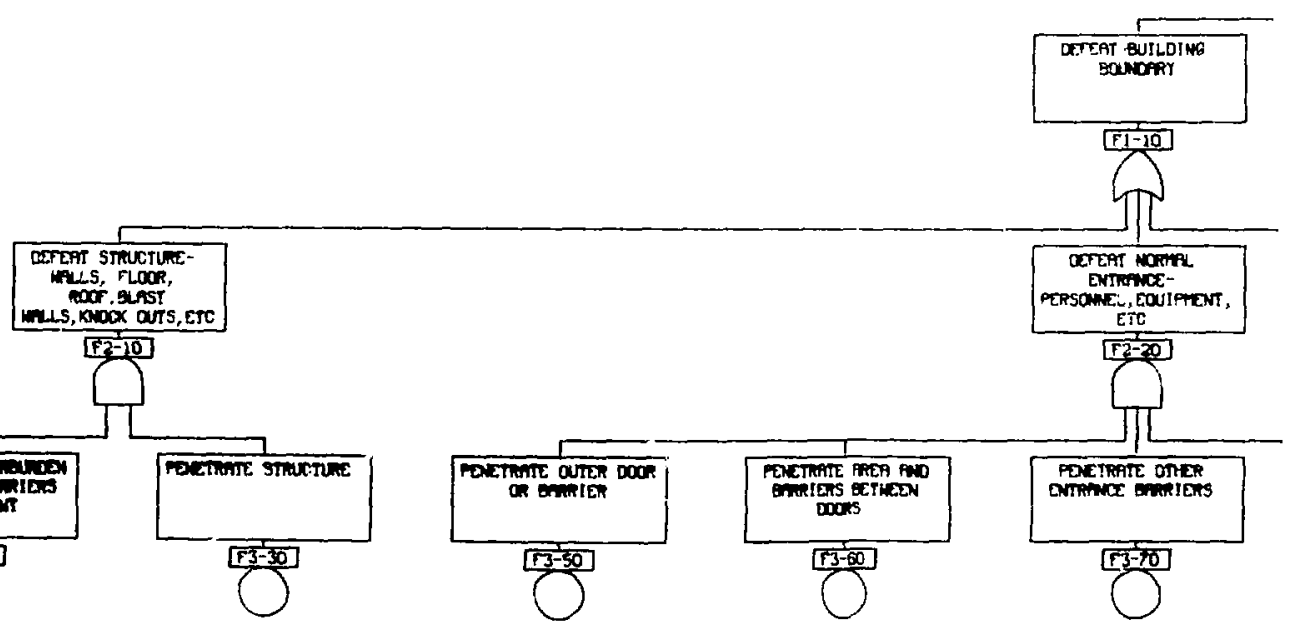


F-B⿺辶一

$7_{11}^{1}$

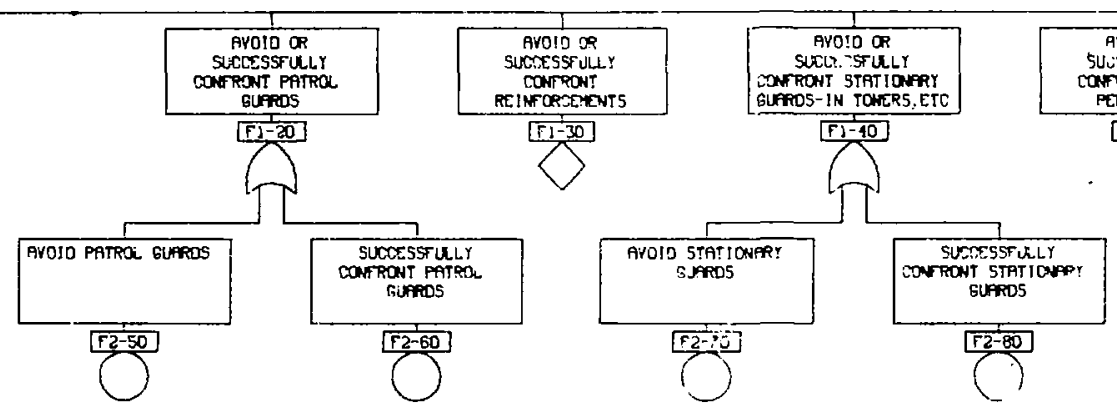

$--1$ i SXRYIGE INLCT EAmIERS

Fs 


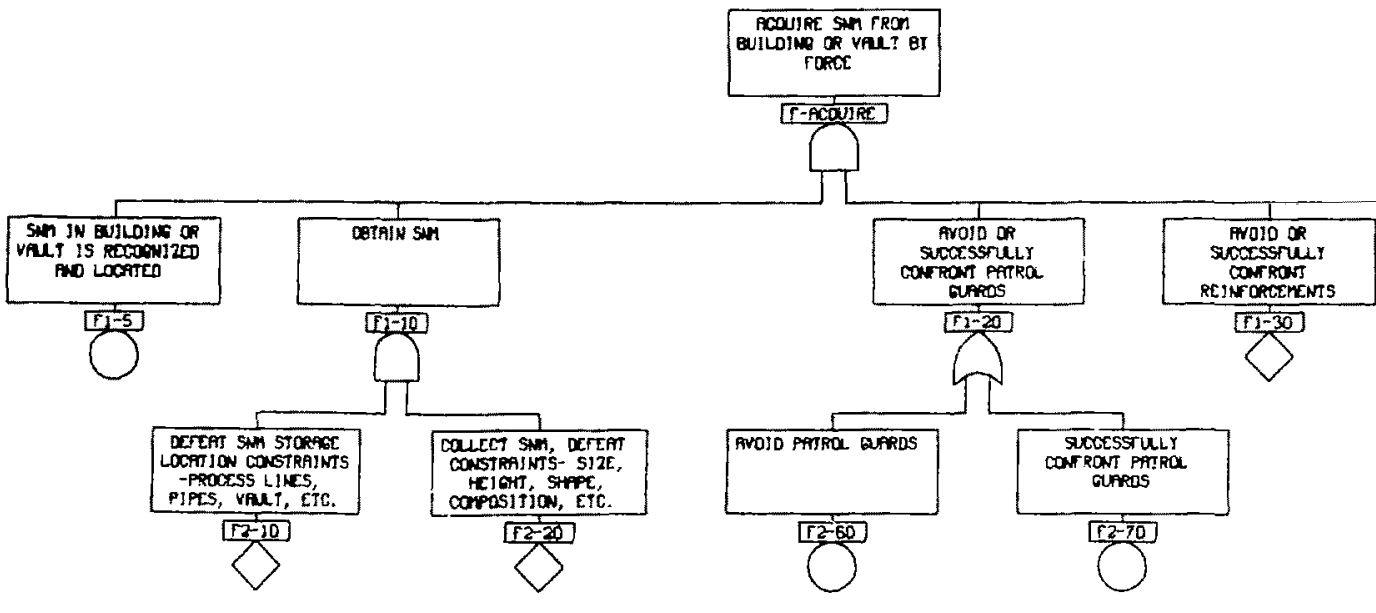


Mulas Sun FRTM

LDIUO OA VRLT BY ropec

$f-$ FCOU!R:

पI

ID Prina gurros

ANOJO OP

sucestuly

CoNTRONT

RE] NFORCLTENTS

evolo of

sucossruLy

Corf Fort FRe

PERSOMEL

curkes

$\frac{1}{[1-30}$

$\frac{1+50}{(1-50}$

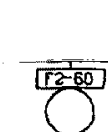

SUXCS5TULI

coNron PfTRO.

curnos 

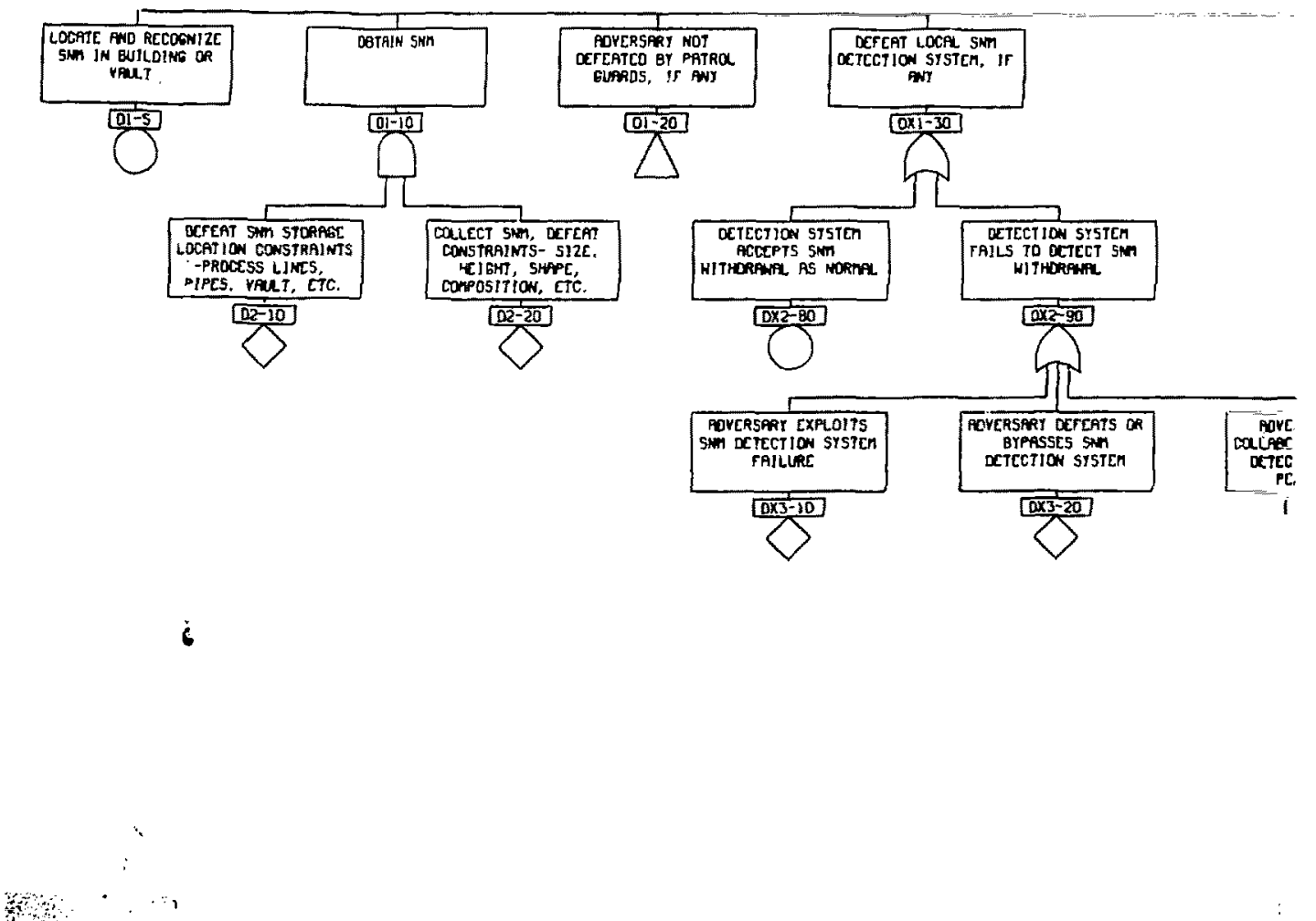


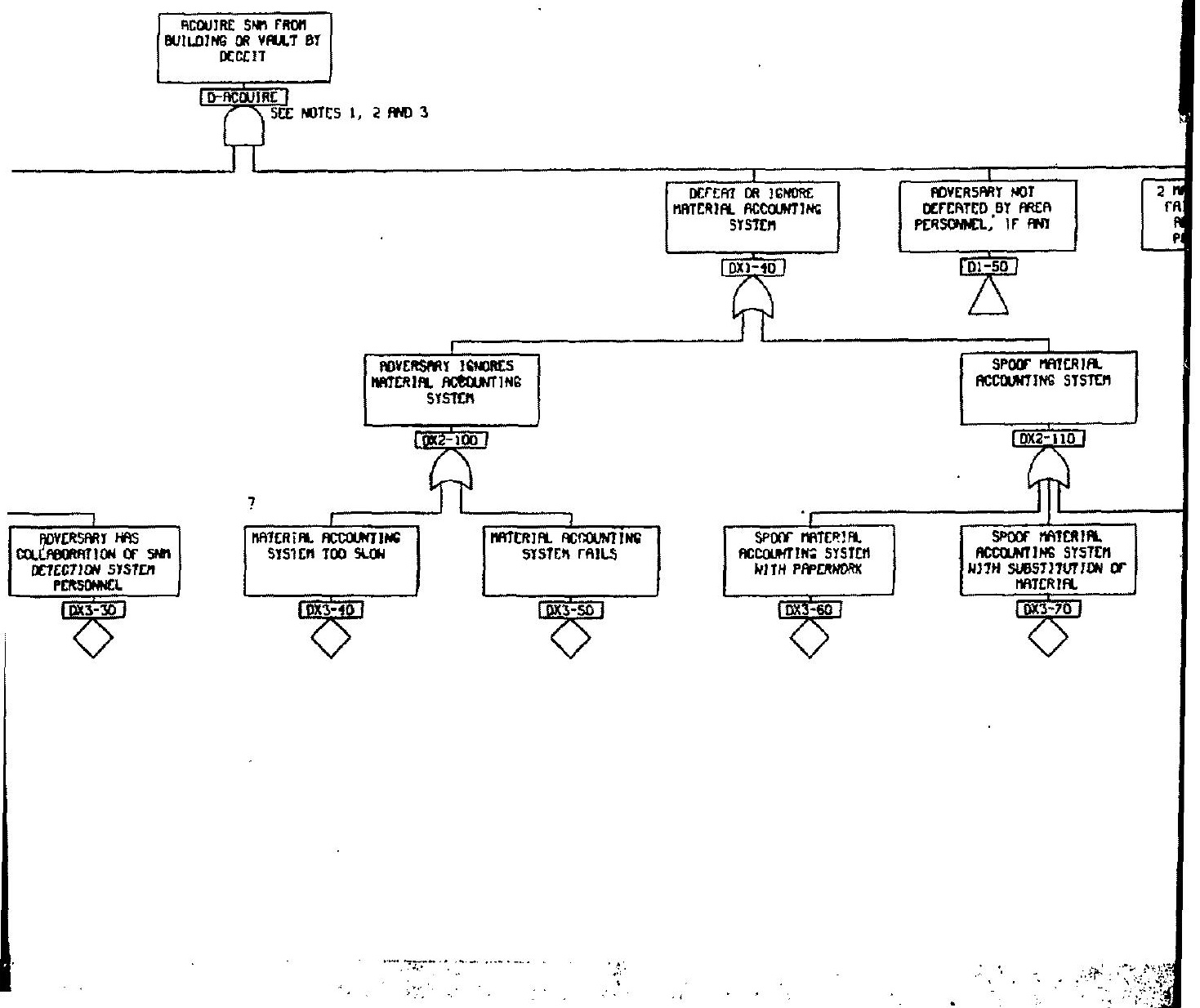


NOTE 1. EXAMPLES OF ADVERSARY OR COLLABORATOR INSIDER

SMPLOYEE OR,

CONTEACTOR

SITE

TYPE OF THPLOYEE

ADMINISTRATIVE

GUARD

GATE

PATROL

STATIONARY...E.G., IN TOHTR

HEALTH PHYSICS

MAINTENANCE

HANAGER/SUPERVISOR

OPERATIONS

2ND PERSON OF TWOMAN TET:

OUTSIDER DISGUISED AS ANY OF

THE ABOVE INSIDERS

NOTE 2. CONDITIONS OF COLLABORATION

COERCED

WILLING

NOTE 3. EXAMPLES OF AREAS

PROTECTED

LIMITED

VITAL

MATERIAL ACCESS

\begin{tabular}{|c|c|}
\hline \multicolumn{2}{|c|}{ 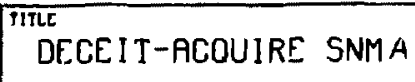 } \\
\hline 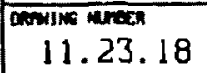 & $\begin{array}{l}\text { one } \\
10 / 09 / 79\end{array}$ \\
\hline
\end{tabular}


(1)

$+2$
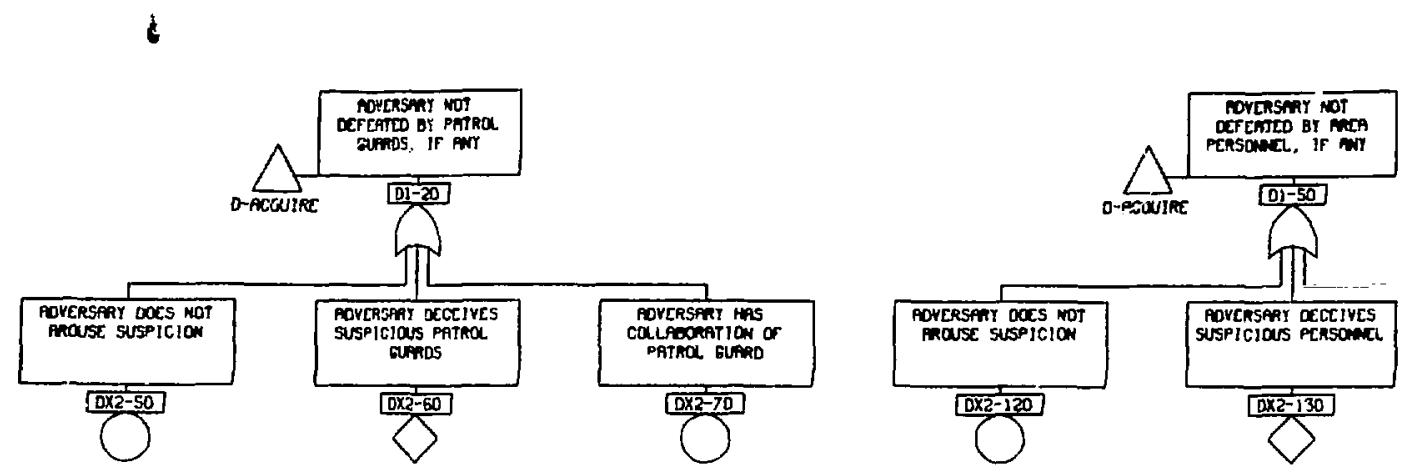


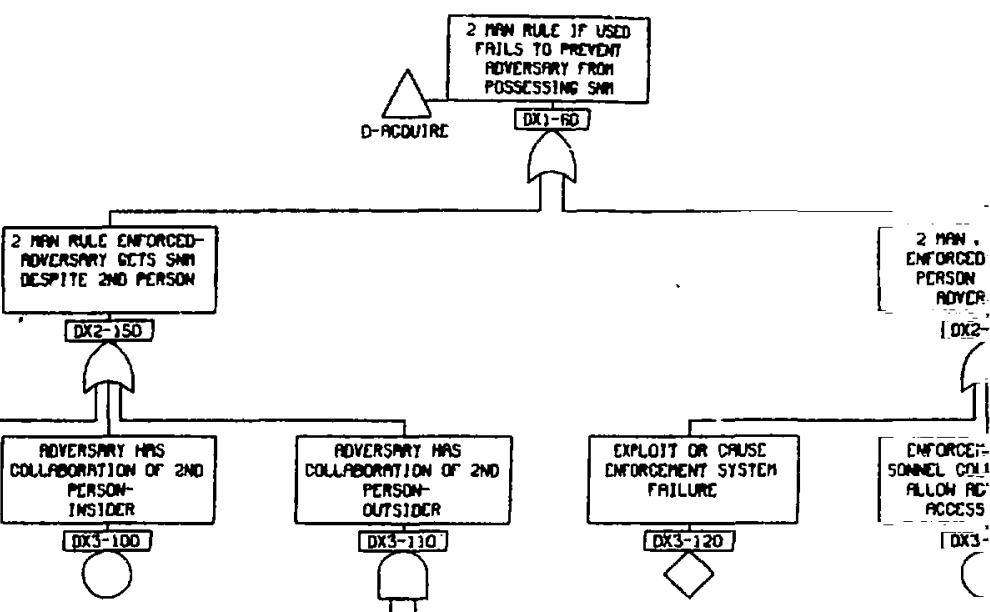

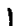

coives

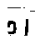

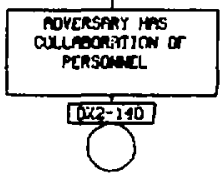

fOVCRSPRY OCCE]VES ZAD PCRSON

ax3-90

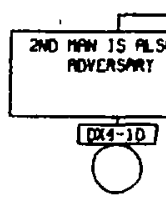

2to naw acoulfes $5 \mathrm{~m}$

rron bulibios on

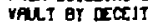

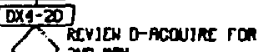





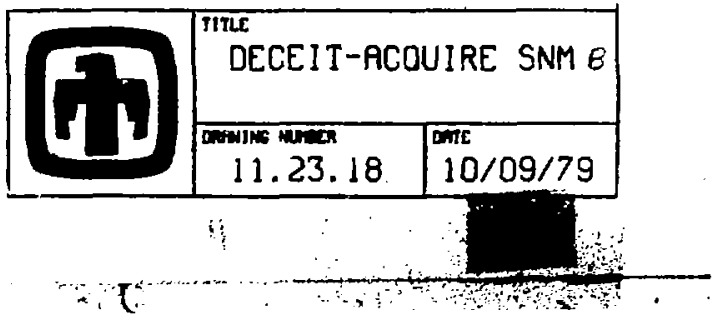


42

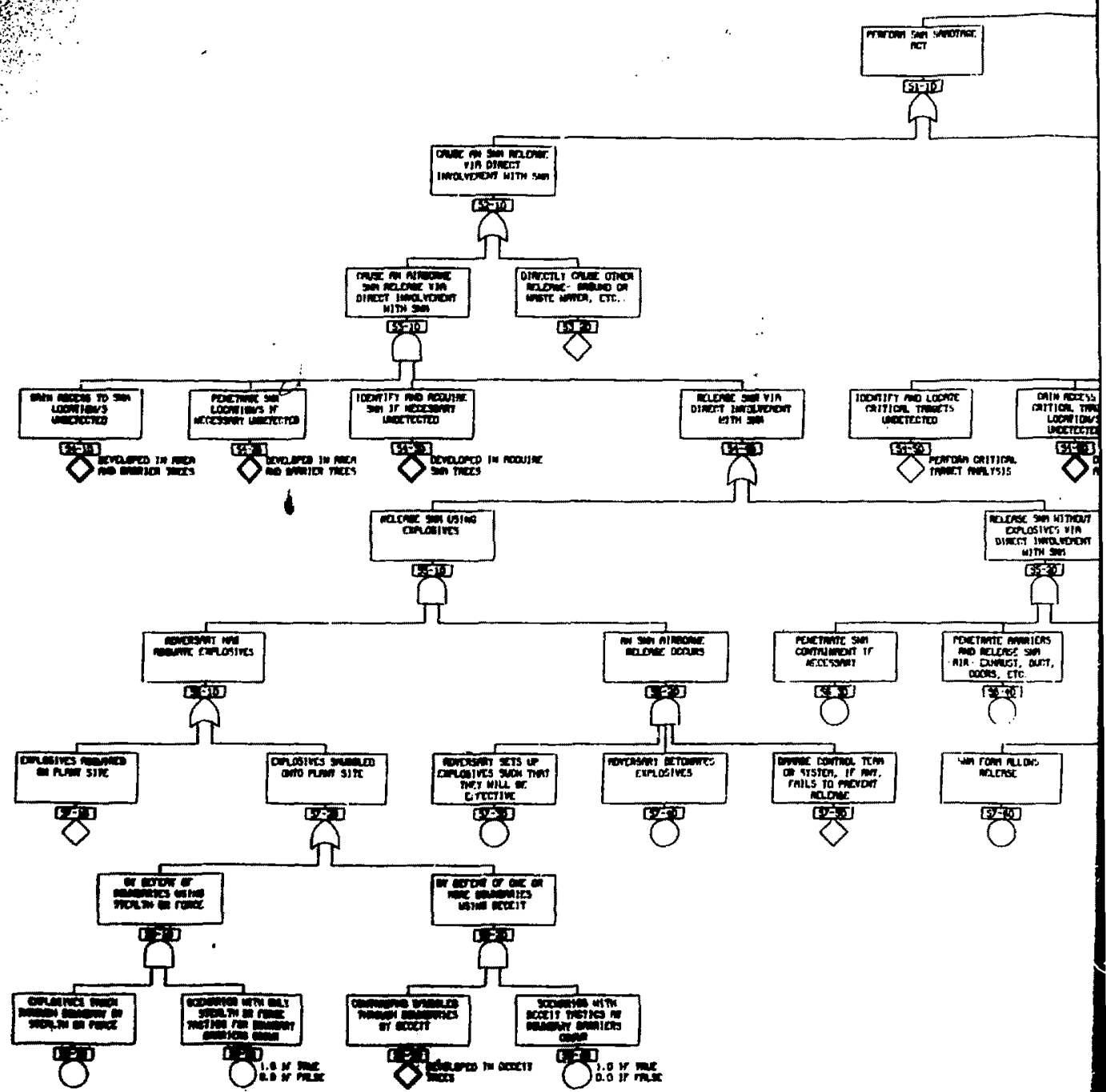




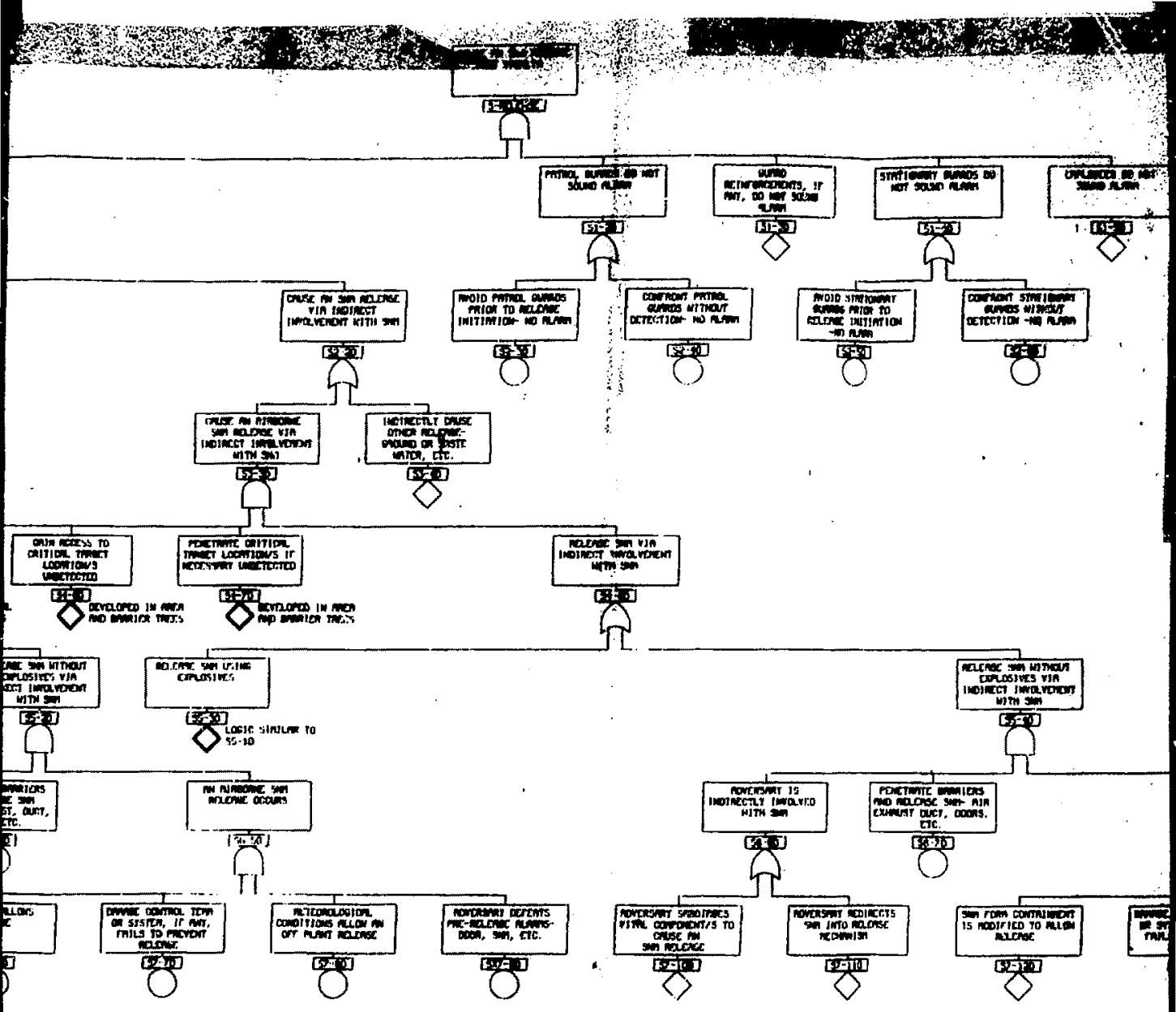




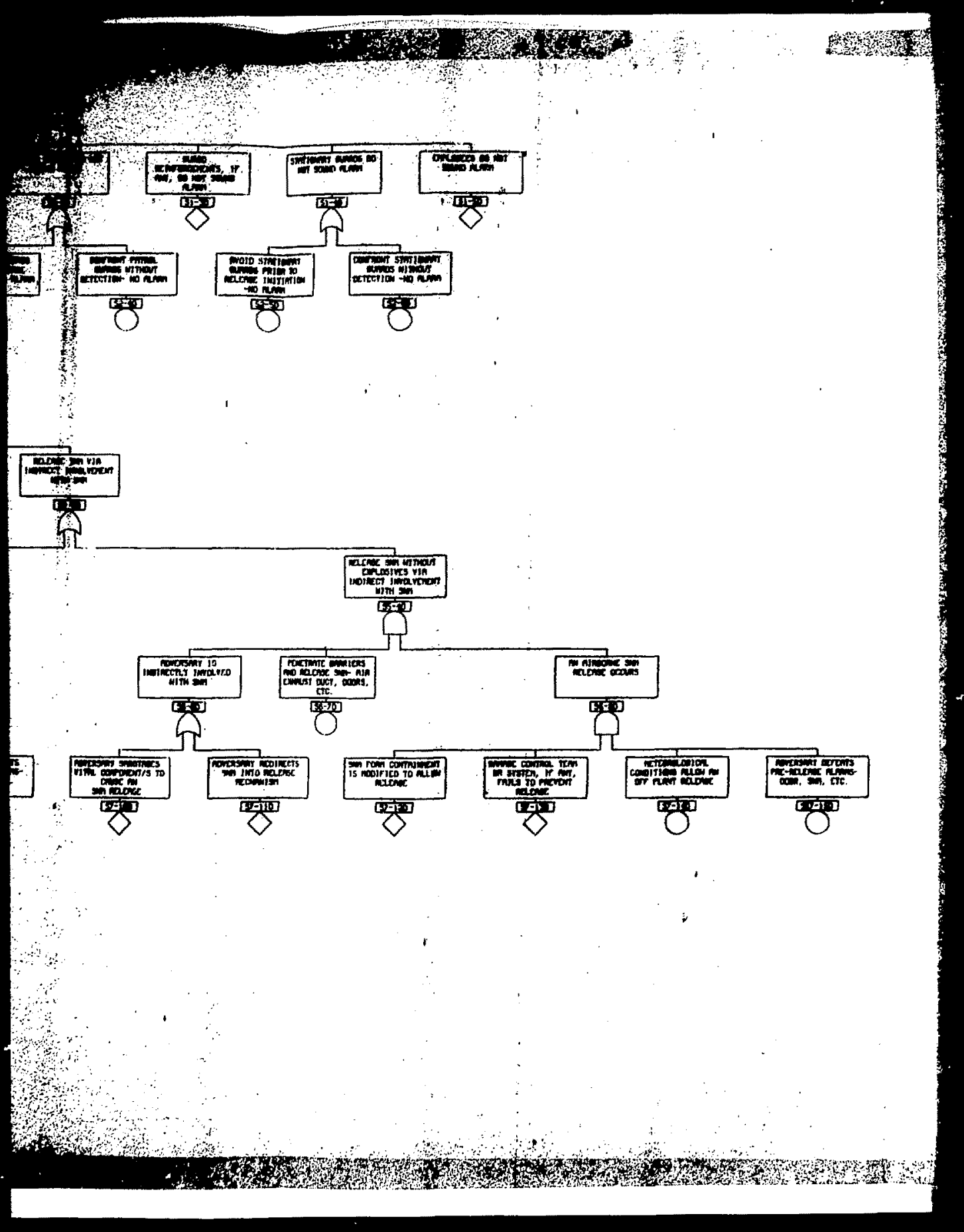

Wrom 

N

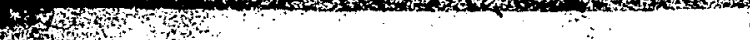

(4)

$\rightarrow$

(3)

4
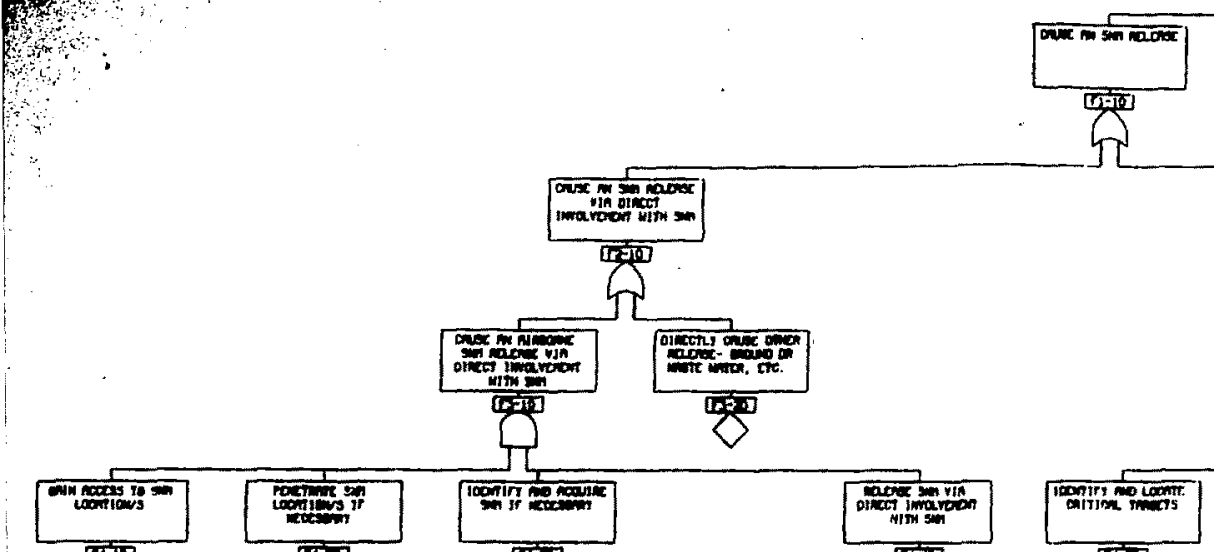

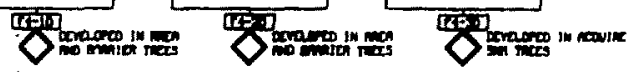
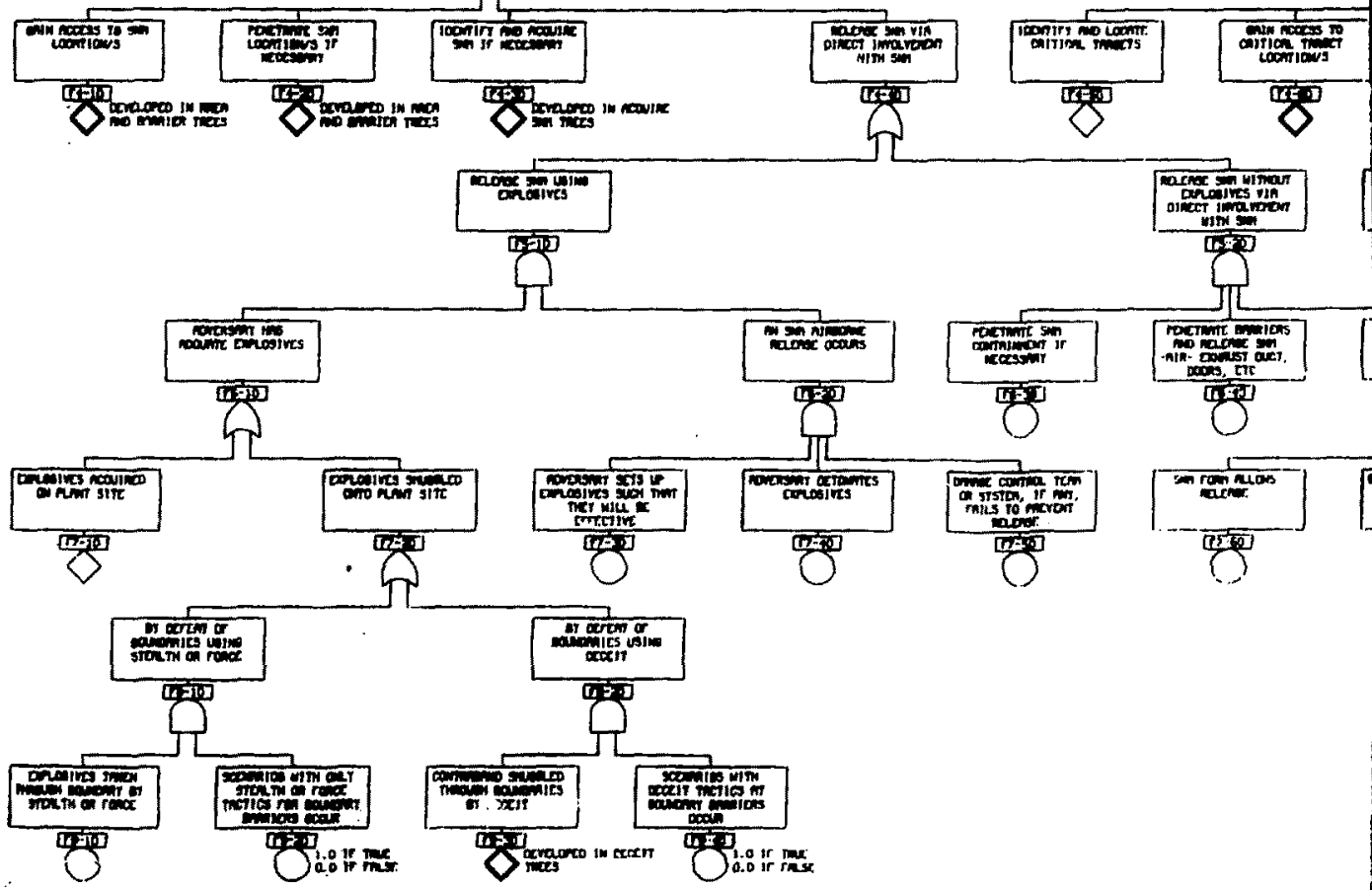

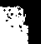




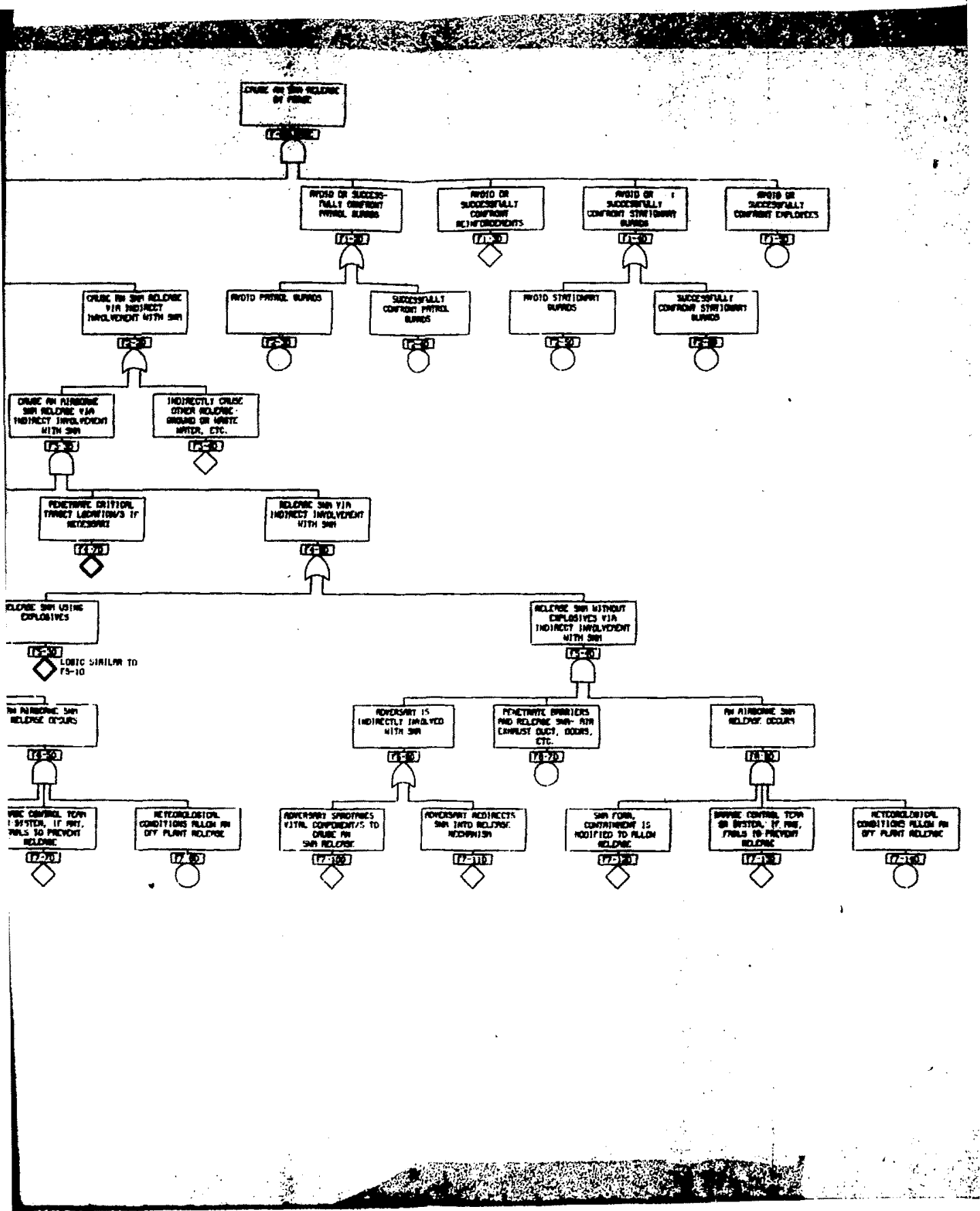




\section{ALTERNATE VERSION OF DECEIT -BOUNDARY LOGIC TREE}

Experience with the DECEIT-BOUNDARY generic physical pratection lagic tree presented in Appendix B has repeatedly led to this criticism: there is something confusing about how the identity check and authorization check subtrees should be interpreted and applied to a real physical protection system. Anticipating that some readers will share this reaction, an alternate version of DECEIT-BOUNDARY is presented in this Appendix. If reaction to this alternate version indicates that it has solved or reduced the problem, it or an improved version will become the single standard DECEIT-BOUNDARY logic tree. Meanwhile, this alternate version of DECEITBOUNDARY is offered for trial and comment,

DECEIT-BOUNDARY has to do with access control, of which identity checks and authorization checks are vital elements. In the alternate logic tree another element is added: a person must be enrolled in the access control system to have his authorization for access established. Event DX1-10 requires that the "Adversary Defeats or Bypasses Enrollment Procedure for Authorization." This event probably takes place long before the scenario when the adversary attempts to gain access through the boundary in question.

As a result of enrollment for access authorization, a record is created to document that person $x$ is authorized to enter area $A$, perhaps under certain conditions. The access authorization is a fact, the result of an adrinistrative action, and exists apart fron any credential which, in the possession of an employee, is meant to certify or refer to the authorization. In the alternate DECEIT-BOUNDARY, all references to "credentials" have been eliminated as possibly misleading. By definition, a credential is something that gives title to credit or confidence; it is presumed to certify authority for access. But devices commonly called credenrials (badges, key cards, etc.) can be forged or stolen and do not warrant naive acceptance. The generic physical protection problem is to check a claim of authorization under the rules of the system. The mechanism for making the claim may or may not be vulnerable to misuse by the adversary. The rules of the system may or may not be likely to expose misuse.

Event DXI-20 requires that the "Adversary Defeats Access Authorization Check." The subtree gives three alternatives: (1) DX2-10, "Correct Access Authorization Claim Confirmed," (2) DX2-20, "Collaborator Accepts Incorrect Access Authorization claim," or (3) DX2-30, "System Falls to feject Incorrect Access Autorization clain."

An identity check is a screening technique to assure that the individual who seeks to have the authorization of $x$ checked and access granted is indeed $x$. Unless the identity is correctly egtablished by a truly unique characterigtic of the individual himself, there is a chance that an adversary can uge the access authorization 
of someone elge. A claim of an identity is made and must be checked so it can be confirmed or rejected.

Event DX1-30 requices that the "Adversary Defeats Identıcy Check." The subtree gives three alternativos as in the case of the authorization check: (1) DX240, "Correct Identity claim Confirmed," (2) Dx2-50, "Collaborator Accepts Incorrect Identity Claim," or (3) DX2-60, "Sygtem Fails to Reject Incorcect Identity Claim."

Other than the above major changes from the DECEIT-BOUNDARY logic tree in Appendix $B$, there are a Eew changes in event descriptions intended to improve understandability and the elimination of a few events that have been found not to be celated to positive measures for physical protection $1 \mathrm{i}$ e., the subtree "Adversary Not Detected Crossing Boundary by Area pecsonnel," since area personnel, excluding guards, normally have no role in access control, and would contribute only accidentally to physical protection). 


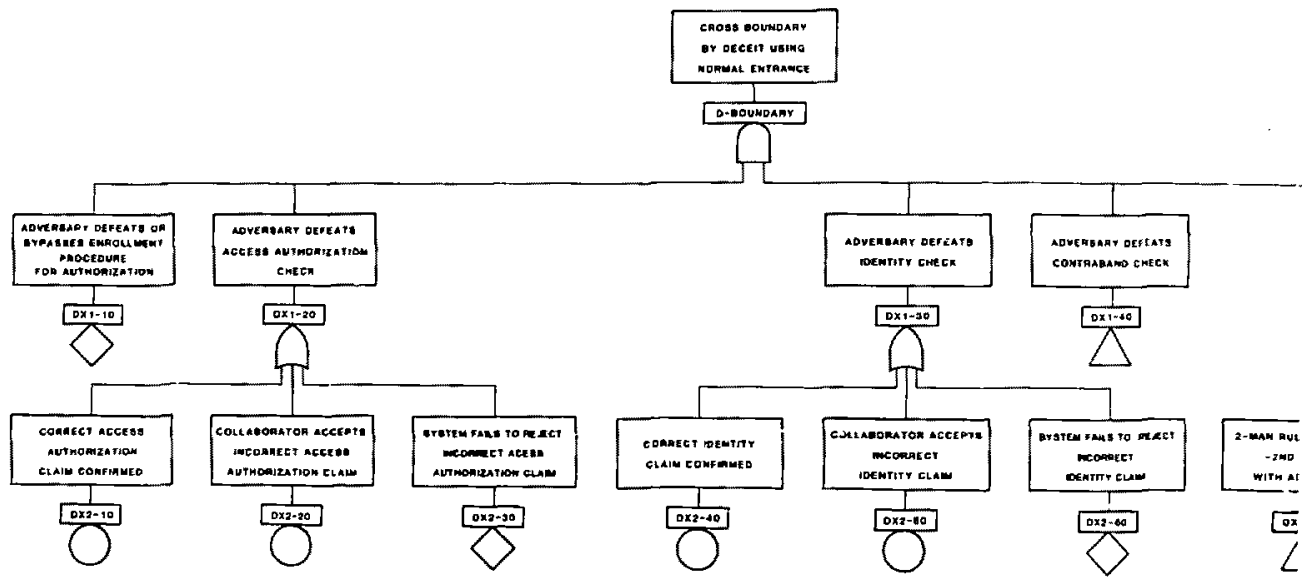




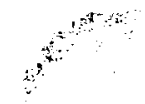

1

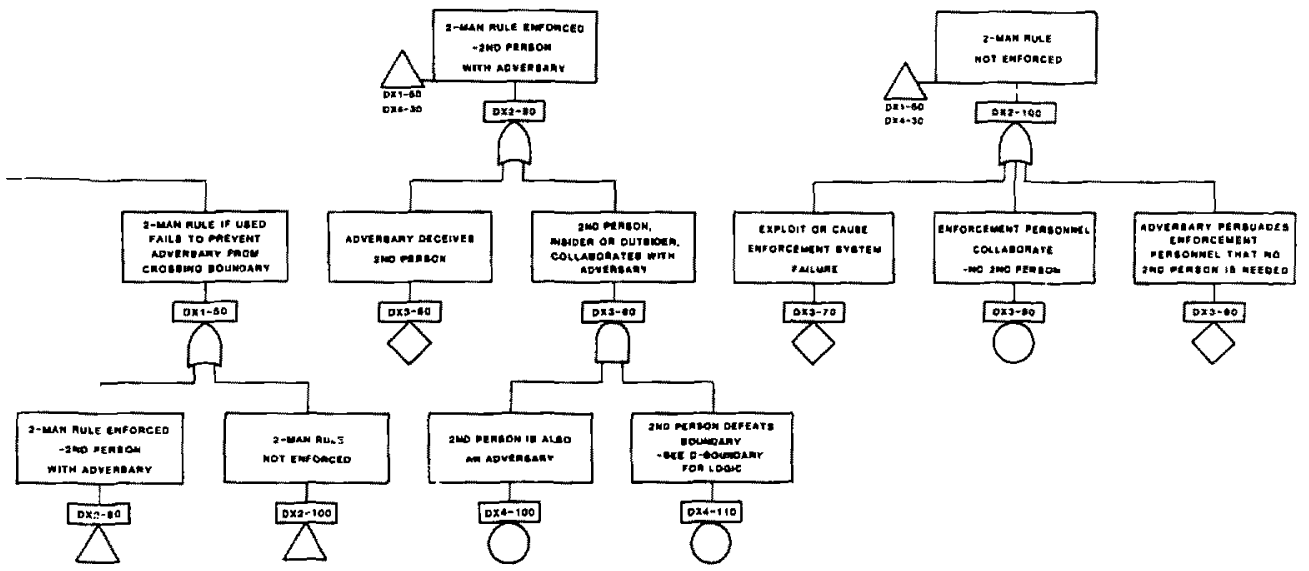




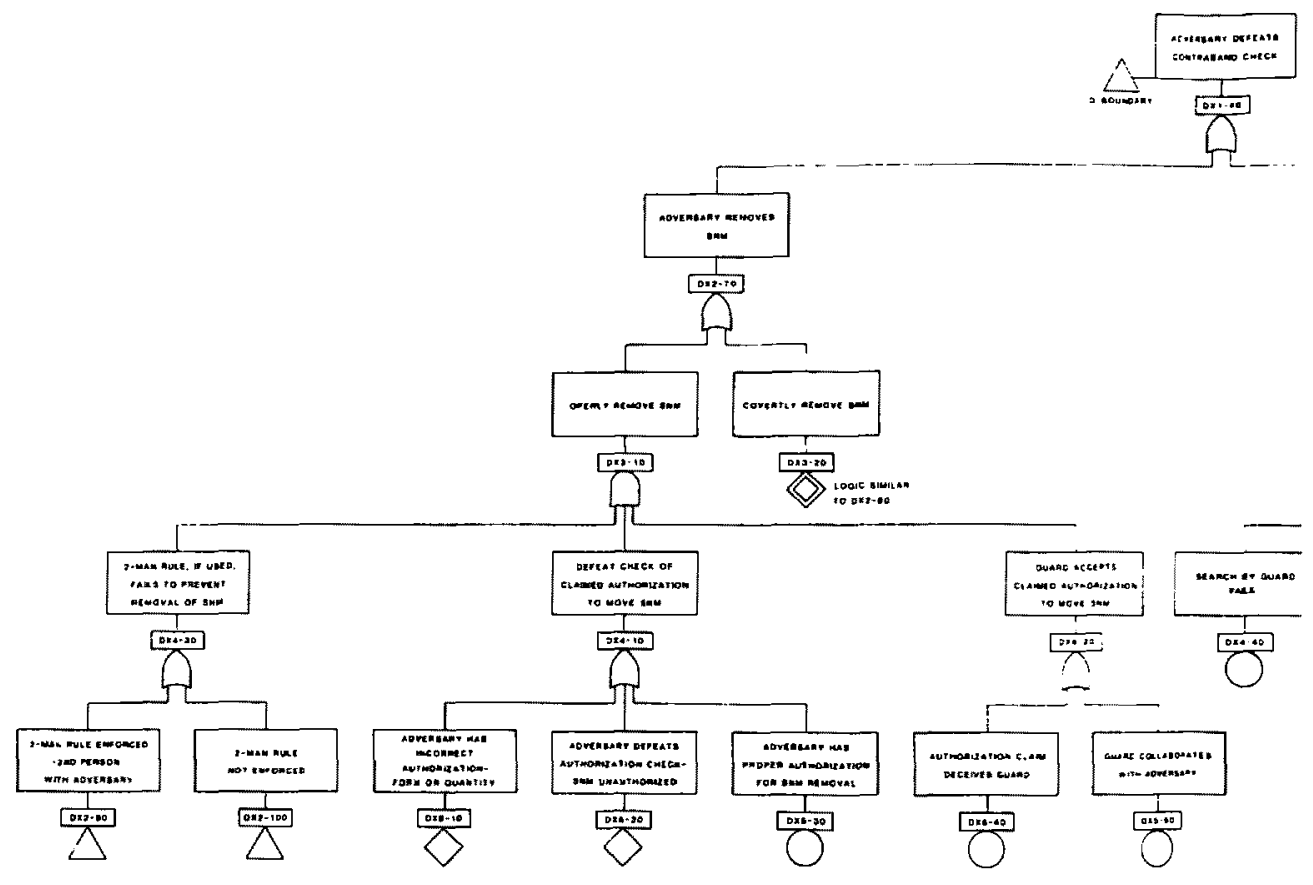




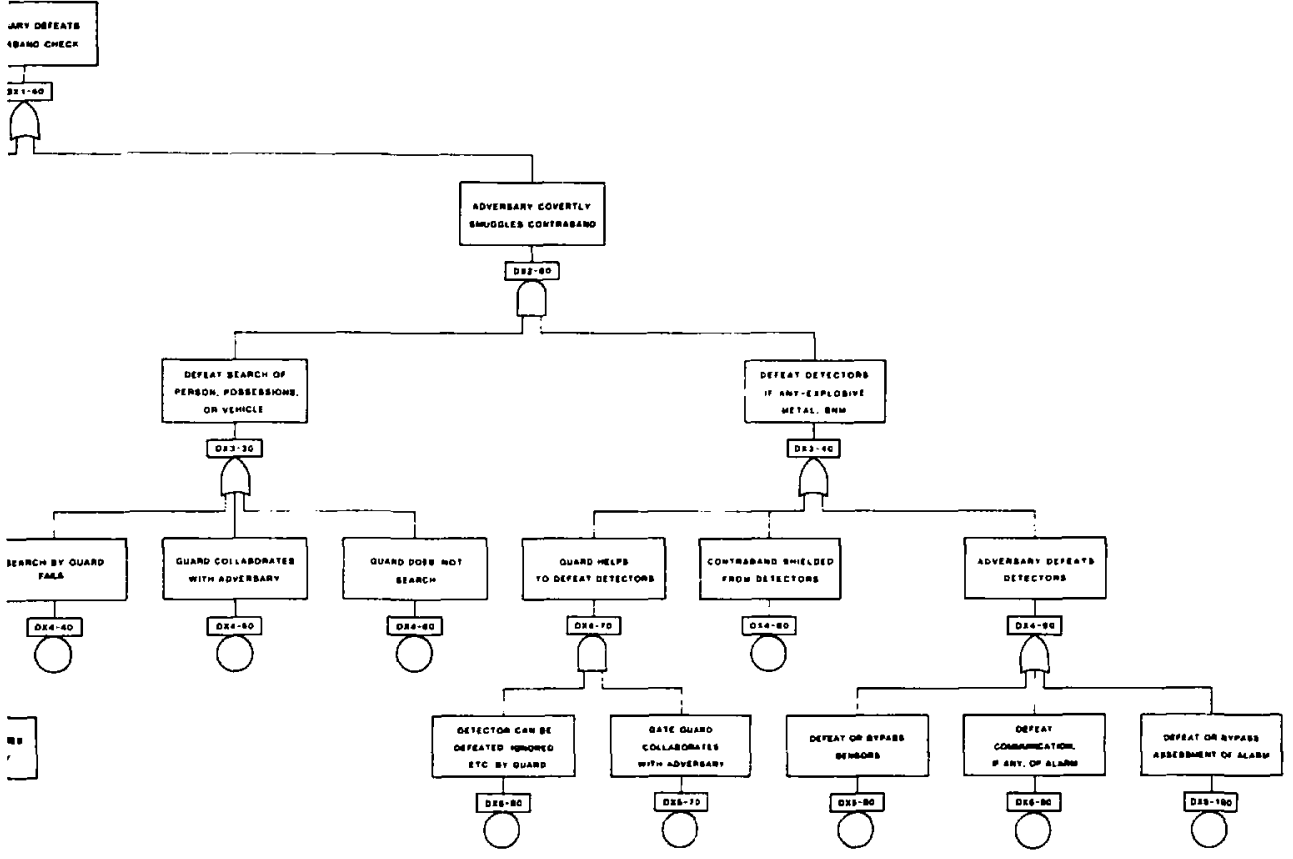

